"Made availabte under NASA sponsorshib in the interest of early and wide dis. Semination of Earth Resources Survey tor ony use mation and without liability

\title{
A COMPARISON OF SKYLAB AND ERTS DATA FOR AGRICULTURAL CROP AND NATURAL VEGETATION INTERPRETATION
}

\author{
Technical Report \\ Prepared for NASA \\ by \\ EARTH SATELLITE CORPORATION
}

July 1, 1974

Original photography may be purchared from

EROS Data Center 10th and Dakota Avenue Sioux Falls, SD 57198
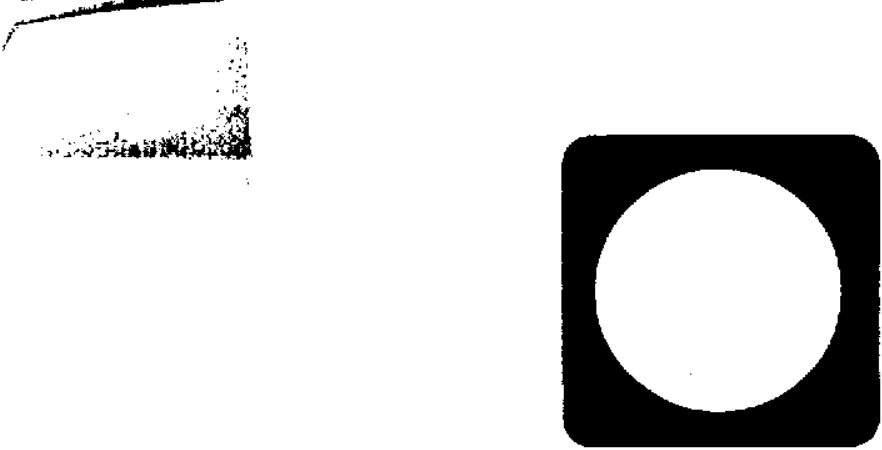

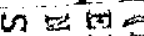
a) 200 et $1+3$ (0) U⿺辶一 س $1+10$

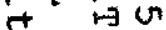
$\pi<\infty$ tor

0 to

$\rightarrow \rightarrow 0$

n

- mi 25

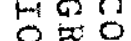
坚

$\Pi \pi$ ث $\mathrm{s}$ $00 t$ ( )

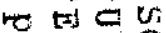
एक I त以

tho ot $\rightarrow 0$ or 0 L a

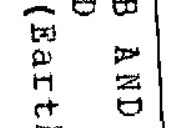




\section{PREFACE}

This report was prepared in response to a request by NASA for a comparative evaluation of the utility of Skylab EREP and ERTS MSS data for agricultural crop and natural vegetation interpretation. It was compiled as an adjunct to Skylab EREP Investigation No. 510 (Dr. Charles E. Poulton, Principle Investigator) by:

Robert N. Colwe11

Lawrence R. Pettinger

Charles E. Poulton

Robin I. Welch

The assistance and contributions of the following individuals is also acknowledged: S. Benedict Levin, Philip G. Langley, Dennis Jacques, Jeannie Kalivoda, Terrill D. Smith, William Myers, and Steven J. Daus.

This report was completed under NASA Contract No. NAS 9-13286 (EarthSat Project No. (G-089). 
I. INTRODUCTION 5

A. PROBLEM STATEMENT 6

1. Agricultural Test Area 6

(Northern Great Valley of California)

2. Natural Vegetation Test Area (Colorado Plateau) 7

B. $A P P R O A C H \quad 8$

C. SCOPE OF STUDY 9

D. TEST SITE DESCRIPTION 9

1. Northern Great Valley Test Area 11

2. Colorado Plateau Test Area 18

E. IMAGERY ACQUIRED 24

II. QUANTITATIVE TEST OBJECTIVES 26

A. AGRICULTURAL CROP TESTS 26

B. NATURAL VEGETATION TESTS 26

III. QUANTITATIVE TEST PROCEDURES 28

A. IMAGE FORMAT 28

B. GENERAL METHODOLOGY 30

C. ADDITIONAL BACKGROUND PROVIDED TO INTERPRETERS 36 FOR NATURAL VEGETATION TESTS

IV. SUBJECTIVE TEST PROCEDURES 39

A. NORTHERN GREAT VALLEY TEST AREA

1. Minimum Field Size and General Land Use 39

2. Seasonal Aspects and Frequency of Coverage 40

3. Crop Vigor Evaluation and Plant Stress Detection 40

4. Multidate Image Enhancement 40 
B. COLORADO PLATEAU TEST AREA 41

V. QUANTITATIVE TEST RESULTS AND ANALYSIS 42

A. NORTHERN GREAT VALLEY TEST AREA 42

1. Test 1 - Crop Identification, 42 Late Summer Seasonal State

2. Test 2 - Crop Identification, 46 Late Spring Seasonal State

3. Test 3 - Stratification of Rice-Growing Regions 51

B. COLORADO PLATEAU TEST AREA 52

1. Test 4 - Natural Vegetation Identification, 52 Summer Seasonal State

2. Test 5 - Natural Vegetation Identification - 58 Stereoscopic vs. Monoscopic Viewing

VI. SUBJECTIVE TEST RESULTS AND ANALYSIS 62

A. NORTHERN GREAT VALLEY TEST AREA 62

1. Minimum Field Size and General Land Use 62

2. Seasonal Aspects and Frequency of Coverage 69

3. Crop Vigor Evaluation and Plant Stress Detection 72

4. Multidate Image Enhancement 80

B. COLORADO PLATEAU TEST AREA 81

1. Subjective Image Evaluation 81

2. Vegetation Mapping 83

3. Image Quality 85

VII. CONCLUSIONS

A. VEGETATION COMPLEX IDENTIFICATION 88

1. Agricultural Crops 88

2. Natural Vegetation 91

3. Combined Ranking for Agricultural Crop 92 and Natural Vegetation Identification 
B. VEGETATION COMPLEX DELINEATION 93

1. Agricultural Crops 93

2. Natural Vegetation 94

C. VEGETATION VIGOR AND CONDITION 94

1. Agricultural Crops 94

2. Natural Vegetation 97

D. IMAGE QUALITY CONSIDERATIONS 97

APPENDIX A - TEST IMAGE EXAMPLES 98

APPENDIX B - INFORMATION AND PROCEDURES FOR 134

PHOTO INTERPRETERS TAKING QUANTITATIVE TESTS 


\section{SUMMARY}

An investigation was undertaken which compared images taken from the Skylab Earth Resources Experimental Package (EREP) system (S190A and S190B) with the Earth Resources Technology Satellite (ERTS-1) multispectral scanner (MSS). The study compared the effectiveness of each system for identifying and delineating natural vegetation complexes in the Colorado Plateau and agricultural croplands in the Northern Great Valley of California.

Images from each system taken over each test area at comparable dates were selected and photo interpretation tests were conducted using the prepared materials and a team of 40 photo interpreters. Selected image features on each image type were identified by each interpreter according to a prescribed set of instructions during formal test periods. In addition, experienced staff interpreters compared images from the EREP and ERTS systems, making subjective evaluations of questions not addressed by the formal testing.

More than 40,000 individual test responses were generated from these tests, thus providing a solid statistical base for assessing the relative interpretability of each image type. The test responses were scored using ground data obtained by on-site visits and from large scale aircraft photographs where features were easily identifiable. Statistical analyses were performed using the test results, and conclusions were reached regarding the relative utility of each system. 
The eight image types used were EREP S190A color and color infrared, and also black-and-white images in the red and near infrared spectral regions; S190B high resolution color; and ERTS color composite (color infrared simulation -- bands 4,5 and 7) and MSS black-and-white bands 5 and 7. ERTS and EREP data were acquired as follows:

Test Area

Northern Great Valley of California

Colorado Plateau
System

ERTS

EREP

ERTS

EREP
Date (1973)

May 28 , September 13

June 3 , September 12

August 16

August 3 and 8

The following statements summarize the results of this study:

- For identification of agricultural crops in the Northern Great Valley of California at the late summer seasonal state, the ERTS color composite (bands $4,5,7$ ) and EREP ST TOA color IR image are judged best of the eight image types tested.

- For crop identification at the late spring seasonal state in the Northern Great Valley Test Area of California, the EREP S190A color and color IR images are judged best of the eight image types tested. Comparable accuracy for overall crop identification was obtained at the two dates. A particular film type would be specified only if high identification accuracy were required for a particular crop type.

- Multidate additive color enhancement is valuable for assessing year-to-year change in area of rice culture.

- For identification of natural vegetation types in the Colorado Plateau Test Area, the EREP S190A color IR image was judged better than all other image types tested. 
- For overall identification of both natural and agricultural vegetation complexes, the eight image types rank as follows (from best to worst):

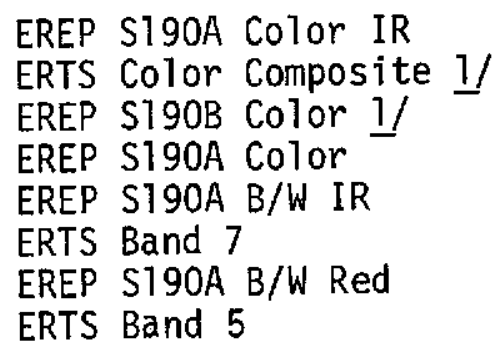

1/ These image types rank equally high for some purposes.

- Interpretation results for stereoscopic interpretation by skilled interpreters who understand the relationship between vegetation types and landform/topography are markediy better than results obtained by monoscopic interpretation.

- Minimum detectable field size is smallest for images of highest resolution (e.g., EREP S190B and S190A color) and greatest for images of poorest resolution (ERTS).

- Delineation of rice-growing areas was accomplished with $90.7 \%$ accuracy using an early summer ERTS color composite and $82.1 \%$ accuracy with early summer EREP S190A color IR imagery.

- EREP SI9OA color IR and SI9OB color, in that order, are judged to be best for mapping of natural vegetation types in the Colorado Plateau Test Area.

- Color infrared imagery was the most useful for evaluating crop vigor and plant stress.

- ERTS and EREP SITOA systems are considered adequate for regional crop survey studies (such as regional drought assessment from season to season), but the EREP S190B system is required as a data source for making most crop management decisions.

- EREP ST9OB imagery is also required for assessing the extent of lodging in rice fields on a field by field basis. 
- The frequency of coverage is difficult to specify for any system without a thorough study of prevailing weather conditions and a study of the occurrence of critical crop events. Delays of more than a few days in receipt of data from satellite systems can cause severe problems in their use for crop management and marketing decisions. For regional surveys, on the other hand, delays of up to several weeks can be tolerated. 


\section{INTRODUCTION}

Photo interpretation of earth resources requires a series of complex judgements by the image analyst. The difficulty with which these judgements are made and the frequency and importance of the associated errors made in analyzing remote sensing images are a function of many factors. This report considers only those image factors related to spatial resolution, the effects of various black-and-white and color images, and the temporal considerations of sequential coverage.

While an all-inclusive test could be designed to study the effects of various seasonal photo inputs, scale factors and human interpretation problems, only a limited number of images were available from the Skylab overpasses, restricting the coverage that could be used in this study and therefore the questions that could be addressed. However, it is believed that the questions dealt with in this study were clearly among the most important ones that would need to be dealt with, even in a more comprehensive test.

Several factors interact to determine the nature of the images obtained from Skylab and ERTS. The Skylab EREP system used cameras which take photographs by conventional means. Film was returned to earth from orbit by the astronauts. ERTS MSS images, on the other hand, were obtained by an optical mechanical scanner and the image data were telemetered to earth from orbit by digital means. Skylab multispectral scanner images were also acquired but were not available for this investigation. 
It was recognized at the outset that certain important differences in image characteristics existed between EREP and ERTS and that those differences restricted the comparisons that could be made. However, for conventional visual image analysis questions, the image differences (inherent in scanner imagery vs. photography) would not restrict the making of certain judgements regarding spatial resolution and multiband interpretation.

The following problem statement was made at the beginning of the study to guide the investigation.

\title{
A. PROBLEM STATEMENT
}

Evaluate and compare the usefulness of EREP and ERTS remote sensing systems for identification and evaluation of vegetation resources by testing the ability of photo interpreters to make the desired interpretations on selected types of EREP and ERTS imagery.

1. Agricultural Test Area_Northern Great Valley of California)

a. How effective is each system for delineating and identifying land use in the Northern Great Valley Test Area?

\section{Land Use Categories:}

\author{
Agriculture \\ Dryland pasture \\ Woodlot \\ Urban \\ Unused 1and \\ Water bodies and drainage \\ b. Which system provides maximum accuracy in crop
} identification? 


\section{Agricultural Crop Categories:}

Rice

Orchard

Alfalfa

Fallow

Dryland pasture

Other agricultural crops

c. Which system provides the best means to evaluate

crop vigor and determine the effects of yield

limiting agents?

2. Natural Vegetation Test Area (Colorado Plateau)

a. How effective is each system for identifying natural vegetation units in the Colorado Plateau Test Area?

Vegetation Categories:

Pinyon-juniper woodland

Ponderosa pine forest

Sedge (wet) meadow

Aspen forest

Spruce-fir forest

other vegetational types

b. Will stereoscopic viewing increase the information derivable from S190A imagery over monocular viewing for the above question? 
Systems and Image Types Evaluated:

\begin{tabular}{|c|c|c|c|}
\hline System & Image Type & Spectral Band, $\mu \mathrm{m}$ & Nominal Resolution, Ft. 1 \\
\hline ERTS MSS & $\begin{array}{l}\text { Band } 5 \\
\text { Band } 7 \\
\text { Color Composite }\end{array}$ & $\begin{array}{l}0.6-0.7 \\
0.8-1.1 \\
0.5-1.1\end{array}$ & $\begin{array}{l}200 \\
200 \\
200\end{array}$ \\
\hline EREP S190A & $\begin{array}{l}\text { B/W Red } \\
\text { B/W IR } \\
\text { Color } \\
\text { Color IR }\end{array}$ & $\begin{array}{l}0.6-0.7 \\
0.8-0.9 \\
0.4-0.7 \\
0.5-0.88\end{array}$ & $\begin{array}{r}91 \\
223 \\
78 \\
187\end{array}$ \\
\hline EREP S190B & Color & $0.4-0.7$ & 50 \\
\hline
\end{tabular}

\section{B. APPROACH}

Selected image examples which had been acquired nearly concurrently from EREP (ST90A and S190B) and ERTS (MSS) overpasses were used to perform a series of photo interpretation tests to determine the usefulness of each system for the questions defined above. Further nontesting subjective analysis was performed by personnel who have extensive experience in this and related studies to make judgements not conveniently accomplished with quantitative tests.

The results of these quantitative and qualitative tests led to a series of conclusions regarding the adequacy of the images tested with respect to a) spatial resolution and b) tonal and color quality for identification and delineation of the natural vegetation and agricultural categories. In addition, determinations were made as to the interpretability 
of crops on various kinds of ERTS and EREP imagery taken at two different seasonal states, viz., late spring and late summer. The results and conclusions from these tests are contained in later sections of this report.

c. SCOPE OF STUDY

Because of limitations of availability of suitable EREP and ERTS coverage, PI testing was performed on one natural vegetation area at one seasonal state and one agricultural area at two seasonal states. Additional factors were considered for both sites by a nontesting subjective analysis using direct comparisons of EREP and ERTS images. For those features where positive identification was available by ground observation or by photo interpretation of large scale aerial photos, a ground data map was prepared and used in selecting test fields, in scoring the PI tests, and for making subjective evaluations.

\section{TEST SITE DESCRIPTION}

The geographic areas selected for interpretation testing are those in which the investigators currently have active ERTS-1 and EREP experiments. The Northern Great Valley of California (Figure 1) is a region of varied agricultural practices. Current ERTS and EREP studies focus on interpretation of the rice crop in this area. Since the region contains a variety of other agricultural crops, it is also an ideal location for assessing the photo interpretability of several 


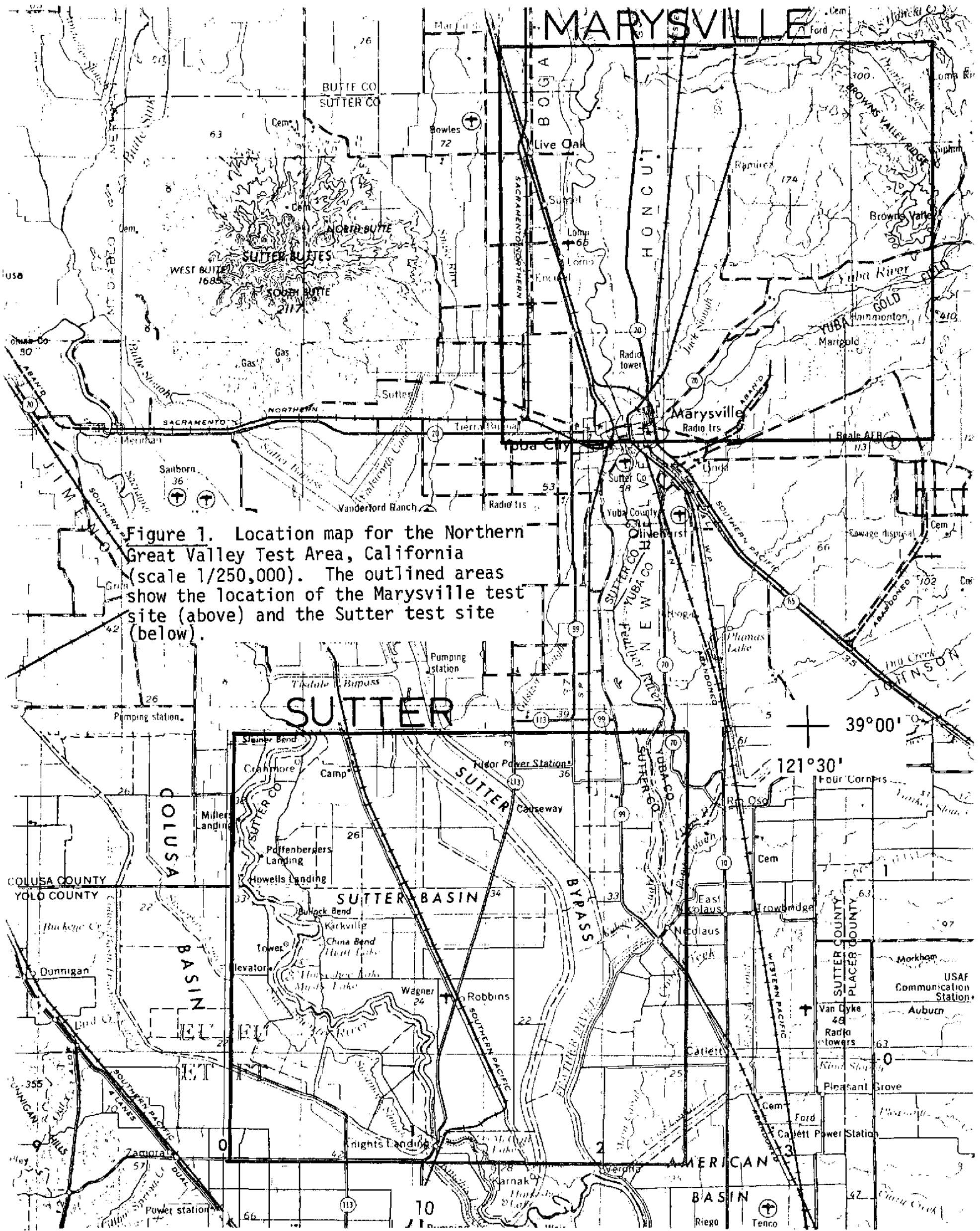


crop types as well as general land use patterns. The Colorado Plateau Test Area (Figure 2) is a region of wide elevation ranges and a correspondingly wide range in vegetation types.

\section{Northern Great Valley Test Area}

The Northern Great Valley Test Area is located in the northern half of the Central Valley of California. The climate of the area is Mediterranean to semi-continental. The winters are cool to cold with temperature ranges from $25^{\circ}$ to $70^{\circ} \mathrm{F}$. Most of the precipitation occurs in the winter and the rainy season normally extends from November to March. The summers are warm and dry; temperatures range from $60^{\circ}$ to over $100^{\circ} \mathrm{F}$. with some precipitation falling from sporadic thundershowers. The soils consist primarily of alluvial loamy sands. Over the entire area the crop type diversity is great, including rice, tomatoes, alfalfa, sugar beets, corn, sorghum, beans, peppers, wheat, barley, oats, safflower, orchards, vineyards and pasture. The combination of clear arid summer weather and the high crop diversity creates an excellent study area.

Within the Test Area, field size is variable. In broad level areas of intensive cultivation (especially where rice culture predominates), common field sizes are 40,80 and 160 acres, and fields of 160 acres are most common. In other areas (for example, along irregular river channeis), average field 


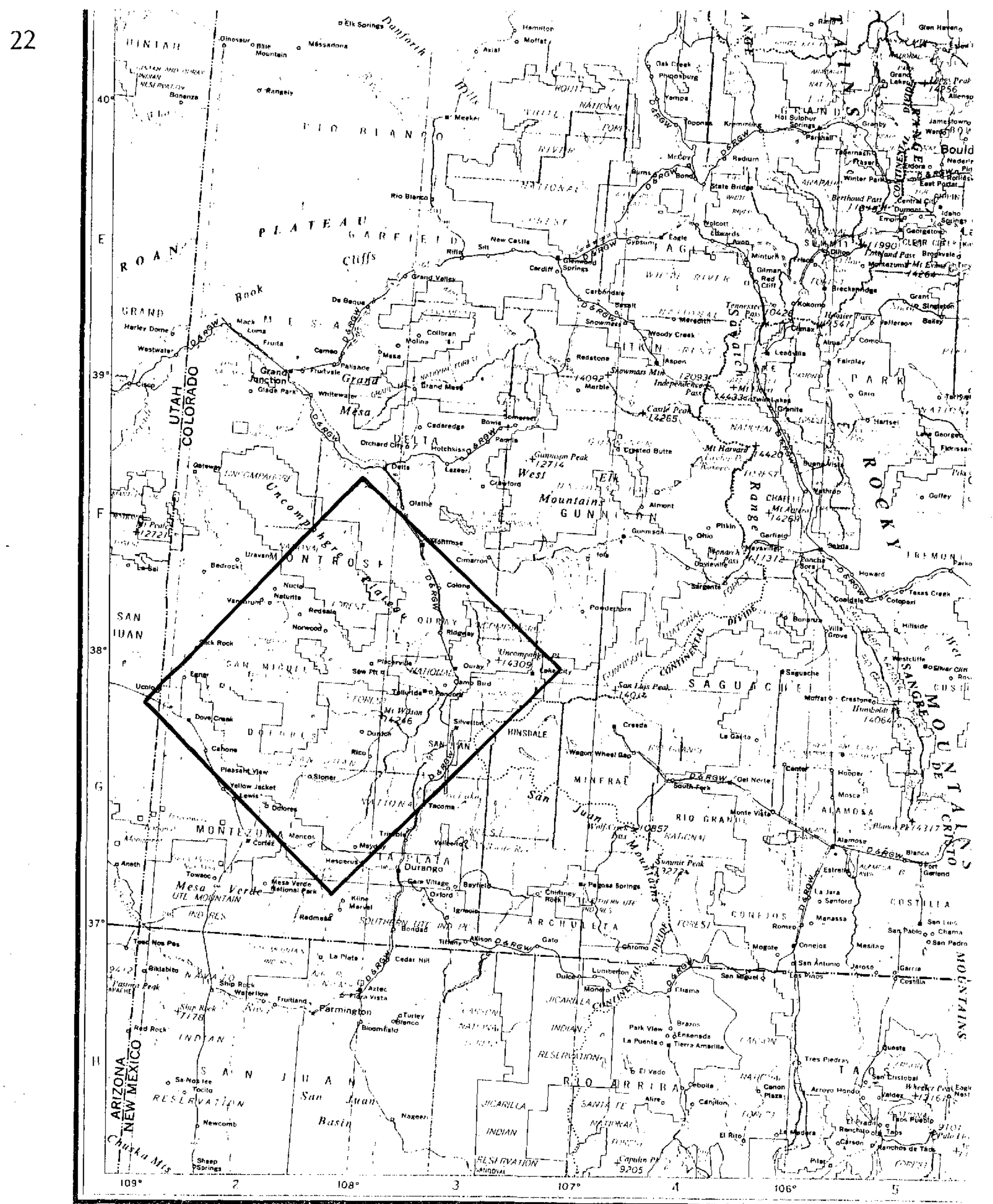

Figure 2. Location map for the Colorado Plateau Test Area (scale 1/2,000,000). 
size is 30 to 40 acres and ranges from 10 to 80 acres. Field shapes generally conform to the township and range subdivision used in California.

Within this Test Area, two test sites were selected, as described below:

Sutter Test Site

This site is located approximately 20 miles north and west of Sacramento, California (Figure 1). The site is approximately 100 square nautical miles in size, and contains the town of Robbins. The area is flat-lying with the only major feature being the Sutter Bypass, a flood diversion channel from the Sacramento River. The parent material is recent alluvium deposited by the Sacramento and Feather Rivers. The soils consist of deep and moderately to poorly drained sandy clay loams and are rich and well suited for all forms of agriculture. The climate is influenced slightly by the delta region. Precipitation generally ranges from 20 to 30 inches per year, mostly falling during the winter as rain, with scattered thundershowers in the summer. Frosts are common beginning in September and continuing through May.

The major crop types found in the Sutter area are rice, tomatoes, safflower, alfalfa, corn, sugar beets, orchards and vineyards, wheat, barley, and assorted row crops. 
A brief description of the crop types composing the interpretation categories is as follows:

1. Rice. Fields are diked and flooded in March, seeded by airplane in April or May and kept continuously flooded almost until harvest in September. There are four major varieties, two of which are early varieties and two of which are late varieties. This mixture of varieties creates a complex mosaic of planting dates and phenological development. The crop emerges above the water in about four weeks and soon forms a complete cover. Vegetative growth takes about two months, during which time the fields are top dressed with nitrogen fertilizer by airplane. Heading and the onset of maturity occur at about 90 to 120 days after planting, depending on variety. The rice crop is harvested by combines when the grain has dried to $20 \%$ moisture content. Neither weeds nor diseases present a serious problem.

2. Alfaifa. The season starts around March and runs until late 0ctober. Generally, five mowings are made in a season. After each mowing, the cut alfalfa is laid in rows for drying (a week to ten days) before baling. After baling, the crop is flooded and the cycle begins again. The result is a crop which fluctuates from $10-15 \%$ cover to $100 \%$ cover four or five times a year. 
3. Orchards and vineyards. These are perennial woody crops of many types including walnuts, peaches, prunes, almonds, pears, apricots, plums and grapes. On large scale aerial photos these areas are distinctive by their consistent cover and pattern.

4. Other crop types. These crops include tomatoes, cereal grains, safflower, corn, sugar beets, beans, melons, bell peppers, onions and potatoes. The crop phenologies are dependent on the characteristics of each crop type. While it usually would be desirable to differentiate these widely varying crops from each other, in the present tests it was considered to be both necessary and sufficient to combine them into a single category and thus to determine whether this group of crops was likely to be confused with the primary crop types being tested.

In addition to the intensive types of agriculture, there are also present more extensive forms such as irrigated and non-irrigated pasture. These areas support cattle and sheep for the production of milk, meat, wool and hides. The appearance of irrigated pastures is dependent on the irrigation cycles and the type of forage crop present. The development of non-irrigated rangelands is tied to the annual weather patterns. 
Marysville Test Site

The Marysville Test Site is located on the east side of the Sacramento Valley about five miles north and east of Marysville-Yuba City. Like the Sutter Test Site, this site also contains a 100 square nautical mile block. This unit is located a little higher up on the alluvial terrace and hence the soil types consist of coarser sandy loams than are found in the Sutter Test Site. Most of these soils are moderately to well drained and are excellent agricultural soils. The climate is slightly more extreme than in the Sutter area due to the more continental location. Rainfall is a little higher and temperature fluctuations are greater.

The major crop types in the Marysville Test Site are rice, orchards, and extensive dryland pasture, with some alfalfa occurring in the southeastern portion of the block. Photo examples of these crop types (except alfalfa) appear in Figures 3 and 4 . These crop types occupy fairly homogeneous blocks within the test site, corresponding roughly to their distance from, and elevation above, the river bottom area. The orchards are found in the river bottom, occupying the western third of the block. Rice occupies a large block of land in the middle of the test site; the eastern portion, which merges into the foothills of the 


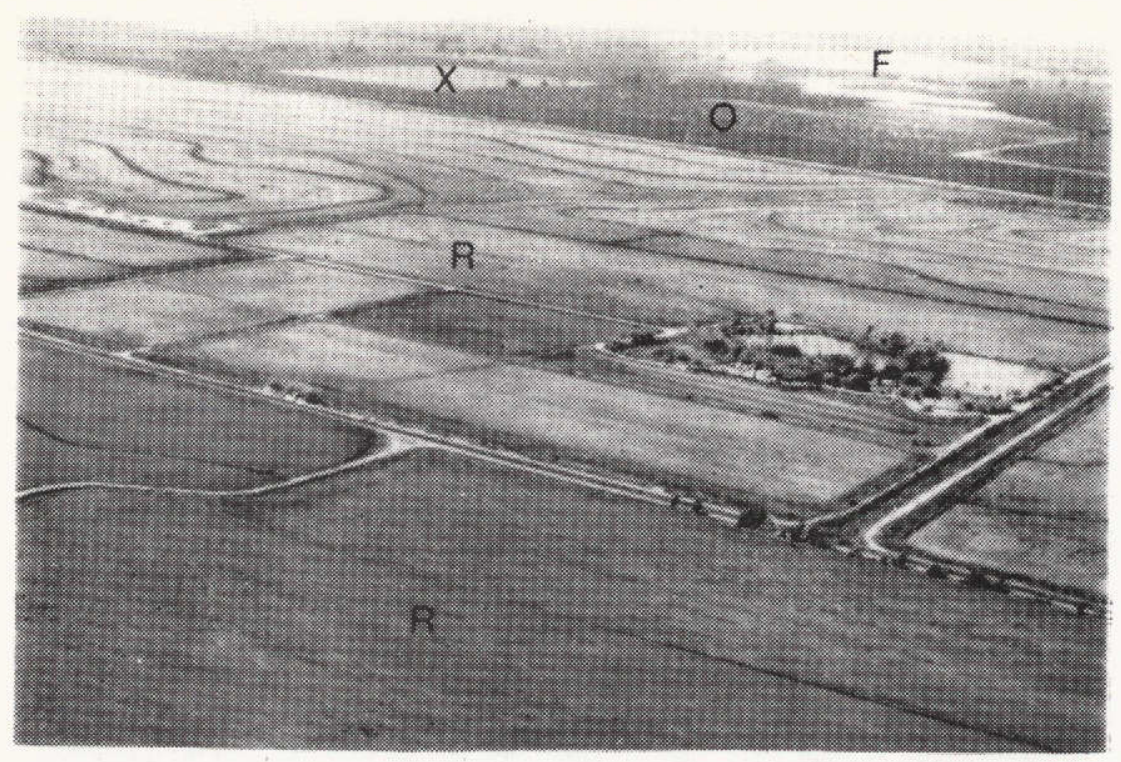

Figure 3. Oblique aerial view (August 28, 1973) showing a portion of the Marysville Test Site. Examples of the following crop categories (used in the quantitative tests) are annotated above: rice $(R)$, orchard $(0)$, fallow (F) and other agricultural crops $(X)$. Two different stages of growth are exhibited by the rice fields. Those in the center (1ight green) are maturing and the foliage has begun to dry out. The dark green fields in the foreground have not yet begun to mature and still have green foliage. Note the incidence of lodging (patches of the fields have fallen over) in both groups of rice fields.

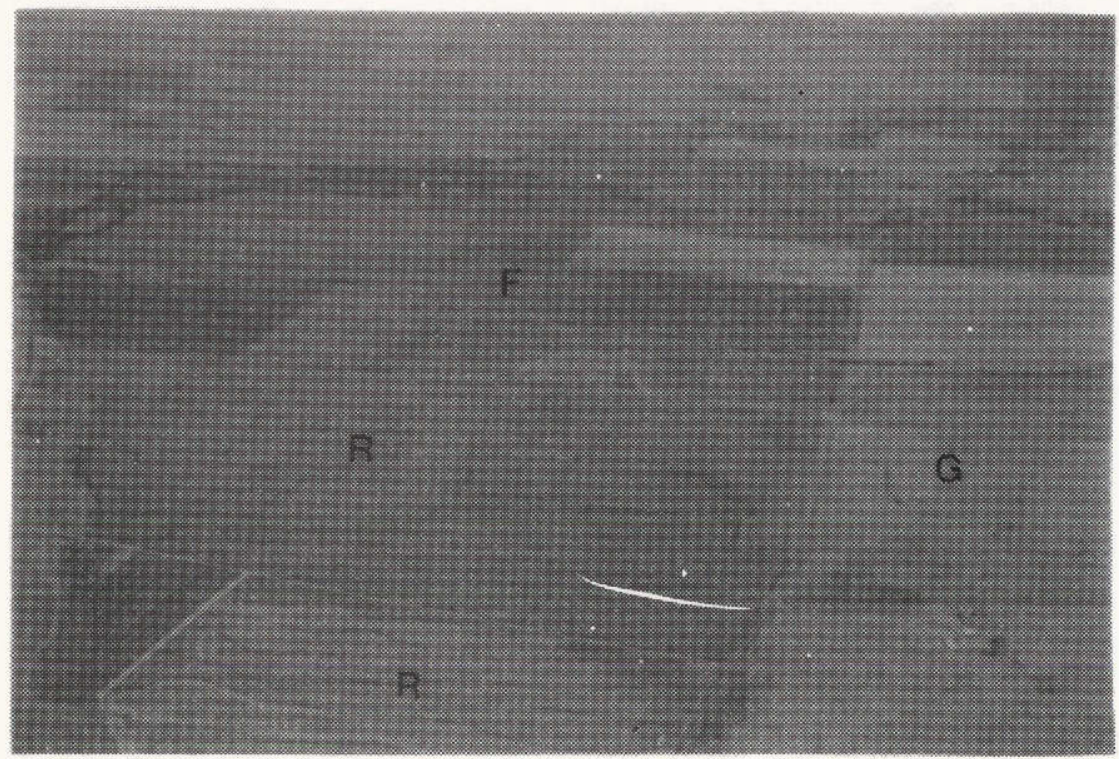

Figure 4. 0b1ique aerial view (September 13, 1973) of a portion of the Marysvil1e Test Site showing representative examples of some of the crop categories used in the quantitative tests: rice $(R)$, dryland pasture $(G)$, and fallow $(F)$. The rice fields in this scene are also at two stages of maturity, as described in Figure 3. Note how the dikes in the rice fields (which permit uniform flooding) are much more prominent in the fields of advancing maturity (light green) than in those which are not yet maturing (dark green). 
Sierra Nevada Mountains, contains the extensive dryland pastures of the natural rangeland. Crop phenologies are essentially the same as in the Sutter Test Site.

\section{Colorado Plateau Test Area}

This test area, located in southwestern colorado, intersects an almost ideal transect of natural vegetation from sagebrush steppe through spruce-fir and alpine forest conditions. The approximate center of the test area is 10 ated at latitude $38^{\circ} 00^{\prime}$ north and longitude $108^{\circ} 20^{\prime}$ west. The approximate dimensions of the test area are 20 by 60 nautical miles. The area extends from the vicinity of Montrose, Colorado across the Uncompahgre Plateau, the San Miguel River, Disappointment and Dry Creek Valleys to the Dolores River near Cortez, Colorado. The test area also includes the small agricultural area around Norwood, Colorado.

The elevations range from high valleys at about 5,900 to 7,000 feet to mountain ridges and peaks between 9,500 and 10,000 feet.

The vegetational transect includes an excellent representation of broad, zonal vegetation types which have analogs widely represented in western North America. The vegetational zones and major types represented are sagebrush, pinyon-juniper, Rocky Mt. oakbrush, ponderosa pine, and spruce-fir, with extensive stands of aspen and many mountain meadows interspersed through the sprucefir zone. Photo examples of these types appear in Figures 5 through 15. In general, the pinyon-juniper zone begins 

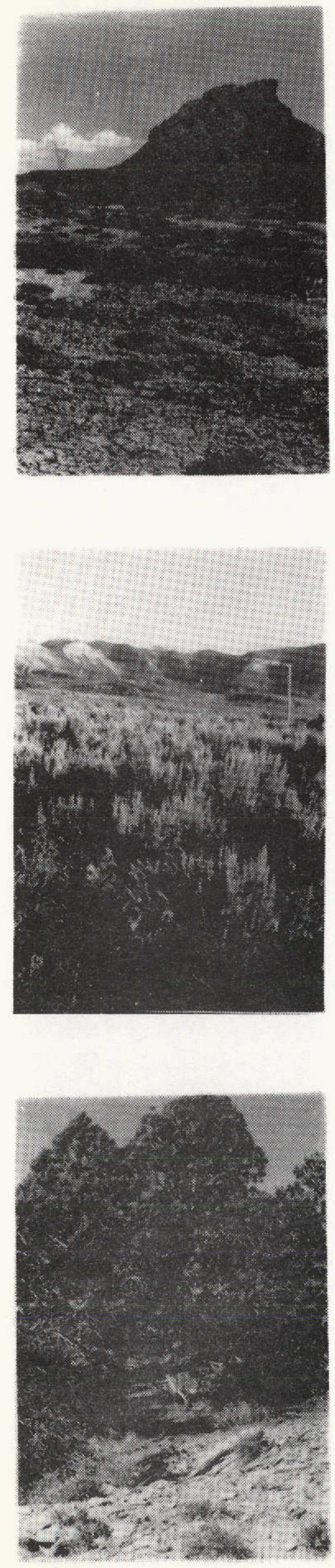

Figure 5. The vegetation type at lowest elevation in the test area is salt desert or shadescale (Atriplex confertifolia).

This scene is typical of the stature and sparse vegetation cover in this zone.

Figure 6. View of the sagebrush (Artemisia tridentata) vegetation type, which typical1y lies between the salt desert and the pinyonjuniper types, extending into the latter zone as an understory but occurring also as pure types or inclusions of sagebrush throughout the pinyon-juniper zone and into the ponderosa pine zone.

Figure 7. A typical stand of pinyon-juniper (Juniperus osteosperma-Pinus edul is). In some areas this type includes a broadleafed deciduous shrub associate, oakbrush (Quercus gambelii). In some cases, oakbrush wi 17 form pure stands within the pinyon-juniper zone where moisture levels are more favorable. 


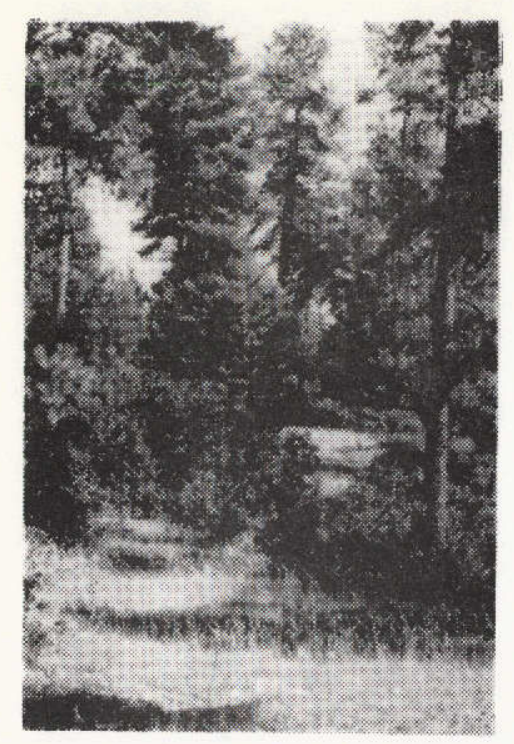

Figure 8. A typical stand of ponderosa pine (Pinus ponderosa). The understory cover in this community may vary from pure bunchgrass or sagebrush-grass mixture on drier sites to an oakbrush understory on moist sites. The prominent undergrowth shrubs in this scene are oakbrush.

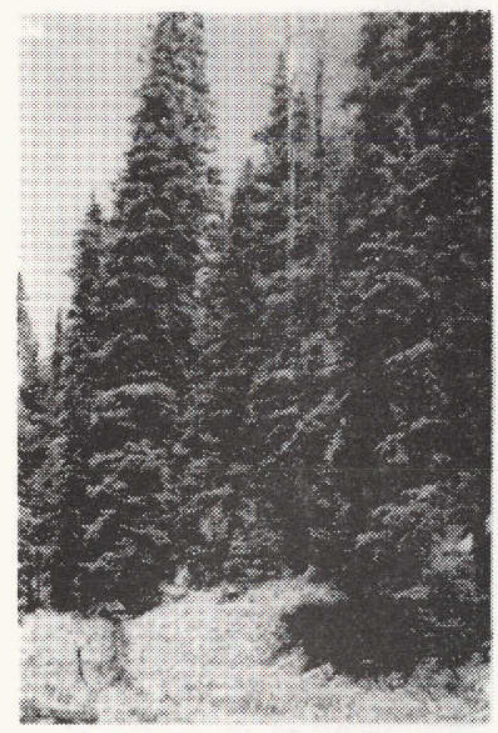

Figure 9. This is a typical ground view of the highest elevation forest type in the test region, spruce-fir (Picea engelmannij-Abies lasiocarpa). This forest type extends to timberline in the high mountains. Small lakes, ponds, and meadows are quite common, as the foreground suggests.

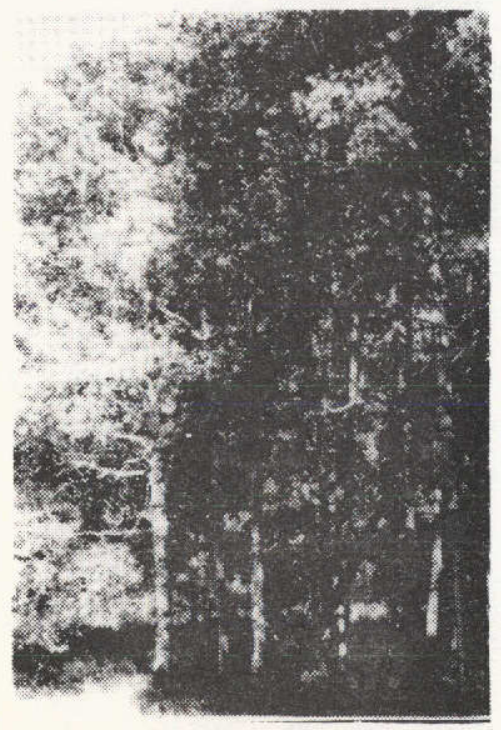

Figure 10. A typical stand of aspen (Populus tremuloides). This deciduous woodland is found in the spruce-fir zone where it becomes the prominent tree species after severe burns. It is therefore found in all degrees of mixture with spruce and fir as natural succession returns to the latter coniferous forest type. 

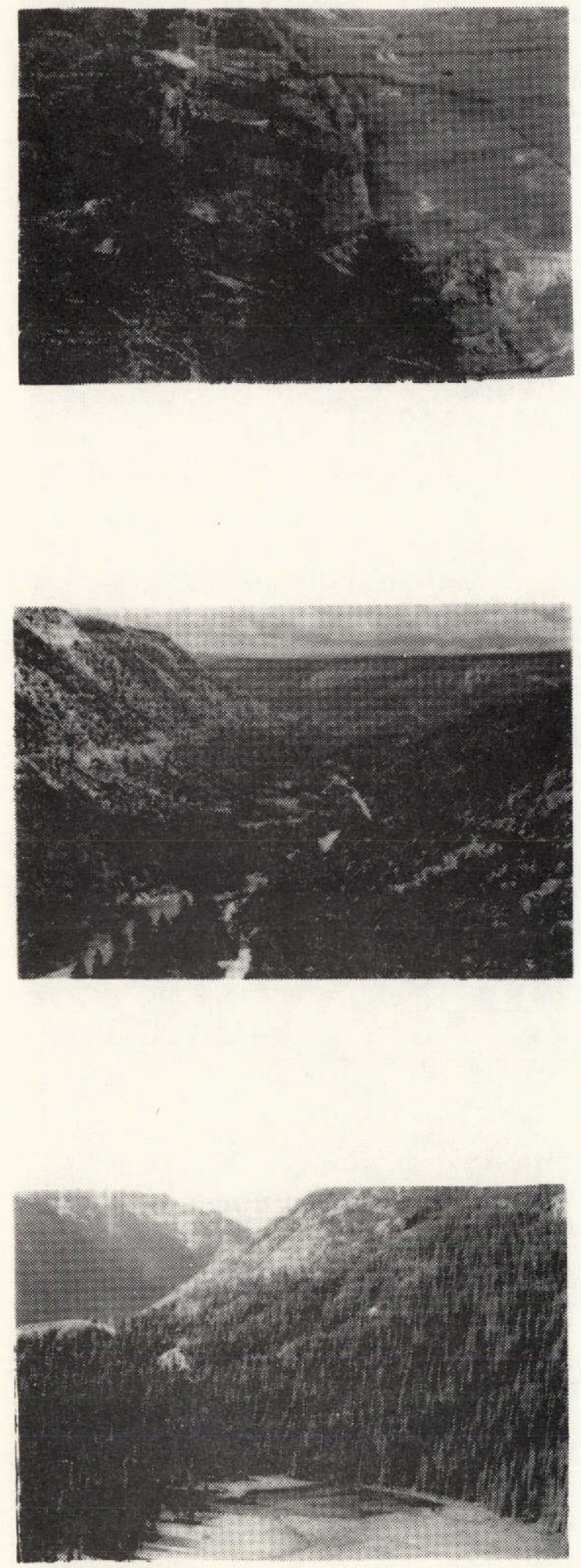

Figure 11. This scene shows a representatively sharp ecotone between the brownish saltdesert vegetation on the right and the typical pinyon-juniper vegetation on the left. In these arid and semi-arid regions, vegetation very commonly changes with landform and geologic types, as in this example.

Eigure 12. This scene illustrates the normal variability in density of the pinyon-juniper type as influenced by aspect and soil conditions. The valley slopes are covered by the pinyon-juniper type and the tall trees on the plateau in the right background are ponderosa pine. Note also the typical extension of spruce, oakbrush, and other mountain shrub types down the valley bottom.

Figure 13. This scene is typical of the spruce-fir type as it approaches timberline where barren rock and true alpine vegetation determine image characteristics. Note especially the meadow type and lake in the foreground. Ecotones between forest and meadow generally tend to be abrupt, as in this scene. 


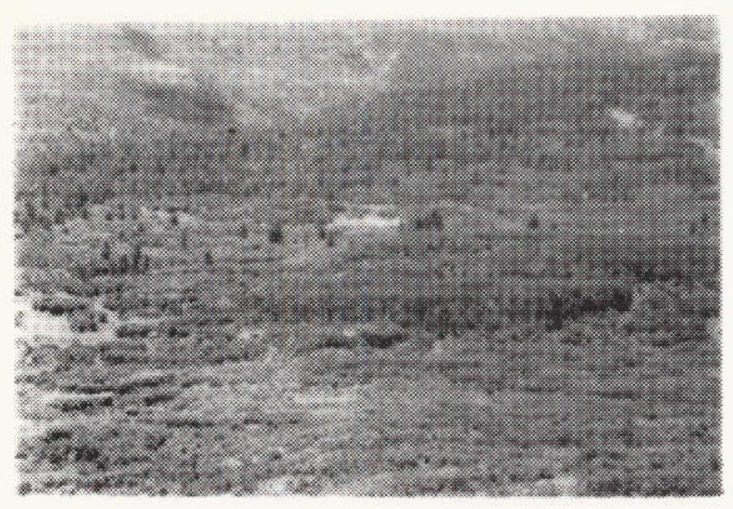

Figure 14. Important vegetation changes occur within highly similar landforms at higher elevations under sub-humid conditions. However, these changes usually occur in response to more subtle soil differences. For example, the foreground of this view consists of oakbrush. A stand of aspen occurs in the mid-ground on the right, and the coniferous forest type in the background is ponderosa pine. Note the difficulty one would anticipate in accurately mapping this vegation mosaic at exceedingly small scales. The most feasible separation would be merely between (a) the oakbrush, with its inclusions of aspen and grassland, and (b) the ponderosa pine type.

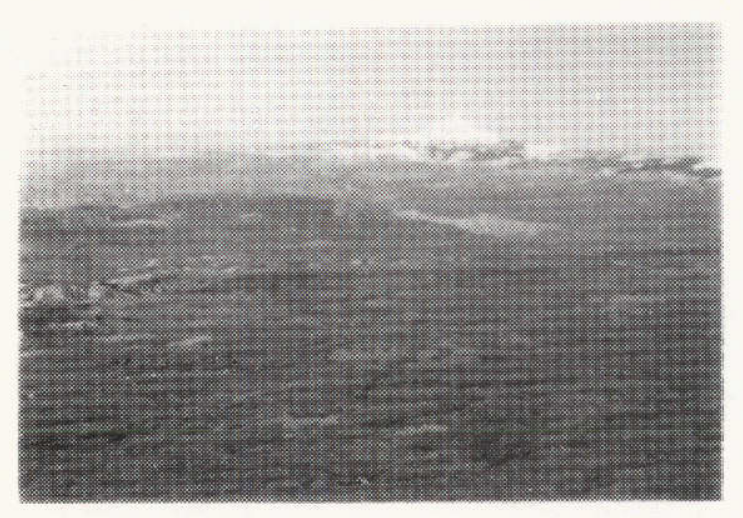

Eigure 15. This scene provides a perspective of the high elevation zonational pattern. This photograph was taken in May as the first clones of aspen were beginning to leaf out at the lower elevations (note the green patch of aspen in the foreground). The extensive surrounding type is oakbrush in the deciduous stage. The gray areas in the foreground and the grayish belt just below the snow and conifer line in the background are stands of aspen. The darker toned areas around the lake are ponderosa pine, and the near black areas interspered with the snow fields are spruce-fir. 
at about 5,900 to 6,000 feet elevation and the commercial forest types at about 7,000 to 8,000 feet. Spruce-fir and aspen are common in the 9,000 to 10,000 foot elevations and timberline generally is well above 10,000 feet.

Landforms are particularly evident on the imagery and, for the experienced interpreter, the landform-vegetation relationships are a particular aid to interpretation.

This test area is judged to be excellent for the purposes of this study because:

1. Coverage was acquired with all of the ERTS and EREP image types being tested. In addition, stereo coverage with the EREP SI9OA color infrared film was also obtained. All are of good quality and provide very suitable test material.

2. A large amount of excellent ground data is avajlable, carefully and accurately plotted on 1/250,000 topographic map sheets, which permitted accurate identification of both training examples and test items throughout the test area.

3. Broad vegetation zones are well represented in the test area.

4. In addition to the broad vegetation zonation, there are extremely intricate patterns of vegetation that, in some areas, alternate sharply between both contrasting and noncontrasting vegetation types. This provides an excellent opportunity for. comparing the power of the image types to resolve the intricate 
patterns as well as to record an identifiable signature.

5. There is an extremely diverse land use pattern in the area which helps to give the test a particular practical meaning and value. Forestry, range, wildlife, agriculture, watershed, and recreation are all important 1and uses, with some mineral development in or close to the test area.

The only imagery-related difficulty encountered was that cloud cover somewhat restricted the selection of training examples and test items for the image date common to both systems. Nevertheless, a valid representation of each category was selected from the cloud-free image area.

\section{E. IMAGERY ACQUIRED}

On each of three occasions during the 1973 growing season both test areas were imaged by ERTS and EREP systems on nearly the same calendar dates. The dates of coverage are summarized as follows:

\section{Test Site/Seasonal State}

Northern Great Valley/Late Spring Colorado Plateau/Summer Northern Great Valley/Late Summer

$$
\text { ERTS } \frac{\text { Date of Coverage }}{\underline{\text { EREP }}}
$$

May 28, $1973 \quad$ June 3, 1973 August 16, $1973 \quad$ August $3 \& 8,1973$ September 13, 1973 September 12, 1973

Table 1 contains a detailed Tisting of the imagery data, grouped by system and test area, which pertain to the images selected for the test. 
TABLE 1

IMAGES USED FOR ERTS/SKYLAB INTERPRETATION TESTS

OF AGRICULTURAL AND NATURAL VEGETATION FEATURES

\begin{tabular}{|c|c|c|c|c|c|}
\hline MISSION & SENSOR & TEST AREA & DATE & IMAGE ID & FILM -FILTER/WAVELENGTH INTERVAL, $\mu \mathrm{m}$ \\
\hline \multirow[t]{3}{*}{ ERTS- 1} & \multirow[t]{3}{*}{$\begin{array}{l}\text { Multispectral } \\
\text { Scanner (MSS) }\end{array}$} & \multirow[t]{2}{*}{$\begin{array}{l}\text { Sacramento } \\
\text { Valley, CA }\end{array}$} & May 28,1973 & $1309-18174$ & $\begin{array}{l}\text { Band } 5 / 0.6-0.7 \\
\text { Band } 7 / 0.8-1.1 \\
\text { Color Composite }-- \\
\quad \text { Bands } 4,5,7 / 0.5-1.1\end{array}$ \\
\hline & & & Sept. 13, 1973 & $1417-18161$ & $\begin{array}{l}\text { Band } 5 / 0.6-0.7 \\
\text { Band } 7 / 0.8-1.1 \\
\text { Color Composite }-- \\
\quad \text { Bands } 4,5,7 / 0.5-1.1\end{array}$ \\
\hline & & $\begin{array}{l}\text { Colorado } \\
\text { Plateau }\end{array}$ & Aug. 16, 1973 & $1389-17195$ & $\begin{array}{l}\text { Band } 5 / 0.6-0.7 \\
\text { Band } 7 / 0.8-1.1 \\
\text { Color Composite }-- \\
\quad \text { Bands } 5,7 / 0.6-1.1 \\
\end{array}$ \\
\hline SKYLAB 2 & $\begin{array}{l}\text { S190A Multi- } \\
\text { spectral Photo- } \\
\text { graphic Camerá } \\
\text { (MPC) }\end{array}$ & $\begin{array}{l}\text { Sacramento } \\
\text { Valley, CA }\end{array}$ & June 3,1973 & $\begin{array}{l}\text { (ro11- frame) } \\
05-157 \\
02-157 \\
04-157 \\
03-157\end{array}$ & $\begin{array}{l}\text { Pan-X B/W (SO-022) - BB/0.6-0.7 } \\
\text { IR B/W (EK 2424) - DD/0.8-0.9 } \\
\text { High Resolution Color (S0-356) - FF/0.4-0.7 } \\
\text { Color IR (EK 2443) - EE/0.5-0.88 }\end{array}$ \\
\hline \multirow[t]{4}{*}{ SKYLAB 3} & \multirow[t]{2}{*}{$\begin{array}{l}\text { S190A Multi- } \\
\text { spectral Photo- } \\
\text { graphic Camera } \\
\text { (MPC) }\end{array}$} & $\begin{array}{l}\text { Colorado } \\
\text { Plateau }\end{array}$ & August 3,1973 & $\begin{array}{l}23-003 \\
20-003 \\
22-003 \\
21-003,004\end{array}$ & $\begin{array}{l}\text { Pan-X B/W (SO-022) - BB/0.6-0.7 } \\
\text { IR B/W (EK 2424) - DD/0.8-0.9 } \\
\text { High Resolution Color }(S 0-356)-F F / 0.4-0.7 \\
\text { Color IR (EK 2443)- EE/0.5-0.88 }\end{array}$ \\
\hline & & $\begin{array}{l}\text { Sacramento } \\
\text { Valley, CA }\end{array}$ & Sept. 12,1973 & $\begin{array}{l}41-140 \\
38-140 \\
40-140 \\
39-140 \\
\end{array}$ & $\begin{array}{l}\text { Pan-X B/W (SO-022) - BB/0.6-0.7 } \\
\text { IR B/W (EK 2424) - DD/0.8-0.9 } \\
\text { High Resolution Color (SO-356) - FF/0.4-0.7 } \\
\text { Color IR (EK 2443)- EE/0.5-0.88 }\end{array}$ \\
\hline & \multirow[t]{2}{*}{$\begin{array}{l}\text { S190B Earth } \\
\text { Terrain Camera } \\
\text { (ETC) }\end{array}$} & $\begin{array}{l}\text { Colorado } \\
\text { Plateau }\end{array}$ & August 8,1973 & 83-309 & High Resolution Color (S0-242) - none/0.4-0.7 \\
\hline & & $\begin{array}{l}\text { Sacramento } \\
\text { Valley, CA }\end{array}$ & Sept. 12, 1973 & $86-320$ & High Resolution Color (S0-242) - none/0.4-0.7 \\
\hline
\end{tabular}




\section{QUANTITATIVE TEST OBJECTIVES}

The specific objectives of the quantitative agricultural crop and natural vegetation tests, respectively, were as follows:

A. AGRICULTURAL CROP TESTS

Test 1: To determine the relative crop identification accuracy achieved with eight types of ERTS and EREP imagery acquired at one seasonal state (late summer) for one agricultural area (Northern Great Valley of California).

Test 2: To determine the relative crop identification accuracy achieved with seven types of ERTS and EREP imagery acquired at a different seasonal state (late spring) for a portion of the same geographic area as selected for Test 1. The value of each season (late spring and late summer) for crop identification was also assessed.

Test 3: To determine the relative accuracy of ERTS color composite imagery and EREP SI9OA IR color photography for stratification (delineation) of rice-growing regions within selected portions of the Northern Great Valley Test Area (late spring seasonal state).

B. NATURAL VEGETATION TESTS

Test 4: To determine the relative accuracy of identification of natural vegetation types achieved with eight types of ERTS and EREP imagery acquired at one seasonal state (summer) for one wildland area (Colorado Plateau). 
Test 5: To determine the value of stereoscopic viewing for identification of natural vegetation types using one type of EREP imagery (S190A color IR). 


\section{QUANTITATIVE TEST PROCEDURES}

\section{A. IMAGE FORMAT}

Preliminary tests were made by EarthSat personnel to estab7ish the fact that enlarged positive prints were essentially as interpretable as positive transparencies. Consequently it was decided to administer the interpretation tests using entarged positive prints for the following two reasons:

1) At least five copies of each image were needed so that each section of five interpreters (from a group of 20) could interpret the same image at the same time.

2) Substantial image enlargement was required so that test items could be annotated without confusion and interpretation could proceed without providing each interpreter with high-powered magnification capability.

All formal photo interpretation testing was accomplished using the imagery in a positive print form ( $1 / 150,000$ scale for the Northern Great Valley area; 1/500,000 scale for the Colorado Plateau area). These prints were made from copy negatives produced from the positive transparencies sent to the investigators for their ERTS and EREP experiments. Of the black-and-white negatives received, only the EREP negatives were of sufficient quality to permit direct enlargement (printing) from them. ERTS black-and-white negatives were too dense; the positive transparencies 
were used as the image source instead, with copy negatives made as the interim step to obtain positive prints. Examples of each of the image types tested appear in Appendix $A$ and should be referred to when the interpretation test results derived from those particular images are discussed.

Much of the subjective (non-testing) analys is was undertaken with the positive transparencies in order that unnecessary variation in photographic characteristics could be avoided. Since the subjective analysis was undertaken by only one or two individuals at a time, it was feasible to work directly with the positive transparencies under magnification.

The most critical operational problem in testing was the achievement of consistent and uniform color balance among the prints compared. For the Northern Great Valley Test Area a set of test images of uniform quality was used. Although slight variation in image scale did occur for some of the images, this was judged not to affect the image signatures of the test categories. Comparative color balance on the two members of the stereo model used in the natural vegetation test was excellent. Among the color prints used in the monocular natural vegetation test, the EREP S190A color image was undesirably dark in the entire forested area, thus probably detracting from the quality of interpretation of the forest types with this film-filter combination. 
The EREP S190A color infrared image had good color balance and matched rather well the color balance of the frame used for the stereo testing. The EREP ST $90 B$ color image had good color differentiation throughout. The ERTS color composite image was reconstituted from bands 5 and 7 only. These were the only bands available for the required date. It was a rather good quality color product, although it did not contain the typical color signatures to which most experienced interpreters of ERTS color composites made from bands 4,5 and 7 would have been accustomed. Since the training sets were individually identified for each of the film-filter types, this was judged not to be a problem in the evaluation.

B. GENERAL METHODOLOGY

The design and implementation of each test was similar. Therefore, a description of the procedures used for Test 1 will be presented in detail. The specifics of each of the other tests are outlined in Table 2.

Test 1 Objective: To determine the relative identification accuracy for agricultural crops achieved using eight types of ERTS and EREP imagery for one seasonal state (1ate summer) for one agricultural area (Northern Great Valley, California). 
TABLE 2

SUMMARY OF ERTS/EREP IMAGE INTERPRETATION TESTS

\begin{tabular}{|c|c|c|c|c|c|c|}
\hline $\begin{array}{l}\text { TEST } \\
\text { NUMBER } \\
\end{array}$ & $\begin{array}{c}\text { TEST } \\
\text { OBJECTIVE } \\
\end{array}$ & IEST AREA & $\begin{array}{c}\text { NUMBER OF PHOTO } \\
\text { INTERPRETERS }\end{array}$ & IMAGE TYPES & $\begin{array}{l}\text { TEST CATEGORIES/NUMBER } \\
\text { OF TEST ITEMS PER CATEGORY }\end{array}$ & $\begin{array}{l}\text { TOTAL PI RESPONSES PER } \\
\text { CATEGORY PER IMAGE TYPE }\end{array}$ \\
\hline 1 & $\begin{array}{l}\text { Agricultural Crop } \\
\text { Identification } \\
\text { (late summer } \\
\text { seasonal state) }\end{array}$ & $\begin{array}{l}\text { Sacramento Valley, } \\
\text { CA (Marysville and } \\
\text { Sutter Sites) }\end{array}$ & 40 & $\begin{array}{l}\text { ERTS Band } 5 \\
\text { ERTS Band } 7 \\
\text { ERTS Color Composite } \\
\text { SKYLAB } 190 \mathrm{~A} / \mathrm{W} \text { (red) } \\
\text { SKYLAB } 190 \mathrm{~B} / \mathrm{W} \text { (IR) } \\
\text { SKYLAB } 190 \mathrm{~A} \text { Color } \\
\text { SKYLAB 190A Color IR } \\
\text { SKYLAB 190A High Res. } \\
\text { Color }\end{array}$ & $\begin{array}{l}\mathrm{R}(\text { rice }) / 10 \\
0 \text { (archard)/10 } \\
\mathrm{A} \text { (alfalfa)/10 } \\
\mathrm{F} \text { (fallow)/10 } \\
G \text { (dryland pasture)/10 } \\
X \text { (other agric. crops)/10 }\end{array}$ & $\begin{array}{l}400 \\
400 \\
400 \\
400 \\
400 \\
400\end{array}$ \\
\hline 2 & $\begin{array}{l}\text { Agricultural Crop } \\
\text { Identification } \\
\text { (7ate spring } \\
\text { seasonal state) }\end{array}$ & $\begin{array}{l}\text { Sacramento Valley, } \\
\text { CA (Marysville } \\
\text { Site) }\end{array}$ & 10 & $\begin{array}{l}\text { ERTS Band } 5 \\
\text { ERTS Band } 7 \\
\text { ERTS Color Composite } \\
\text { SKYLAB I90A B/W (red) } \\
\text { SKYLAC } 190 A \text { B/W (IR) } \\
\text { SKYLAB 190A Color } \\
\text { SKYLAB 190A Color IR }\end{array}$ & $\begin{array}{l}\mathrm{R} \text { (rice) } / 6 \\
0 \text { (orchard)/7 } \\
\mathrm{A} \text { (alfalfa)/6 } \\
\mathrm{F} \text { (fallow)/3 } \\
\mathrm{G} \text { (dryland pasture) } / 7 \\
\mathrm{X} \text { (other agric. crops) } / 3\end{array}$ & $\begin{array}{l}60 \\
70 \\
60 \\
30 \\
70 \\
30\end{array}$ \\
\hline 3 & $\begin{array}{l}\text { Stratification of } \\
\text { Rice-Growing Region } \\
\text { (late spring } \\
\text { seasonal state) }\end{array}$ & $\begin{array}{l}\text { Sacramento Valley, } \\
\text { CA (Marysville } \\
\text { Site) }\end{array}$ & 10 & $\begin{array}{l}\text { ERTS Color Composite } \\
\text { SKYLAB SI90A Color IR }\end{array}$ & $\begin{array}{l}\text { Rice, non-rice; } 2 \text { outlined } \\
\text { test areas for delineation - } \\
\text { total area }=17 \mathrm{sq} \text {. mi. }\end{array}$ & 20 delineated test areas \\
\hline 4 & $\begin{array}{l}\text { Natural Vegetation } \\
\text { Type Identification } \\
\text { (summer } \\
\text { seasonal state) }\end{array}$ & Colorado Plateau & 40 & $\begin{array}{l}\text { ERTS Band } 5 \\
\text { ERTS Band } 7 \\
\text { ERTS Color Composite } \\
\text { SKYLAB 190A B/W (red) } \\
\text { SKYLAB 190A B/W (IR) } \\
\text { SKYLAB 190A Color } \\
\text { SKYLAB 190A Color IR } \\
\text { SKYLAB 190B High Res. } \\
\text { Color }\end{array}$ & $\begin{array}{l}\mathrm{J} \text { (pinyon-juniper woodland)/10 } \\
\mathrm{P} \text { (ponderosa pine forest)/10 } \\
\mathrm{W} \text { (sedge (wet) meadow)/10 } \\
\mathrm{A} \text { (aspen forest)/10 } \\
\mathrm{S} \text { (spruce-fir forest) } / 10 \\
\mathrm{X} \text { (other vegetation types)/10 }\end{array}$ & $\begin{array}{l}400 \\
400 \\
400 \\
400 \\
400 \\
400\end{array}$ \\
\hline 5 & $\begin{array}{l}\text { Value of Stereo- } \\
\text { scopic Viewing } \\
\text { for Natural } \\
\text { Vegetation Type } \\
\text { Identification } \\
\text { ( summer } \\
\text { seasonal state) }\end{array}$ & Colorado Plateau & 10 & SKYLAB 190A Color IR & $\begin{array}{l}\mathrm{J} \text { (pinyon-juniper woodland)/10 } \\
\mathrm{P} \text { (ponderosa pine forest)/10 } \\
\mathrm{W} \text { (sedge (wet) meadow)/10 } \\
\mathrm{A} \text { (aspen forest)/10 } \\
\mathrm{S} \text { (spruce-fir forest)/10 } \\
\mathrm{X} \text { (other vegetation types } / 10 \text {. }\end{array}$ & $\begin{array}{l}100 \\
100 \\
100 \\
100 \\
100 \\
100\end{array}$ \\
\hline
\end{tabular}


Agricultural Crop Categories:

$\mathrm{R}$ - rice

0 - orchard

A - alfalfa

$F$ - fallow

$G$ - dryTand pasture (grass)

$X$ - other agricultural crops

Image Types (positive prints, approximate scale $=1 / 150,000$ ):

$B / W: 1$. ERTS MSS $B$ and 5

2. ERTS MSS B and 7

3. SKYLAB 190A (red)

4. SKYLAB 190A (infrared)

COLOR: 5. ERTS Color Composite

6. SKYLAB 190A Color

7. SKYLAB 190A Color Infrared

8. SKYLAB 190B Color (high resolution)

Test Format (each test item marked by an annotated dot on an acetate image overlay):

Training examples: 2 per test category per image type

Test $i$ tems: 10 per category per image type ( $=60$ per image type)

Time for interpretation: approximately 5 minutes per image type for training;30 seconds per test item (30 minutes per image type for the actual testing).

Interpreter Assignments (using 40 students who currently were taking photo-interpretation courses at the University of California; see Appendix B):

Group I (20)
Subdivided into sections $A, B, C, D$ Subdivided into II (20)
Sections $A, B, C, D$

Four sections of five interpreters each were chosen in such

a way as to include in each section a range from high to low ability as determined from University course progress. 
Interpretation Sequence (same image sequence and test procedure duplicated for Groups I and II):

The image sequence was rotated so that each image was interpreted in a different sequence by each section of five interpreters, thus minimizing bias due to interpretation sequence. May 16, 1974 - Color Images (5-8)

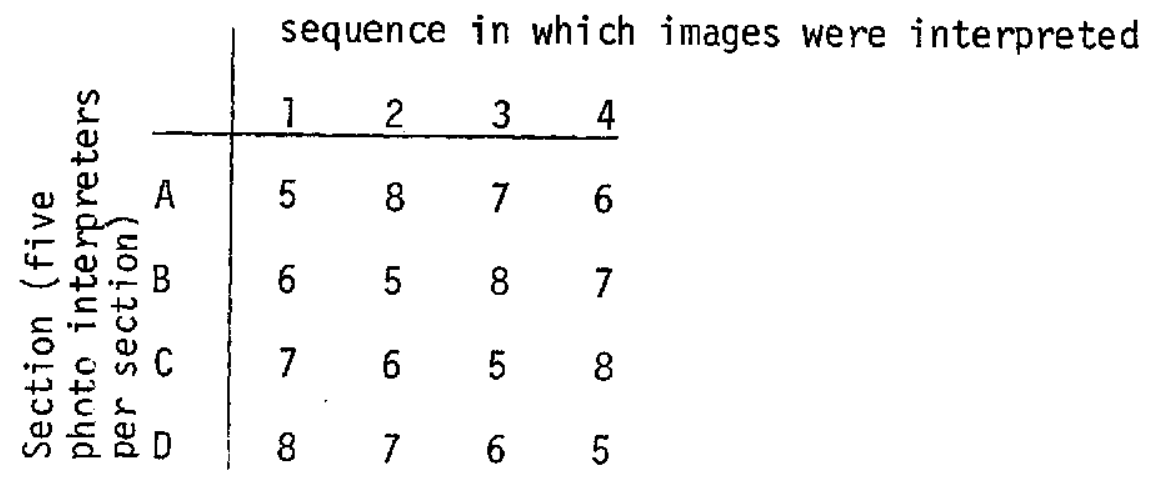

May 23, 1974 - B/W Images (1-4)

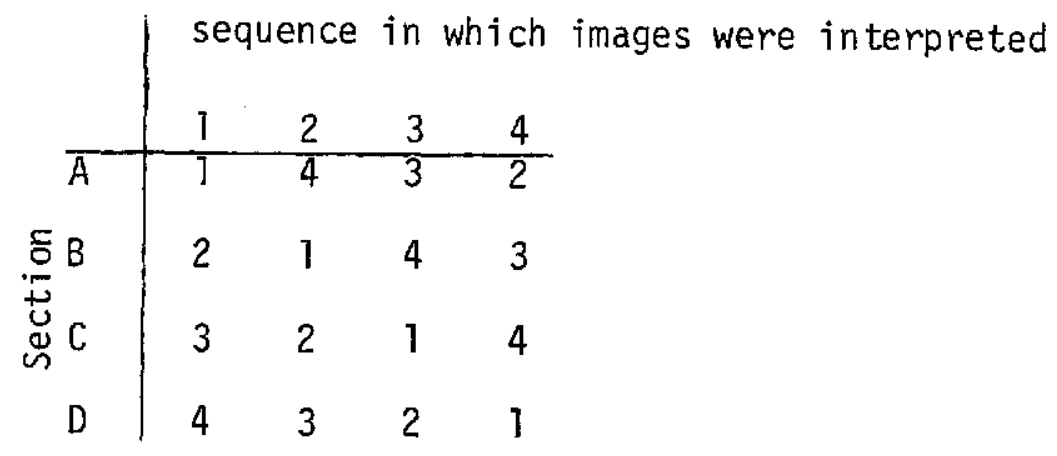

Photo Interpretation Responses (sample response sheet, Figure 16): ( 10 reponses/crop category) $\times(6$ crop categories/image $) \times(8$ images/PI) $=480$ responses $/ \mathrm{PI}$

Each test image was accompanied by a clear acetate overlay containing an annotated sequence of training and test items. With 
Figure 16: Sample interpretation test response sheet

PI RESPONSE SHEET

ERTS SKYLAB AGRICULTURAL PI TEST

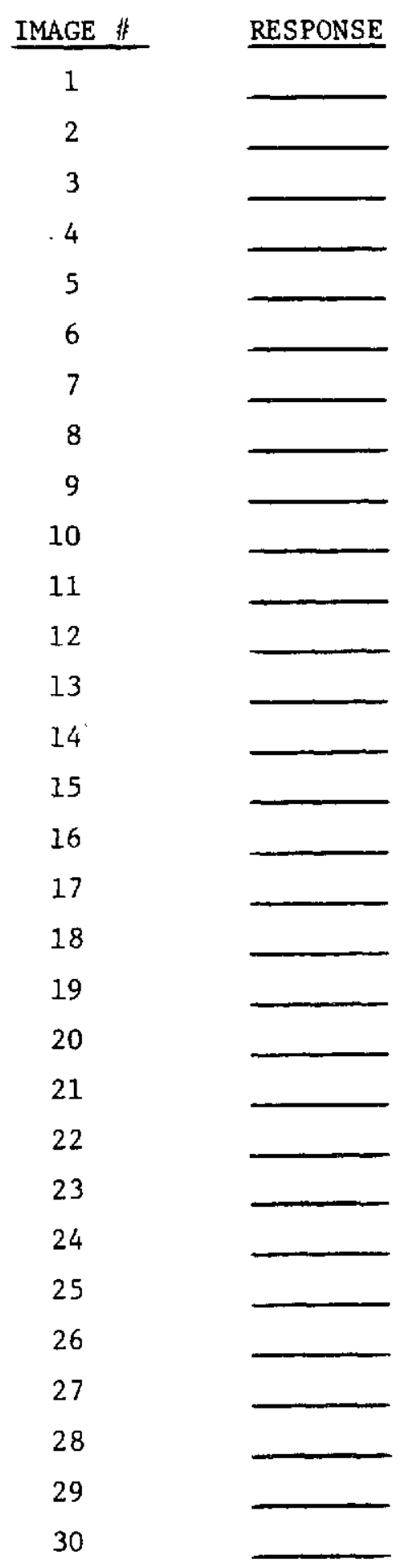

NAME :

IMAGE :

GROUP : SECTION :

\begin{tabular}{|c|c|}
\hline IMAGE 非 & RESPONSE \\
\hline 31 & \\
\hline 32 & \\
\hline 33 & \\
\hline 34 & \\
\hline 35 & \\
\hline 36 & \\
\hline 37 & \\
\hline 38 & \\
\hline 39 & \\
\hline 40 & \\
\hline 41 & \\
\hline 42 & \\
\hline 43 & \\
\hline 44 & \\
\hline 45 & \\
\hline 46 & \\
\hline 47 & \\
\hline 48 & \\
\hline 49 & \\
\hline 50 & \\
\hline 51 & \\
\hline 52 & \\
\hline 53 & \\
\hline 54 & \\
\hline 55 & \\
\hline 56 & \\
\hline 57 & \\
\hline $5 \grave{8}$ & \\
\hline 59 & \\
\hline 60 & \\
\hline
\end{tabular}

KEY TO TEST RESPONSES:

$\mathrm{R}$ - rice

O - orchard

A - alfalfa

F - fallow

$G$ - dryland pasture

$X$ - other agricultural crops 
the overlay positioned correctly, each labelled dot fell well within a uniform image area belonging to one of the test categories. The interpreters were asked to make judgments regarding the identity of the image area within the vicinity of each dot. Instructions were standardized so that each interpreter would proceed in the same manner during the entire testing period (Appendix B). During the training phase, interpreters were instructed to study the image characteristics of each category. Two examples of each category (which were judged to be representative of that category within the test area) were provided for this purpose. The interpreters were asked to establish for themselves the image attributes (color or tone, texture, pattern, shape, topographic position, etc.) which characterized each category. No interpretation key or other descriptive material was provided. Each interpreter, working independently, established his own criteria for identifying the test items.

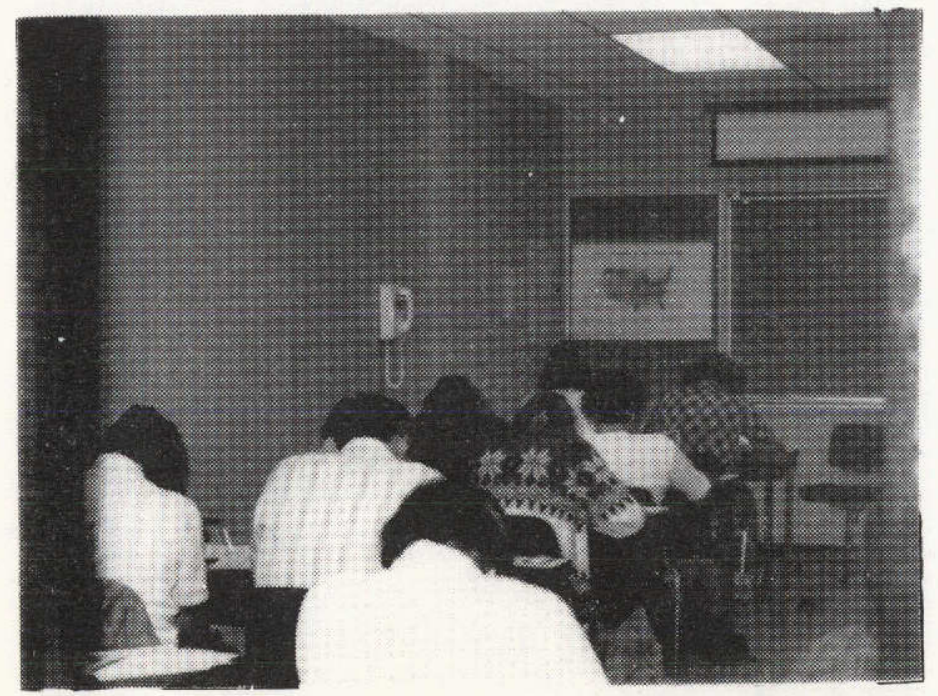

Figure 17. View of one of the interpreter groups at work in the EarthSat Berkeley classroom. 
The testing phase (Figure 17) was accomplished using a uniform time interval of 30 seconds for each test item (30 minutes for each test image of 60 test items). $\underline{1}$ For a particular set (e.g., the eight image types comprising Test 1), the sequence of image types was rotated as previously described. The interpreters were asked to study each test item on a given image type, compare it to the training examples, and decide which of the categories it most closely resembled. The letter code of the category selected for that test item was then to be recorded on the response sheet (Figure 16).

c. ADDITIONAL BACKGROUND PROVIDED TO INTERPRETERS FOR NATURAL VEGETATION TESTS

The ecological knowledge and understanding of the photo interpreter is a strong determinant of both the accuracy and information content of his interpretations of natural vegetation ecosystems. In an operational context, each interpreter must know what to expect on the landscape being interpreted. This means that he must use prior field experience in the project area to understand the kinds of vegetation which occur, the interrelationship of the vegetation types one to another, and their relationship to the topographic and soil environment. To the extent that this knowledge grows, his interpretation ability increases. For an image comparison test, variable knowledge among interpreters regarding

1/ The instructor in charge also served as a "timer" by orally stating (after 25 of the 30 seconds had elapsed for interpreting a given test item) " 5 seconds left" and then by announcing the number of the next test $i$ tem at the end of each 30 second period. The students used in these tests reacted favorably to this procedure. 
the area and its ecology may introduce additional and undesirable variability into the test. Ideally, as a test of the imagery alone, it would be best if all interpreters were at the same knowledge level. Thus, the test results should reflect differences in image characteristics, not differences in interpreter ability.

In this test, photo interpreters were used who, as a group, knew little about the plant ecology of the Colorado Plateau Test Area. A brief illustrated lecture on vegetation types and ecological zonation in the region of the Test Area was presented so that all interpreters would begin at the same level of understanding. The background material was presented without reference to the specific test area or to the ERTS or EREP image signatures of the various classes to be interpreted. The natural vegetation categories discussed are listed in Table 2. The lecture included presentation of the complete zonation of these categories from the saltdesert, shadscale types typical of the deeper, drier valleys through the sagebrush, juniper, ponderosa pine, and spruce-fir zones. Colored photographic illustrations (Figures 5 through 10 ) showed a ground view of the vegetation types that typified each zone. A few low altitude aerial obliques (Figures 11 through 15) were shown to provide the interpreters with a better feeling for the zonation patterns and the ways in which vegetation from one zone interlaces with that of another in the test region. All of the ground shots and aerial obliques, were of analogous locations, not of specific test or training areas. Examples included all of the categories used in the 
test as well as other typical vegetation found in the region but excluded from the test set. The presentation was concluded by showing the interpreters a distant, high oblique view across an analogous zonational pattern near the test area to give them a perspective of the physiographic relationships.

In the above presentation, specific ERTS or Skylab image characteristics associated with each vegetation type were not mentioned. It was left entirely to the individual interpreters as they studied and analyzed the two training examples of each test category to develop the image-subject relationship criteria they would individually use in the interpretation tests. 


\section{SUBJECTIVE TEST PROCEDURES}

A. NORTHERN GREAT VALLEY TEST AREA

1. Minimum Field Size and General Land Use

Time available for formal interpretation testing was limited and certain questions did not lend themselves we 11 to the formal testing procedure. A subjective analysis of the eight different image types was performed by experienced members of the project staff who judged the minimum field size consistently detected and the certainty with which land use categories could be identified on the test images. The subjective analysis was documented by preparing tables listing each of the various $f i l m / f i l t e r / s y s t e m$ combinations and placing interpretation results in the appropriate columns.

Agricultural fields of known sizes were studied on each image type and the minimum field size consistently identifiable was recorded as a range of values for both high and low contrast targets. In a separate anatysis, tables were prepared listing various land use categories and the degree of certainty of detecting and identifying the various land use classes. One tabular display shows the certainty of identification for interpretation of single images. Another was prepared for results from viewing two images at a time, side-by-side, by visual comparison of each feature of interest. 
2. Seasonal Aspects and Frequency of Coverage

The seasonal aspects of agricultural interpretation were also considered, as well as the frequency of image coverage available.

For the Northern Great Valley of California, sequential ERTS-1 coverage was available for the periods from mid-April through September. Using these images taken at 18 day intervals, certain judgements were made regarding the frequency of coverage desired from an observation satellite. A discussion of these findings is contained in Section VI A.

3. Crop Vigor Evaluation and P1 ant Stress Detection

Also included as a phase of qualitative testing was the assessments of the role of ERTS and EREP imagery for evaluating crop vigor and detecting plant stress. The investigators relied heavity upon the experience they have gained from on-going ERTS and SKYLAB experiments to draw conclusions regarding the utility of data from both satellite systems for vigor and stress assessment.

4. Multidate Image Enhancement

Interpreting multidate and multiband images is often a difficult process when done by purely manual means--that is, by visually viewing one image at a time and comparing its informa- 
tion content with that of another image. Several methods of combining multiple images are in use that greatly simplify the display of these images. With these methods, certain unique colors or tonal values are assigned to particular features of interest.

A limited number of jmage enhancements have been prepared for this study which take advantage of the unique color associated with a particular vegetation type when images of the same area from two dates have been combined by additive color projection.

A variety of image combinations can be made, such as using various bands on various dates and even using both positive and negative images in producing additive color photos. Obviously, much unproductive effort can be applied to making various additive color images unless carefur thought is given to the component photos used before starting.

\section{B. COLORADO PLATEAU TEST AREA}

Subjective analysis of the Colorado Plateau Test Area imagery focused on three major tasks: (1) assessing the relative utility of each of the image types for interpretation of natural vegetation categories; (2) ranking the image types according to their usefulness for vegetation mapping, and (3) evaluation of the effect of image quality on vegetation interpretation. These results were undertaken by experienced interpreters well-versed in the ecology of the Test Area and its land form/vegetation relationships. 
V. QUANTITATIVE TEST RESULTS AND ANALYSIS

A. NORTHERN GREAT VALLEY TEST AREA

1. Test 1 -Crop Identification, Late Summer Seasonal State

Interpretation results from each interpreter response sheet were scored and tabulated in matrix form to indicate the correct responses as well as the occurrence of omission and commission errors (Figure 18). For Test 1, a total of 60 responses occupy each such matrix ( 6 categories $\times 10$ test items per category for each image type). Results from Tests 2 through 5 were also tabulated in a similar fashion.

The tabulated data (correct responses) were subjected to a two-way analysis of variance. Tests of significance were performed for the main effects (image type and crop category) and interactions, and all were found to be very highly significant.

Results of pairwise comparisons across the image type effects using Tukey's method are presented in Table 3. Each entry in this table represents the mean number of correct responses (maximum possible $=10$ ) for each crop category from each image type, based on the 400 responses obtained collectively from the 40 students who took this test.

For a given crop category (e.g., within a column on TabTe 3), the starred entries fall within a confidence interval of \pm 0.5 response and are significantly different from the other image types. All other entries in that column fall outside this 


Name Menashe
Group-Section I I - A
Image Skylab 190A CIR

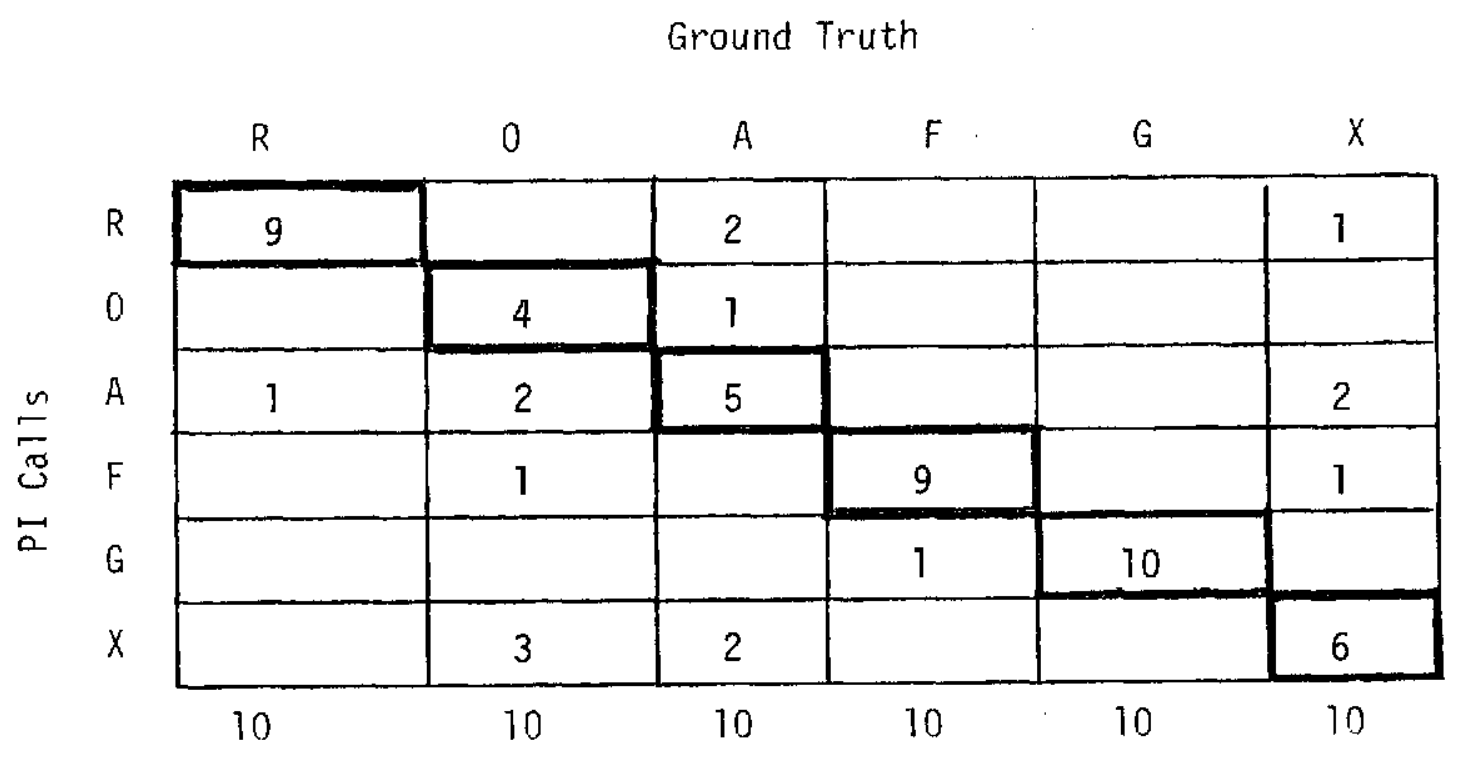

Figure 18. Sample response matrix for Test 1. Correct responses appear in the outlined diagonal boxes. This interpreter achieved $71.7 \%$ correct $(43 / 60)$ for the Skylab 190A CIR image. He made very accurate responses for 3 categories (rice, fallow, and dryland pasture) and was less accurate in his interpretation of orchard, alfalfa, and other agricultural crops. 


\section{TABLE 3}

\section{ANALYSIS OF TEST I DATA \\ (CROP IDENTIFICATION TEST, \\ LATE SUMMER SEASONAL STATE) \\ BY MEANS OF TUKEY'S METHOD OF \\ PAIRWISE COMPARISON}

Entries in the table below are mean number of correct responses per interpreter. Starred entries within a column fall with in a confidence interval of +0.5 response and form an image class which is significantly different from the unstarred entries, and are therefore best for the interpretation of the crop category which heads that column. The far right column contains the average for all categories. Note that the ERTS color composite and EREP I90A Color IR images are significantly different from the other image types and, therefore, better for overall interpretive purposes. If no interpretation errors had been made by any of the 40 students, all entries in this takle would contain the figure "10.0."

\begin{tabular}{|c|c|c|c|c|c|c|c|c|}
\hline & \multicolumn{7}{|c|}{ CROP CATEGORY } \\
\hline & & Rice & Orchard & Alfalfa & Fallow & $\begin{array}{l}\text { Dryland } \\
\text { Pasture }\end{array}$ & $\begin{array}{l}\text { Other } \\
\text { Agric. }\end{array}$ & $\begin{array}{l}\text { Average } \\
\text { for } \\
\text { All } \\
\text { Catagories } \\
\end{array}$ \\
\hline \multirow{8}{*}{ 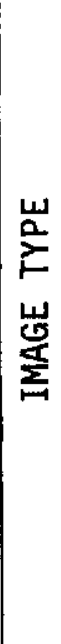 } & ERTS-5 & 4.7 & 4.5 & 5.8 & 5.1 & $* 9.2$ & 3.8 & 5.5 \\
\hline & ERTS-7 & 6.9 & 7.4 & $\star 7.8$ & 3.8 & 7.0 & 5.6 & 6.4 \\
\hline & ERTS Color Composite & 7.1 & $\star 7.9$ & 5.4 & $\star 8.1$ & $* 9.4$ & $* 6.8$ & $\star 7.4$ \\
\hline & EREP $190 \mathrm{~A} \mathrm{~B} / \mathrm{W}$ Red & 5.9 & 4.8 & 4.6 & 6.8 & 8.7 & 5.5 & 6.0 \\
\hline & EREP $190 \mathrm{~A} \mathrm{~B} / \mathrm{W}$ IR & 7.4 & 6.5 & $\star 7.7$ & 4.3 & 7.4 & 6.4 & 6.6 \\
\hline & EREP T9OA CoIor & $* 8.3$ & 7.1 & 4.6 & 6.2 & $* 9.0$ & 5.1 & 6.7 \\
\hline & EREP $190 \mathrm{~A}$ Color IR & 7.3 & $\star 8.0$ & 5.8 & $* 7.8$ & $\star 8.9$ & $\star 7.2$ & $\star 7.5$ \\
\hline & EREP $190 \mathrm{~B}$ CoIor & 7.6 & 7.3 & 4.8 & 6.8 & 8.6 & 5.8 & 6.8 \\
\hline
\end{tabular}


interval. Within the orchard category, for example, the ERTS color composite and EREP ST90A color infrared image form an image set which is significantiy different from the others and best for identifying orchard crops.

Overall identification accuracy is also presented in Table 3 for Test 1. Overa11 results for the ERTS color composite and Skylab S190A images are significantly different from the other image types, but there is no difference between thent. The set of eight image types is ranked in the following manner with no statistical significance assigned to the ranking (extracted from Table 3):

Image Type

EREP ST90A COIOr IR

ERTS Color Composite EREP S190B Color EREP S190A Color EREP SI90A B/W IR ERTS Band 7 EREP S190A B/W Red ERTS Band 5

\section{Overall Average \\ Correct Responses (a) crop categories) $1 /$}

7.5

7.4

6.8

6.7

6.6

6.4

6.0

5.5

I/ Maximum possible $=70$

Commission errors were also analysed using a two-way analysis of variance. Tests of significance were performed for the main effects (image type and crop category) and interactions, and ali were found to be very highly significant. Pairwise comparisons were made using Tukey's method. The image type(s) which 
formed a group that was significantly different from the others (lowest commission error) are listed in Table 4.

From a standpoint of commission error, Table 4 suggests that the ERTS color composite might be favored over the EREP S190A color IR image. This conclusion is indicated because the ERTS coTor composite appears four times in Table 4, while the SI90A color IR image appears only twice.

2. Test 2 - Crop Identification, Late Spring Seasonal State

The objectives and format of Test 2 were parallel to Test 1 with the following exceptions:

1) Imagery for the late spring seasonal state was used instead of late summer seasonal state.

2) Skylab EREP S190B color imagery was not acquired at this date and therefore not tested.

3) The Sutter Test Site was not imaged by Skylab at this date, and the number of test $i$ tems common to both tests (in the Marysville Test Site) was therefore reduced from 60 to 32 .

4) Only 10 students were used for this test. Test responses were normalized and the results expressed on a basis of 10 test items per category. In this way, results of this test can be compared with Test 1 .

The tabulated data were subjected to a two-way analysis of variance. Tests of significance were performed for the main 
TABLE 4

ANALYSIS OF TEST $I$ DATA (CROP IDENTIFICATION TEST)

RANKING BY IMAGE TYPES BY COMMISSION ERROR

For each of the crop categories listed below, the image type(s) are given which form a group that is significantly different from all others in terms of commission error (using Tukey's method of pairwise comparison). These image types are those for which commission errors are lowest.

\section{Crop Category}

Rice

Orchard

Alfalfa

Fallow

Dryland Pasture

Other Agricultural Crops
Image Type

\section{ERTS Band 7}

EREP ST90A B/W IR

ERTS Color Composite EREP S190A Color IR

EREP ST 90A Color

ERTS Band 5

EREP ST $90 A$ B/W IR

ERTS Color Composite

ERTS Color Composite

ERTS Color Composite EREP ST $90 A$ Color IR 
effects (image type and crop category) and interactions, and all were found to be very highly significant.

Results of pairwise comparisons across the image type effects using Tukey's method are tabulated in Table 5. Each entry in this table represents the mean number of correct responses (normalized to a maximum possible of 10 ) for each crop category from each image type.

For a given crop category (e.g., within a column on Table 5), the starred entries fall within a confidence interval of \pm 3.2 responses and are significantly different from the other image types. A1l other entries in that column fall outside this interva?.

Overall identification accuracy is also presented in Table 5 for Test 2. Overall results for the EREP S190A color and EREP ST90A color IR images are significantly different from the other image types, but there is no difference between them. The set of seven image types (EREP S190B color image not tested) is ranked in the following manner (extracted from Table 5):

$\begin{array}{lr}\text { Image Type } & \begin{array}{r}\text { Overal1 } \\ \text { Correct Res } \\ \text { Lall crop cat }\end{array} \\ \text { EREP S190A Color } & 7.1 \\ \text { EREP ST90A Color IR } & 7.0 \\ \text { ERTS Color Composite } & 6.1 \\ \text { ERTS Band 5 } & 5.9 \\ \text { EREP S190A B/W Red } & 5.8 \\ \text { ERTS Band 7 } & 5.6 \\ \text { EREP S190A B/W IR } & 5.4\end{array}$

If Maximum possible $=70$ 
TABLE 5

\section{ANALYSIS OF TEST 2 DATA \\ (CROP IDENTIFICATION TEST, \\ LATE SPRING SEASONAL STATE) \\ BY MEANS OF TUKEY'S METHOD OF \\ PAIRWISE COMPARISON}

Entries in the table below are mean number of correct responses per interpreter. Starred entries within a column fall within a confidence interval of \pm 3.2 responses and form an image class which is significantly different from the unstarred entries, and are therefore best for the interpretation of the crop category which heads that column. The far right column contains the average for all categories. Note that the EREP S190A Color and Color IR images are significantly different from the other image types and, therefore, better for overall interpretive purposes. If no interpretation errors had been made by any of the 10 students, all entries in this table would contain the figure "10.0."

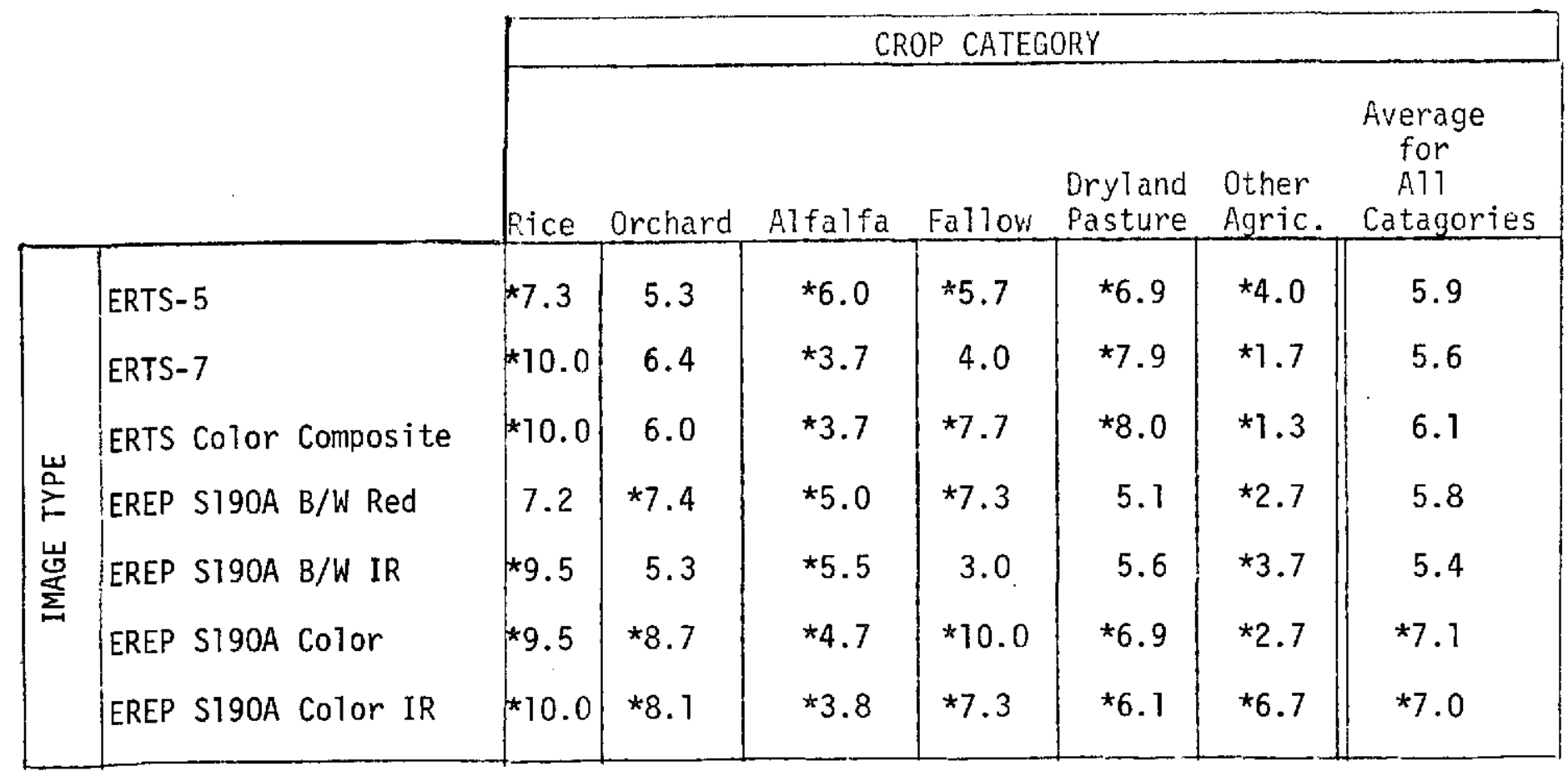


The relative interpretability of the various crop categories at the two seasonal states -- late summer (Test 1) and late spring (Test 2) -- is perhaps best determined by comparing the test results for the EREP ST90A color IR image. This image ranked high in both tests and in both tests was contained in the group of two images that was significantly different from the other test images. Those results, extracted from Tables 3 and 5, are presented here (expressed as mean number of correct responses, maximum possible of 10 in each category):

\begin{tabular}{|c|c|c|c|c|c|c|c|}
\hline \multirow[b]{2}{*}{ Test } & \multicolumn{7}{|c|}{ Crop Category } \\
\hline & Rice & Orchard & Alfalfa & Fallow & $\begin{array}{l}\text { Dryland } \\
\text { Pasture }\end{array}$ & $\begin{array}{l}\text { Other } \\
\text { Agric. }\end{array}$ & $\begin{array}{l}\text { Avg. for all } \\
\text { Categories }\end{array}$ \\
\hline 1 - Late summer & 7.3 & 8.0 & 5.8 & 7.8 & 8.9 & 7.2 & 7.5 \\
\hline 2 - Late spring & 10.0 & 8.7 & 3.8 & 7.3 & 6.1 & 6.7 & 7.0 \\
\hline
\end{tabular}

Overall results for the two seasonal states are comparable (75\% for Test 1,70\% for Test 2). EREP S190A Color IR images acquired in late summer are better for identifying alfalfa and dryland pasture, while rice can be identified with $100 \%$ accuracy on late spring images, a marked improvement over the late summer date. These results indicate that (a) neither date would be preferred for overall identification accuracy, and (b) for identification of certain categories, such as rice, alfalfa and dryland pasture, the choice of image type should be specified. 
The overal1 results obtained for all image types at each of the two dates are as follows (from Tables 3 and 5):

\begin{tabular}{lcc} 
Image Type & \multicolumn{2}{c}{$\begin{array}{c}\text { Overal1 Results } \\
\text { Correct Responses } \\
\text { (all crop categories) }\end{array}$} \\
Late Summer & Late Spring \\
LER S190A Color IR & 7.5 & 7.0 \\
ERTS Color Composite & 7.4 & 6.1 \\
EREP S190B Color & 6.8 & - \\
EREP S190A Color & 6.7 & 7.7 \\
EREP S190A B/W IR & 6.6 & 5.4 \\
ERTS Band 7 & 6.4 & 5.6 \\
EREP S190A B/W Red & 6.0 & 5.8 \\
ERTS Band 5 & 5.5 & 5.9 \\
II Maximum possible $=10$ & &
\end{tabular}

In all but two cases (EREP S190A Color and ERTS Band 5), the late summer date is slightly better than the late spring date. However, the magnitude of the differences is not great enough to suggest a strong preference for either date.

3. Test 3 - Stratification of Rice-Growing Regions

The utility of one ERTS and one EREP image for stratification of a portion of the rice-growing region in the Northern Great Valley Test Area was determined. A 17 square mile area outlined on the ERTS color composite (May 28, 1973) and EREP S190A Color IR images (June 3, 1973) was interpreted by each of 10 interpreters. At this early season date, most rice fields have been flooded and seeded and their identification is 
facilitated. Each interpreted overlay was compared to a ground data map. Dot grids were used to determine the area mapped correctly, as well as the non-rice areas incorrectly mapped as rice (commission error). The results of this interpretation are summarized in Table 6 . A1l results are expressed as area in square miles and percentage of the actual rice area ( 6.75 square miles). Results for both image types are very good, with slightly better results derived from the ERTS color composite than from the EREP SI90A Color IR. These results are reasonable in light of the conclusions of Test 1 , i.e., that these two image types are not significantly different for crop identification purposes under the conditions of the study.

\section{B. COLORADO PLATEAU TEST AREA}

1. Test 4 - Natural Vegetation Identification, Summer Seasonal State

In a manner similar to Test 1, the test data (correct responses) from Test 4 were tabulated in matrix form (Figure 18) and subjected to two-way analys is of variance. Tests of significance were performed for the main effects (image type and natural vegetation category) and interactions, and all were found to be very highly significant.

Results of pairwise comparisons across the image type effects using Tukey's method are tabulated in Table 7. As in 
TABLE 6

INTERPRETATION RESULTS FROM TEST 3

DELINEATION OF RICE-GROWING AREAS

(LATE SPRING SEASONAL STATE)

\begin{tabular}{|c|c|c|c|c|}
\hline & \multicolumn{2}{|c|}{$\begin{array}{l}\text { ERTS Color } \\
\text { Composite }\end{array}$} & \multicolumn{2}{|c|}{$\begin{array}{l}\text { EREP SI9OA } \\
\text { Color IR }\end{array}$} \\
\hline & $\begin{array}{c}\text { Area } \\
\text { (Sq. Miles) }\end{array}$ & Percent & $\begin{array}{c}\text { Area } \\
\text { (Sq. Miles) }\end{array}$ & Percent \\
\hline $\begin{array}{l}\text { Actual Rice Area } \\
\text { (from ground data) }\end{array}$ & 6.75 & 100 & 6.75 & 100 \\
\hline Correct Identification & 6.12 & 90.7 & 5.54 & 82.1 \\
\hline Commission Error & 0.20 & 3.0 & 0.52 & 7.7 \\
\hline
\end{tabular}

If Mean values for ten interpreters 
TABLE 7

\author{
ANALYSIS OF TEST 4 DATA \\ (NATURAL VEGETAT ION IDENTIFICATION TEST) \\ BY MEANS OF TUKEY'S METHOD OF PAIRWISE COMPARISON
}

Entries in the table below are mean number of correct responses per interpreter. Starred entries within a column fall within a confidence interval of \pm 0.6 response and form an image class which is significantly different from the unstarred entries, and are therefore best for the interpretation of the natural vegetation category which heads that column. The far right column contains the average for all natural vegetation categories. Note that the EREP S790A Color IR image is significantly different from all other image types and therefore better for overall interpretive purposes. If no interpretation errors had been made by any of the 40 students, a11 entries in this table would contain the figure "10.0."

\begin{tabular}{|c|c|c|c|c|c|c|c|c|}
\hline & \multicolumn{7}{|c|}{ NATURAL VEGETATION CATEGORY } \\
\hline & & $\begin{array}{l}\text { Pinyon- } \\
\text { Juniper }\end{array}$ & $\begin{array}{l}\text { Ponderosa } \\
\text { Pine } \\
\end{array}$ & $\begin{array}{l}\text { Sedge } \\
\text { Meadow }\end{array}$ & Aspen & $\begin{array}{l}\text { Spruce- } \\
\text { Fir }\end{array}$ & $\begin{array}{c}\text { Other } \\
\text { Natural } \\
\text { Vegetation }\end{array}$ & $\begin{array}{l}\text { Average } \\
\text { for ali } \\
\text { Categories }\end{array}$ \\
\hline \multirow{8}{*}{ 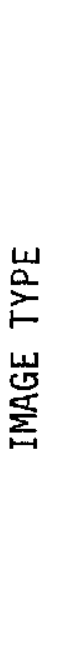 } & ERTS-5 & 6.2 & 6.4 & 2.7 & 4.0 & 5.5 & 2.8 & 4.6 \\
\hline & ERTS-7 & 8.4 & 7.3 & $\star 5.7$ & 6.8 & 7.9 & 1.3 & 6.2 \\
\hline & ERTS Color Composite & $\star 8.5$ & 7.7 & 5.0 & $* 8.8$ & 8.4 & 3.8 & 7.0 \\
\hline & EREP 190A B/W Red & 7.2 & 6.9 & 2.9 & 4.9 & 5.8 & 3.5 & 5.2 \\
\hline & EREP $190 \mathrm{~A} B / \mathrm{W}$ IR & $\star 8.6$ & 7.0 & $\star 5.5$ & 8.2 & 7.8 & 1.2 & 6.4 \\
\hline & EREP 190A Color & 7.8 & 7.3 & 3.3 & 4.5 & 5.7 & 4.6 & 5.5 \\
\hline & EREP 190A Color IR & $\star 9.1$ & $\star 9.2$ & $\star 5.6$ & $* 9.3$ & $* 9.1$ & $\star 5.0$ & $\star 7.9$ \\
\hline & EREP $190 \mathrm{~B}$ Color & $\star 9.1$ & 6.4 & 4.1 & 5.3 & 8.7 & $\star 5.6$ & 6.4 \\
\hline
\end{tabular}


Tables 3 and 5 , each entry represents the average number of correct responses (maximum possible $=10$ ) for each natural vegetation category for each image type.

The EREP S190A Color IR image type was judged to be significantly different from (and better than) the other image types for identifying natural vegetation types. The spectral information of this image contributes largely to this result. Overall identification accuracy is also presented in Table 7 for Test 4. For this test, the set of eight image types is ranked in the following manner:

Image Type

EREP S190A Color IR

ERTS Color Composite

EREP S190B Color

EREP ST $90 A$ B/W IR

ERTS Band 7

EREP ST90A Color

EREP SI9OA B/W Red

ERTS Band 5

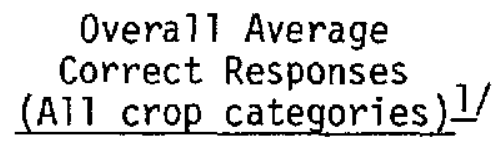

7.9

7.0

6.4

6.4

6.2

5.5

5.2

4.6

1/ Maximum possible $=10$

Commission errors were also analyzed using a two-way analysis of variance. Tests of significance were performed for the main effects (image type and natural vegetation category) and interactions, and all were found to be very highly significant. Pairwise comparisons were made using Tukey's method. The image type(s) which formed a 
group that was significantiy different from the others

(lowest commission error) are listed in Table 8.

The EREP S190A Color IR image appears for all but one of the natural vegetation categories in Table 8 and is clearly the best image for lowest commission error.

A threshold level of 2 commission errors per 10 items in a category was established to indicate a possible confusion level above which special training and care would be justified to minimize the occurrence of commission errors. The following summary was generated using this threshold:

Correct

Category

Pinyon-juniper (J) Ponderosa pine ( $P$ ) Sedge (wet) meadow $(W)$ Aspen (A) Spruce-fir (S)
Other types confused with category on only two or fewer of the test images

With this threshold, fewest commission errors occur with the sedge meadow and spruce-fir categories. Confusing ponderosa pine with sedge meadows was the most common commission error. The examples of sedge meadows used are all very small and interspersed with other vegetation types.

The following ranking indicates those image types for which commission errors were largest: 
TABLE 8

\author{
ANALYSIS OF TEST 4 DATA \\ (NATURAL VEGETATION IDENTIFICATION TEST) \\ RANKING OF IMAGE TYPES \\ BY COMMISSION ERROR
}

For each of the natural vegetation categories listed below, the image type(s) are given which form a group that is significantly different from all others in terms of commission error (using Tukey's method of pairwise comparison). These images are those for which commission errors are lowest.

\begin{tabular}{ll} 
Natural Vegetation Category & \multicolumn{1}{c}{ Image Type } \\
\hline Pinyon-juniper & EREP S190A Color IR \\
Ponderosa pine & EREP S190A Color IR \\
Sedge meadow & EREP S190B Color \\
Aspen & EREP S190A Color IR \\
& EREP S190A Color \\
& EREP S190A B/W IR \\
Spruce-fir & EREP S190A Color IR \\
& EREP S190A B/W IR \\
& ERTS COIOr Composite \\
& EREP S190A Color IR \\
Other natural vegetation & EREP S190A B/W IR \\
& EREP S190B Color
\end{tabular}


Correct

Category

J

$P$

$W$

A

$S$
Image Types/Categories Having Largest Commission Error (decreasing error left to right)

ERTS-5/W

S190A B/W IR/X

ERTS-5/X

S190A Color/S

ST 90 A Color/A
S190A Color/W

ERTS-7/X

ERTS Color Comp/X

S190A B/W Red/S

ERTS-5/A
S190B Color $/ X$

ERTS-5/A

S190A B/W Red/X

ERTS-5/S

S190B Color/A

Commission errors are greatest for the various black-and-white image types ( 9 out of 15 entries). The natural vegetation categories having largest commission errors from this array are aspen (A), spruce-fir (S), and other vegetation types $(X)$.

2. Test 5 - Natural Vegetation Identification - Stereoscopic vs. Monoscopic Viewing

Test responses were tabulated for the 10 interpreters who completed both the monoscopic and stereoscopic interpretation of natural vegetation types using the EREP S190A color IR images (Table 9). The following overall percent correct results were recorded: monoscopic interpretation: $82.7 \%$; stereoscopic interpretation: $77.3 \%$. The two sets of data were not significantly different when subjected to a paired $t$ test ( 0.01 level of significance). Two reasons are offered to explain the fact that stereo results were not markedly higher than monoscopic results: (a) although the students had unimpaired stereo vision, none had spent extensive periods of time engaged in stereoscopic interpretation; (b) also, none of the students had experience in relating ecological relationships (such as were 
TABLE 9

RESULTS OF TEST 5:- STEREOSCOPIC VS. MONOSCOPIC INTERPRETATION OF NATURAL VEGETATION TYPES USING THE EREP S19OA COLOR IR IMAGE

The matrices below contain the sums of the responses for the 10 interpreters who completed this test. Entries in the heavily outlined boxes along the diagonal are correct responses.

MONOSCOPIC INTERPRETATION (496 Correct/600 possible $=82.7 \%$ )

\section{CORRECT IDENTITY}

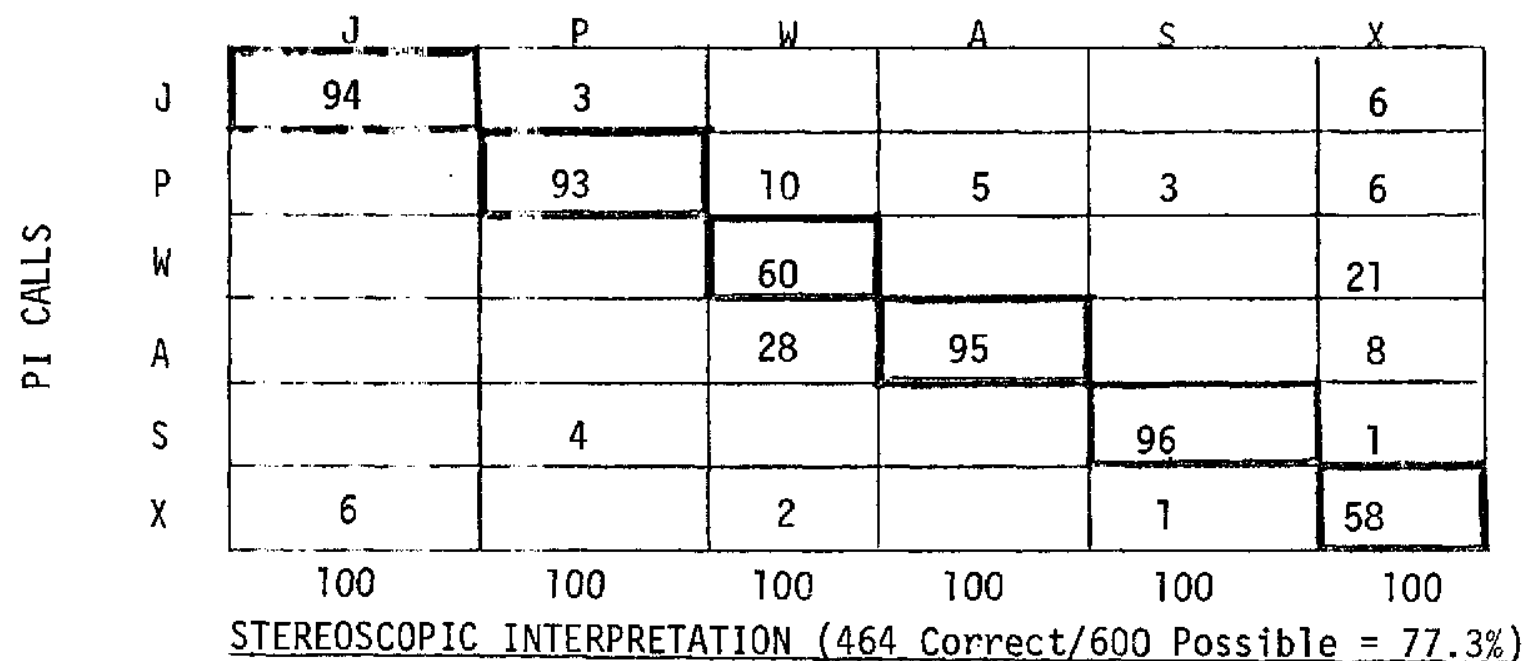

STEREOSCOPIC INTERPRETATION (464 Correct $/ 600$ Possible $=77.3 \%$ )

CORRECT IDENTITY

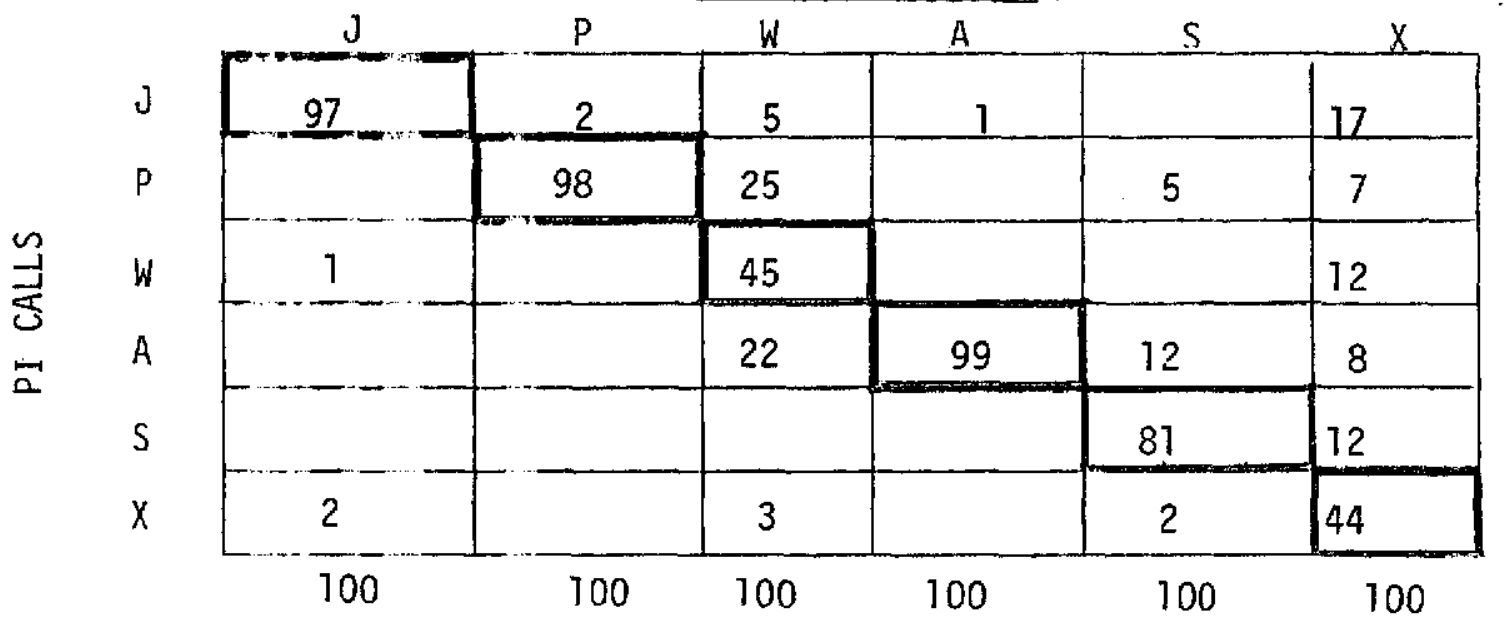


presented in the illustrated introduction to the natural vegetation tests) to stereoscopic mode1s.

To assess whether the results of a trained interpreter might be better than those of the student group, one of the investigators took the same test. This individual had extensive stereoscopic viewing experience and understood the relationships between vegetation and landform/elevation. His results are summarized below:

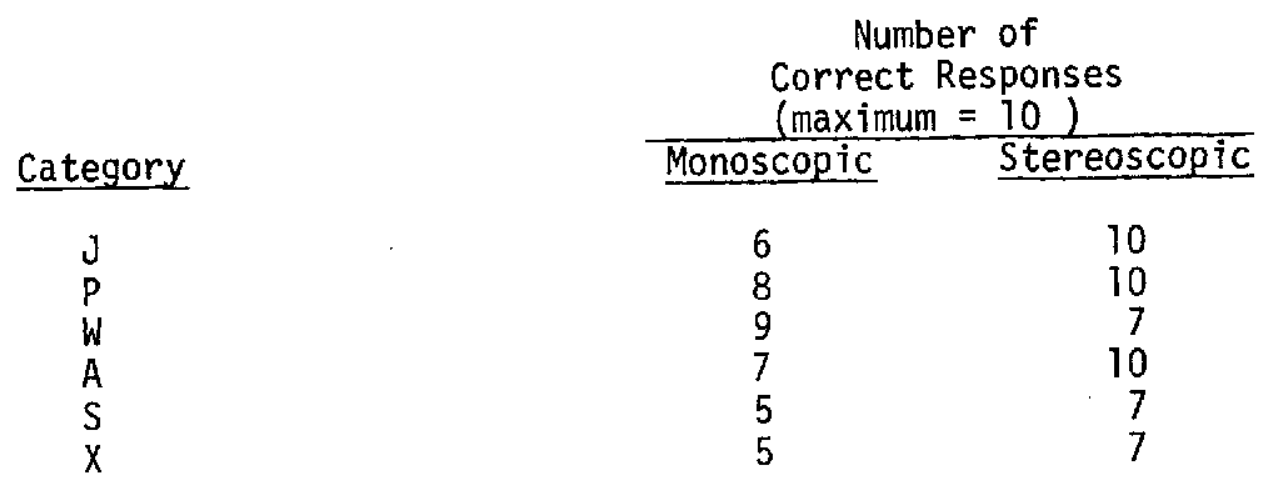

Pronounced improvement in identification accuracy was noted for all categories but one. This category -- sedge meadow (W) -- is of small image size and was sometimes difficult to see clearly on the stereo image pair. This stereo pair was printed at smaller scale than the monoscopic test image so that, when the pair was viewed stereoscopically with a pocket stereoscope, the scales of the two test sets would be approximately equal. This limited comparison highlights the important role to be played by a trained interpreter when extracting image information from a complex landscape. Knowledge 
of the ecological relationships present in that landscape is essential to accurate interpretation. Under these circumstances, stereoscopic interpretation will produce markediy improved results over monoscopic interpretation. 
VI. SUBJECTIVE TEST RESULTS AND ANALYSIS

A. NORTHERN GREAT VALLEY TEST AREA

1. Minimum Field Size and General Land Use

The relative merits of each image type for detecting and delineating individual agricultural fields was assessed. It was recognized that the ease with which individual fields can be detected is a function of both the spatial and spectral resolution characteristics of the images. Fields of low or high tone or color contrast can be discriminated if the image has sufficiently high resolution. As resolution becomes poorer, fields which contrast sharply with their surroundings are still discernible. However, fields having low tone or color contrast in comparison to their surroundings are not easily detectable.

These statements are substantiated by the subjective estimates of minimum detectable field size (Table 10). The order of these estimates also correlates well with the ranking of expected resolution (NASA estimates) for each image type ( 1 isted from poor to good):

\begin{tabular}{|c|c|c|c|}
\hline \multirow[b]{2}{*}{ Image Type } & \multirow[b]{2}{*}{$\begin{array}{c}\text { NASA Estimate } \\
\text { of Expected } \\
\text { Resolution (Ft.) }\end{array}$} & \multicolumn{2}{|c|}{$\frac{\text { Minimum Field Size (Acres) }}{\text { (extracted from Table 10) }}$} \\
\hline & & $\begin{array}{c}\text { High } \\
\text { Contrast } \\
\end{array}$ & $\begin{array}{c}\text { Low } \\
\text { Contrast } \\
\end{array}$ \\
\hline $\begin{array}{l}\text { B/W IR } \\
\text { Color IR } \\
\text { B/W Red } \\
\text { Color } \\
\text { Color (high }\end{array}$ & $\begin{array}{r}223 \\
187 \\
91 \\
78 \\
50\end{array}$ & $\begin{array}{l}8-12 \\
8-12 \\
3-5 \\
3-5 \\
3-5\end{array}$ & $\begin{array}{c}30-40 \\
12-17 \\
5-10 \\
5-8 \\
5-8\end{array}$ \\
\hline
\end{tabular}


TABLE 10

MINIMUM AGRICULTURAL FIELD SIZE (ACRES)

CONSISTENTLY DETECTED ON EREP AND ERTS IMAGES

\begin{tabular}{|c|c|c|c|c|c|c|c|c|}
\hline \multirow[b]{3}{*}{ Contrast } & \multicolumn{5}{|c|}{ EREP - Sastember 12, 1973} & \multirow{2}{*}{\multicolumn{3}{|c|}{ ERTS MSS - September 13, 1973}} \\
\hline & & 519 & & & ST90B & & & \\
\hline & $B / W \operatorname{Red}$ & $\mathrm{B} / \mathrm{W}$ IR Band & Color & Color IR & Color & Band 5 & Band 7 & $\begin{array}{l}\text { Color } \\
\text { Composite } \\
4,5 \& 7\end{array}$ \\
\hline High & $3-5$ & $8-12$ & $3-5$ & $8-12$ & $3-5$ & $10-20$ & $10-20$ & $10-15$ \\
\hline Low & $5-10$ & $30-40$ & $5-8$ & $12-17$ & $5-8$ & $30-40$ & $30-40$ & $20-30$ \\
\hline
\end{tabular}


In all cases, fields of high tone or color contrast can be discerned at smaller size limits than fields of low contrast. The nominal resolution of the 7 ast three images listed above permits substantially smaller fields to be discerned than does the resolution of the first two images.

A similar case can be made for ERTS imagery. In this case, the spatial resolution of the three ERTS images used is theoretically fixed by the inherent pixel size. The process of generating the color composite image from 3 separate MSS bands might logically be thought to result in an image of even lower resolution than the black-and-white bands, 5 and 7 . However, the improvement in color contrast afforded by a color image permits the detection of smaller (not larger) fields than is possible on the black-and-white images:

\section{Minimum Field Size (Acres)}

(Extracted from TabTe 10)

ERTS Image Type

Band 5

Band 7

Color Composite (Bands 4, 5, 7)

Especially for low contrast targets, this added spectral resolution of the color composite is valuable for detecting smaller fields.
High Contrast Low Contrast

$30-40$

$30-40$

20-30 
In comparing EREP and ERTS data, one can draw comparable conclusions regarding minimum field size for the ERTS images as a group compared to the EREP S19OA B/W IR image. Only this EREP image type was similar to the ERTS images, however. With all other EREP images, smaller fields could be detected as image resolution increased. Subtle improvements were observed between the $5190 \mathrm{~A} B / \mathrm{W}$ red image and the $S 190 \mathrm{~A}$ and $\mathrm{S} 190 \mathrm{~B}$ color images. The increased spectral discrimination of individual fields using a color image in comparison to a black-and-white image is suggested as the most significant reason, even though slight resolution differences also exist for these image types.

Another question of interest in these subjective studies dealt with identifying and delineating land use in the Northern Great Valley Test Area. Using the same images as presented to the test subjects in this study, a series of land use categories was 1 isted and the certainty with which positive identification and boundary delineations could be made by interpreting one image at a time was estimated by non-testing (subjective) analysis. The results of that effort appear in Table 11. The same type of analysis was made while comparing various combinations of EREP and ERTS images. The results of that effort are listed in Table 12. In each of these tables, subjective interpretation certainty is given by the following rating scale: 
TABLE 11

INTERPRETATION CERTAINTY FOR LAND USE IDENTIFICATION

AND DELINEATION

(Late Summer Seasonal State - Single Image)

\begin{tabular}{|c|c|c|c|c|c|c|c|c|}
\hline \multirow[b]{3}{*}{$\begin{array}{l}\text { LAND USE } \\
\text { CATEGORY }\end{array}$} & \multicolumn{5}{|c|}{ EREP - September 12,1973} & \multirow{2}{*}{\multicolumn{3}{|c|}{ ERTS - September 13, 1973}} \\
\hline & & & 90A & & 51908 & & & \\
\hline & B/W Red & $\mathrm{B} / \mathrm{W} \mathrm{IR}$ & Color & Color IR & Color & Band 5 & Band 7 & $\begin{array}{l}\text { Color } \\
\text { Composite }\end{array}$ \\
\hline Agriculture & 2 & 2 & 1 & 2 & 1 & 3 & 3 & 2 \\
\hline $\begin{array}{l}\text { Dryland } \\
\text { Pasture }\end{array}$ & 2 & 3 & 2 & 3 & 1 & 3 & 3 & 2 \\
\hline Woodlot & 4 & 4 & 3 & 2 & 2 & 4 & 4 & 3 \\
\hline Urban & 2 & 4 & 1 & 3 & 1 & 4 & 4 & 4 \\
\hline Unused Land & 3 & 4 & 2 & 2 & 1 & 4 & 4 & 3 \\
\hline $\begin{array}{l}\text { Water Bodies } \\
\text { \& Drainage }\end{array}$ & 3 & 2 & 2 & 2 & 2 & 4 & 2 & 1 \\
\hline Total & 16 & 19 & 11 & 14 & 8 & 22 & 20 & 15 \\
\hline
\end{tabular}

KEY TO INTERPRETATION CERTAINTY:

$T=$ Certain

$2=$ Probable

$3=$ Possible

4 = Uncertain
LAND USE CATEGORY LEGEND:

Agricutture - cultivated land

Pasture - natural grassland used for livestock grazing or watershed

Urban - residential, commercial, industrial; small and large cities

Unused Land - dumps, floodplains, wasteland Woodl ot - farm tree lots, 20 acres or larger in size

Water Bodies and Drainage - lakes, reservoirs, ponds, rivers, streams 
TABLE 12

\section{INTERPRETATION CERTAINTY FOR LAND USE IDENTIFICATION AND DELINEATION \\ (Late Summer Seasonal State - Multiple Images)}

\begin{tabular}{|c|c|c|c|c|c|c|c|c|c|}
\hline \multirow[b]{2}{*}{$\begin{array}{l}\text { LAND USE } \\
\text { CATEGORY }\end{array}$} & \multicolumn{6}{|c|}{ EREP S190A - September 12, 1973} & \multicolumn{3}{|c|}{ ERTS - September 13, 1973} \\
\hline & $\begin{array}{c}B / W \text { Red } \\
\& \\
B / W \text { IR }\end{array}$ & $\begin{array}{c}\text { B/W Red } \\
\& \\
\text { Color }\end{array}$ & $\begin{array}{l}\text { B/W Red } \\
\& \\
\text { Color IR }\end{array}$ & $\begin{array}{c}B / W \cdot I R \\
\& \\
\text { Color }\end{array}$ & $\begin{array}{l}B / W \text { IR } \\
\& \\
\text { Color IR }\end{array}$ & $\begin{array}{l}\text { Color } \\
\& \\
\text { color IR }\end{array}$ & $\begin{array}{l}\text { Bands } \\
5 \& 7\end{array}$ & $\begin{array}{c}5 \& \\
\text { Color } \\
\text { Composite }\end{array}$ & $\begin{array}{c}7 \& \\
\text { Color } \\
\text { Composite }\end{array}$ \\
\hline Agriculture & 2 & 1 & 1 & 1 & 2 & 1 & 3 & 2 & 2 \\
\hline $\begin{array}{l}\text { Dry land } \\
\text { Pas ture }\end{array}$ & 2 & 2 & 2 & 2 & 3 & 2 & 3 & 2 & 2 \\
\hline Woodlot & 4 & 3 & 2 & 3 & 2 & 2 & 4 & 3 & 3 \\
\hline Urban & 2 & 1 & 2 & 1 & 3 & 1 & 4 & 4 & 4 \\
\hline Unused Land & 3 & 2 & 2 & 2 & 2 & 2 & 3 & 3 & 3 \\
\hline $\begin{array}{l}\text { Water Bodies } \\
\text { \& Drainage }\end{array}$ & 2 & 2 & 2 & 2 & 2 & 2 & 2 & 1 & 1 \\
\hline Total & 15 & 11 & 11 & 11 & 14 & 10 & 19 & 15 & 15 \\
\hline
\end{tabular}

KEY TO INTERPRETATION CERTAINTY:

$$
\begin{aligned}
& 1=\text { Certain } \\
& 2=\text { Probable } \\
& 3=\text { Possible } \\
& 4=\text { Uncertain }
\end{aligned}
$$




$$
\begin{aligned}
& 1=\text { certain } \\
& 2=\text { probable } \\
& 3=\text { possible } \\
& 4=\text { uncertain }
\end{aligned}
$$

The relative ranking of the 8 image types for single image interpretation was determined by summing the interpreation certainty for the various land use categories:

Image Type

EREP S190B Color

EREP S190A Color

EREP S190A Color IR

ERTS Color Composite

EREP S190A B/W Red

EREP S190A B/W IR

ERTS Band 7

ERTS Band 5
Total Certainty Ranking $1 /$

8

11

14

15

16

19

20

22

Although significant differences cannot be derived from this array, it does represent the concensus of the investigators regarding the interpretation of general land use categories, and suggests the magnitude of relative accuracy ratings.

In general, interpretation of two images in concert results in slightly improved interpretation accuracy for some image pairs, and no improvement for others. Ratings of the pairs of black-andwhite images improve when they are interpreted together. However, interpretation of a color or color IR image is not improved by the addition of information from a black-and-white image.

$1 / 6=$ certain ranking for al1 categories. 


\section{Seasonal Aspects and Frequency of Coverage}

Parallel studies have been conducted for the rice crops on the Coastal Plain of Louisiana and the Northern Great Valley of Cálifornia using EREP and ERTS data. For California, weather conditions during the 1973 rice growing season were favorable for satellite image coverage and an excellent series of ERTS coverages was acquired on the 18 day cycle.

In Louisiana, on the other hand, weather conditions during 1973 were unfavorable and a complete series of images was not acquired during the growing season from either ERTS or the Skylab satellite. One usable ERTS image was acquired at the beginning of the season during planting of the rice crop and one was acquired at the end, after harvest. No coverage was obtained of the Louisiana test area during the 1973 rice growing season from Skylab. Such problems can be anticipated in those agricultural areas characterized by high atmospheric humidity and persistent daytime cloudiness.

Because of certain critical rice crop events (planting, emergence, heading and harvest) the 18 day period for repeat cloud-free ERTS coverage is acceptable. However, if one or more of those sequential overflights is lost due to cloud cover, the time span between image dates during critical crop events becomes unacceptable, as it was in Louisiana during 1973. Weather records 
of the Louisiana test area have not been analyzed to determine what frequency of overfights would have provided adequate coverage during the growing season. Obviously, the 18 day cycle was not satisfactory.

Photographic image quality is an important factor which greatly impacted interpretability of land use categories on sequential ERTS imagery. The certainty with which each of severa1 land use categories can be identified was determined for various ERTS and EREP images acquired throughout the 1973 growing season (Table 13). Band registration, color fidelity and print density are the three aspects that varied from one date to the next in this series of images. In addition, atmospheric effects such as haze and cloud cover influenced the interpretability of some of these images.

It should be noted that the ERTS image of the highest quality in all factors - atmospheric clarity, color fidelity, band registration and print density - was the September 13, 1973 color composite supplied to the investigators. This factor is reflected in Table 13 where it was possible to identify with certainty all land use classes except woodlots on that frame. Some other ERTS prints provided were of relatively poor quality, such as the July 21, 1973 ERTS color composite. Skylab reproductions were fully satisfactory for evaluation purposes. 
TABLE 13

MULTIDATE INTERPRETATION OF

LAND USE IDENTIFICATION AND DELINEATION

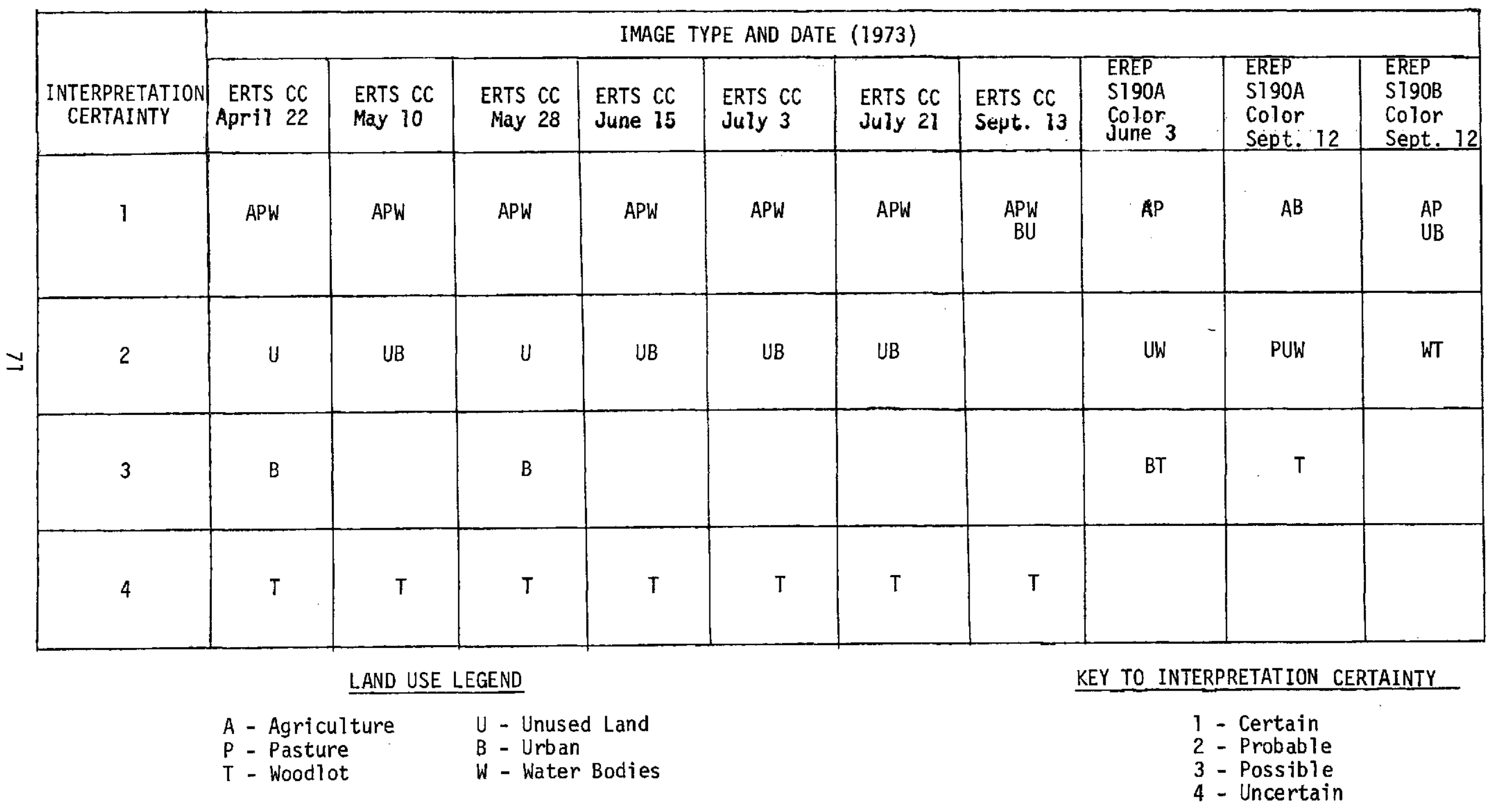


It is not possible to make meaningful judgments regarding image interpretability for some features when print quality is variable.

3. Crop Vigor Evaluation and Plant Stress Detection

of all images tested in this study, color infrared images provided the best means to detect differences in crop vigor and for detecting plant stress caused by drought, soil deficiencies, disease, etc. Color infrared images record the spectral energy reflectance differences that occur between vigorously growing plants and stressed or damaged plants. In the near infrared spectral region, healthy plants reflect relatively high amounts of energy while stressed (unhealthy, wilted) plants reflect relatively low amounts of energy. This factor, coupled with the fact that the near infrared region is not as seriously affected by atmospheric haze as the visible spectrum, makes color infrared sensing an ideal method for recording information on plant vigor and stress when used from space and high flying aircraft.

A study of numerous ERTS color composite images (color IR simulations using bands 4,5 and 7) acquired over a variety of vegetation scenes and several dates confirm that spectral reflectance differences in plant vigor and plants under stress from soil nutrient or moisture deficiencies can be distinguished visually from those plants that are healthy. An excellent example of this 
situation was observed by comparing an ERTS color composite image (1256-16421) of Northern Texas taken on Apri1 5, 1973 with a color composite image (1616-16362) taken at about the same time (March 31) in 1974, when severe drought conditions were experienced. As seen in Figure 19, these two color prints display a significant difference in overall red coloration because of the influence of drought in the 1974 period.

It is interesting to note that, in the Northern Texas drought region (Young County) where these photos were taken, the predicted 1974 winter wheat crop yield was about half as great as the actual 1973 winter wheat crop yield, in spite of an estimated $22 \%$ increase in wheat acreage planted for 1974 crops. In this case, the image differences correspond to significant differences in yield. Similar differences in plant vigor were visible on other ERTS color composites in the Northern Great Valley of California where stressed fields were observed as a result of soil nutrient and moisture deficiencies.

The minimum field size in which plant vigor problems can be detected is determined by several factors, including surface area affected, severity of the problem and characteristics of surrounding plants and soils. Perhaps the most useful analysis that can be made at the ERTS resolution level involves comparing images of a scene taken over a period of time whereby changes in red coloration of selected regions are observed and correlated with known ground conditions (drought, disease, etc.) 


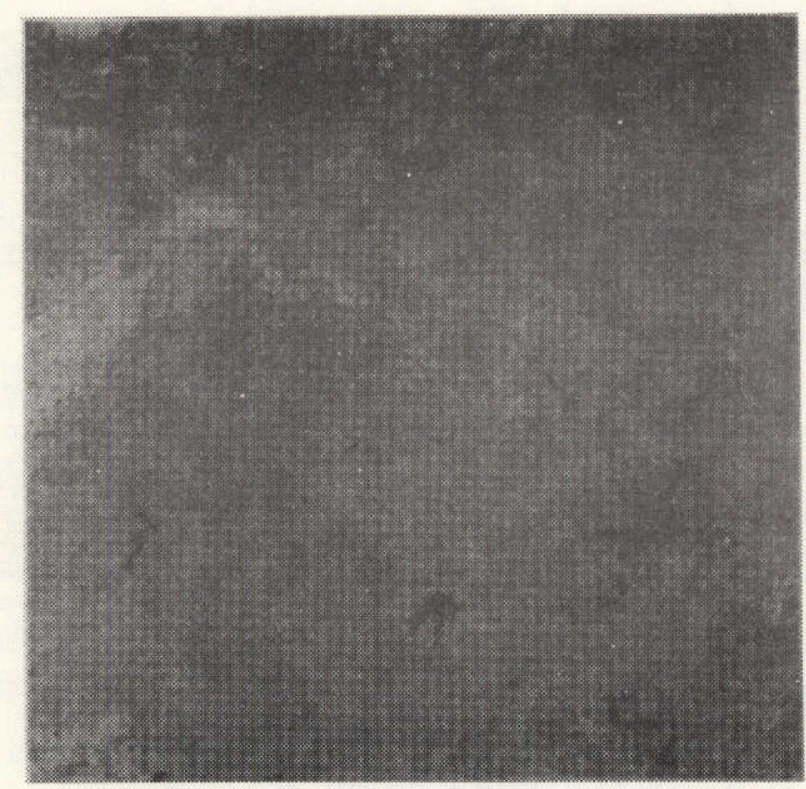

Apri1 5, 1973

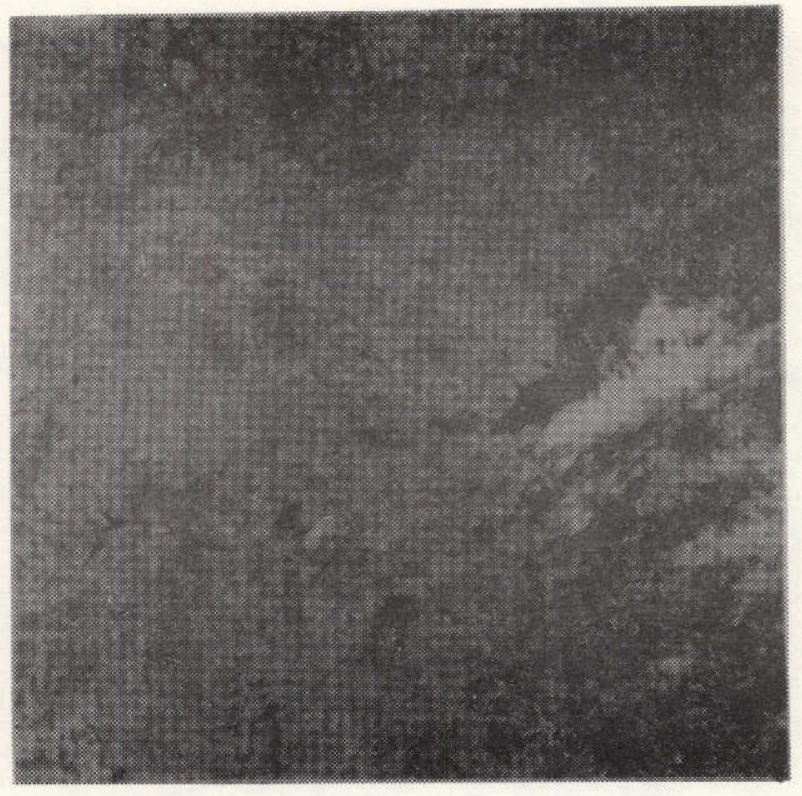

March 31, 1974

Figure 19. ERTS prints of North Texas (Young County) wheat growing area affected by extended drought in 1974. Print on left was taken April 5, 1973. Note overall reddish color indicating presence of growing plants. Print on right was taken March 31, 1974. Note absence of reddish color due to drought except in isolated agricultural areas where some irrigation has taken place. On the transparencies from which these prints were made, it was possible to detect significantly lower levels of water in lakes and reservoirs on right-hand print taken during the drought period than on the left-hand print. The presence of the reddish color on the left print is even more apparent on the original transparencies than on these copy prints. 
As noted earlier in this report (Table 10) even for high contrast ground features the smallest field that can be detected on ERTS images is 10-15 acres. Most plant stress situations have low contrast image signature. This requires that such anomalies have an areal extent of at least 20-30 acres for consistent detectability.

For EREP STIOA color IR images, the minimum detectable field size is 12-17 acres for low contrast targets, and for EREP S190B high resolution color images, the size drops farther to the 5-8 acre range for features of low contrast.

It is recalled that for regional crop surveys a range of minimum field sizes detectable at the level of 20-30 acres seems reasonable, but for the data to be useful to the farm manager (who can take corrective action if notified of a condition in time) a minimum detectable stressed area size of 5-10 acres is much more desirable. The question of minimum field size depends largely, however, on the size of farms being managed as a unit, cost of various corrective measures versus associated benefits, and farm practices common to the region concerned. It has been noted from past experience with high resolution aerial photos that, even when detailed information on crop problems is available to the farmer from aerial photo interpretation, corrective actions 
are often reluctantly taken because of the high costs involved. Only in some of the more progressive farm regions have the use of aerial photographs been exploited to any degree for operational crop management.

For an ERTS-type system to provide a low contrast minimum field size detectable at the 5 acre level, a minimum size of perhaps 1 to 2 acres for high contrast fields should be set as a detectability range. From Table 10 it is apparent that such a change would require a spatial resolution improvement of $1 / 5$ to $1 / 10$ or more over present levels. Whether such a change can be justified at present levels of costs, technology and data benefits is very questionable since many farms are presently not in a position to utilize such data even if it were available on a timely basis. The data dissemination problem (making current information available to farmers on a weekly if not semi-weekly basis) is extremely complex and therefore the question of improving resolution for farm use may not be the controlling factor.

A limited assessment of the recognition of lodging on rice fields was undertaken. Portions of rice fields which are lodged (plants have been blown over by winds or other disturbance) are more difficult to harvest, and reduced yields of varying magnitudes result. For purposes of crop forecasting, lodging estimates are important inputs to the prediction of yield reduction at the appropriate stages of crop development. 
A number of low altitude aerial oblique photographs were taken prior to (August 28, 1973) and coincident with (September 13, 1973) the ERTS and EREP overpasses of the Sutter and Marysville Test Sites. The proportion of individual fields containing lodging and the location of lodged areas within each field are easily seen on these photographs (Figures 20 and 21). The corresponding areas covered by these photographs were studied on each of the EREP and ERTS positive transparency images as well as on color and color IR high altitude aircraft photographs (scale $1 / 120,000$ ) acquired coincident with the ERTS and EREP overpasses.

The detection of lodged rice areas is more dependant upon spatial than spectral resolution. Lodged areas were easily recognized on the high altitude aircraft color and color IR photographs. The light color of lodged areas contrasts well with the darker color of standing grain (see also Figure 21). The difference is as apparent with either film type.

Many areas of lodging were clearly evident on the EREP S190B color image. The resolutuion of this system (NASA estimate $=50$ feet) was sufficient to recognize the lodging pattern evident in the area of Figure 20, while the lodging in Figure 21 appeared only as a subtle color difference. Oniy large, sharply defined areas of lodging were discernible on the EREP S190A color image. Its resolution (NASA estimate $=78$ feet) was judged to be markedly poorer than the EREP S190B color for lodging detection. It should be noted that an occasional large lodged area could be picked out on the ERTS color composite, 


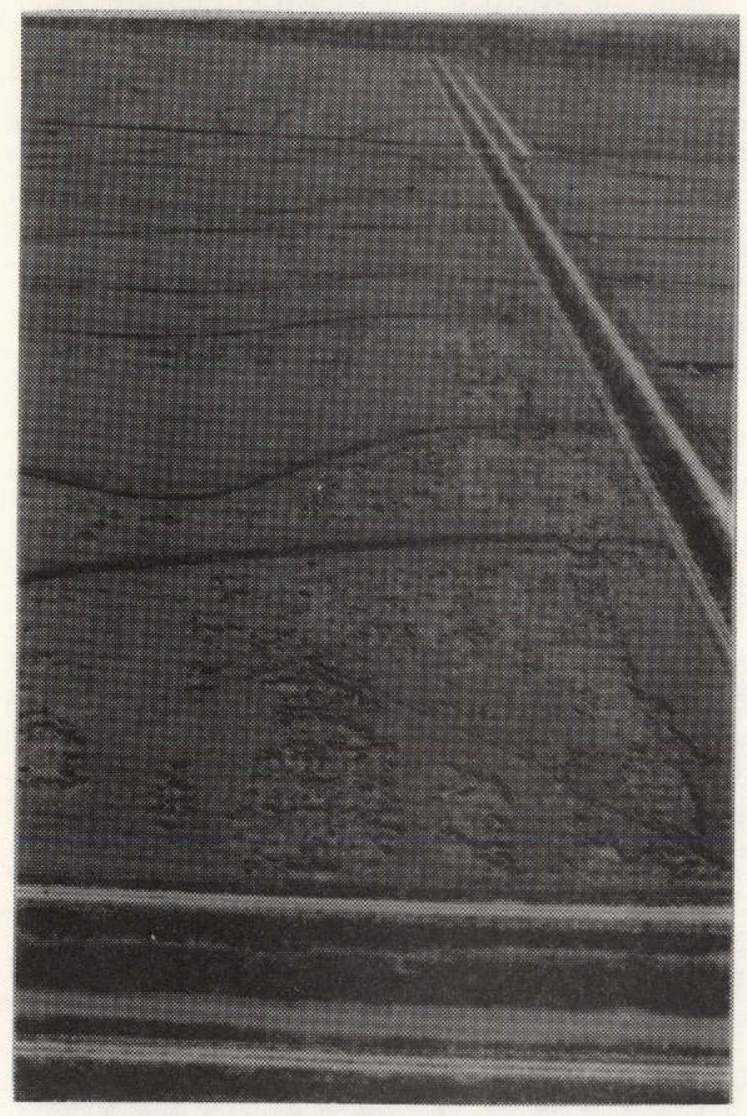

Figure 20. Example of lodged rice in the Sutter Test Site. (August 28, 1973).

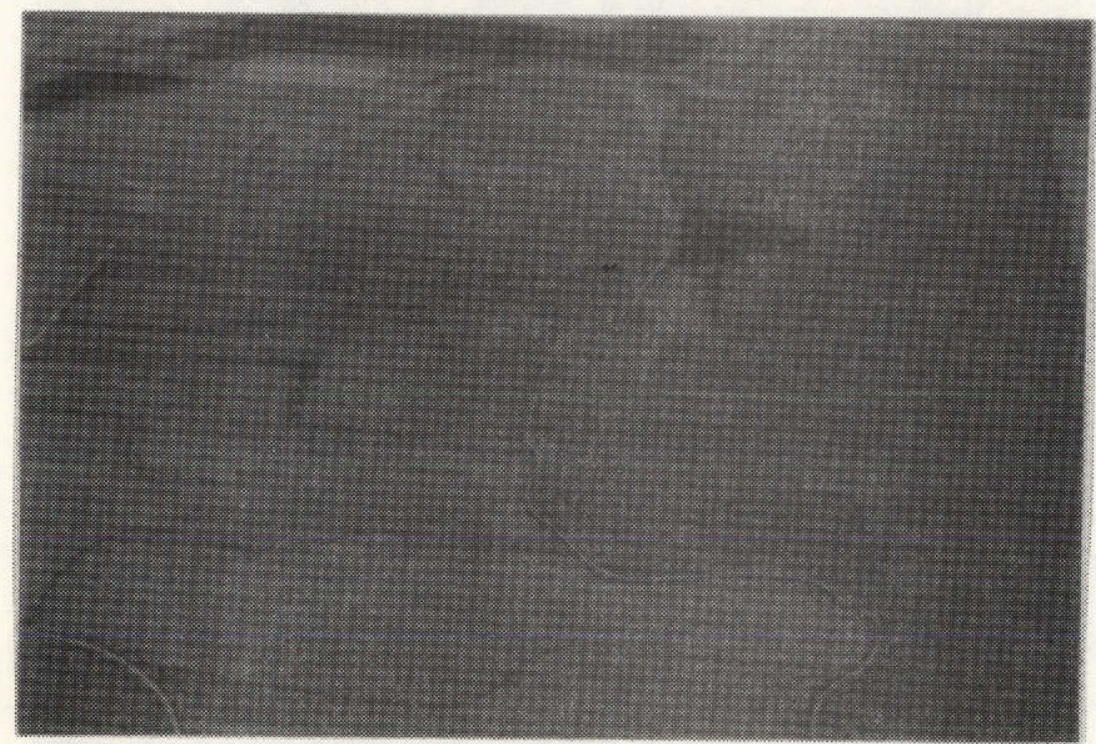

Figure 21. Example of lodged rice in the Marysville Test Site (September 13, 1973). The light color of lodged rice contrasts more sharply with standing rice in the dark fields on the right which have not begun to dry and mature than with the standing rice in the light fields on the left which are already maturing. 
but only with prior knowledge as to its location.

The only possible feature that might be confused with lodging at this date is the pattern of early maturing rice. Patches of a field which ripen prematureiy (due to early drying of parts of fields) resemble lodging in that they are also light in color. The overall incidence of early maturity of parts of fields is much less common than lodging of an entire field. Hence, this confounding factor is not judged to affect significantly the conclusions reached above. 


\section{Multidate Image Enhancement}

A limited number of multidate additive enhancements were prepared as part of the subjective analysis for crop identification to enhance the pattern of rice culture during 1972 and 1973. In particular, three categories of rice culture were distinguished:

a) fields containing rice during both 1972 and 1973

b) fields containing rice in 1972 and another crop in 1973

c) fields containing another crop in 1972 and rice in 1973

Information of this type has a variety of uses, including a) the study of crop rotation and fallowing practices (for individual fields and on a regional basis), and b) the assessment, on a regional basis, of the year-to-year variation in total acreage devoted to rice culture.

Only ERTS imagery was used for enhancement of year-to-year changes because the Skylab imagery acquired fell entirely within the 1973 growing season. Nevertheless, enhanced images generated from ERTS data are suggestive of the type of product that can be created from any type of multiband satellite image. The $I^{2} S$ Addcol (additive color viewer) was used to produce the examples described below.

The enhancement procedure used is summarized as follows:

Image Type/Date Filter Image Color Derived on Each Date

ERTS Band 5/July 26, 1972 ERTS Band 5/August 8, 1973

Red Dark Blue Dark

Red Blue 
Examples of the enhancements produced by this setup appear in Figure 22 (Sutter and Marysvilie Test Sites). Within the rice-growing areas (characterized by large fields of rectangular shape) the color sequence on the enhanced images is as follows:

1972

Crop

Rice

Rice

Other agricultural crop
1973

Crop

Rice

Other agricultural crop Rice
Color on Enhanced Images

Comparison of the enhanced images with maps of ground data document the above sequence.

It must be stressed that the multidate or multiband enhancement process is successful only if the input images contain inherent spectral or temporal differences. The enhancement procedure can facilitate or enhance the interpretation of multiband or multidate images that meet this criterion. In addition, the enhancement procedure must be implemented by persons knowledgeable in the objectives of each enhancement as well as the signatures of each category on the input image. In this way the effectiveness of the enhancement procedure can be maximized.

\section{B. COLORADO PLATEAU TEST AREA}

1. Subjective Image Evaluation

A subjective assessment of the relative discriminability of vegetation and related landform features on each of the image types was completed by two experienced interpreters. They rated the imagery types in the following order from best to poorest: 


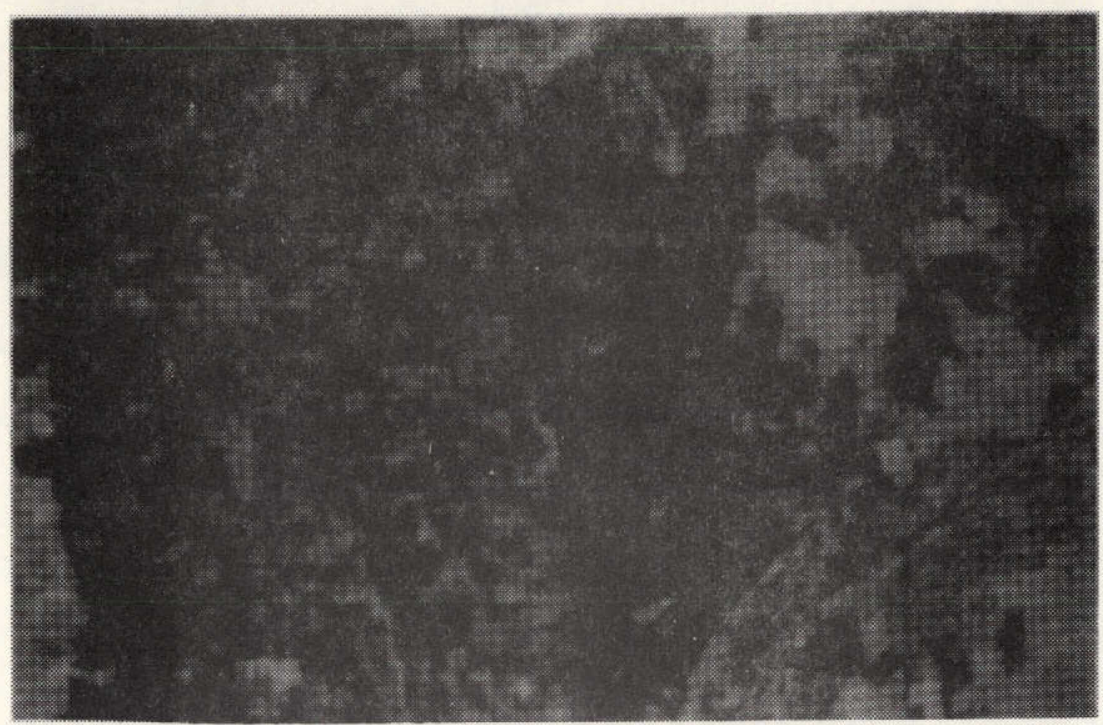

Marysville Test Site

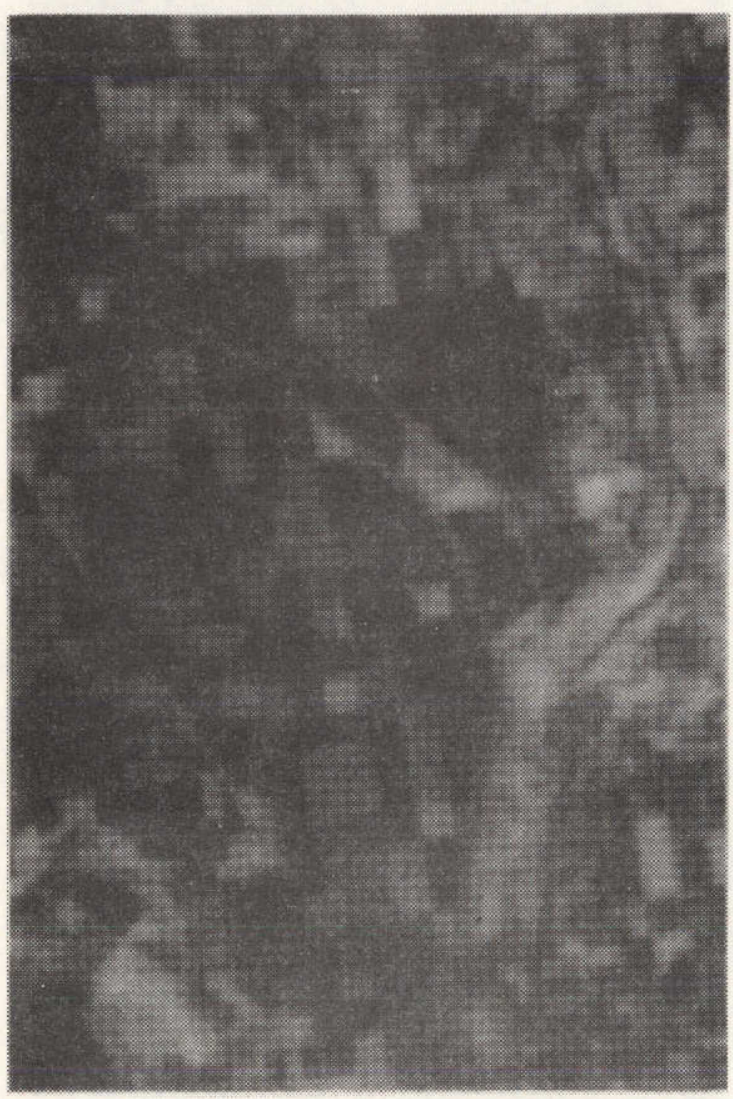

Sutter Test Site

Figure 22. Multidate additive color enhancements of the Marysville and Sutter Test Sites. Within the rice growing areas characterized by large fields of rectangular shape, the color codes have the following significance: dark: rice in 1972 and 1973; blue: rice in 1972, other agricultural crop in 1973; red: other agricultural crop in 1972, rice in 1973. See text for further discussion. 
EREP ST90B Color

EREP S190A Color IR

EREP S190A Color

ERTS Color Composite (bands 5 and 7 only) 1 /

EREP S190A B/W RedI/

ERTS Band 5

EREP SI90A B/W IR

ERTS Band 7

1/ These imagery types are of equal rank for this comparison.

Although the particular test print of the EREP SI90A

color image was not of high quality, the ranking of this image type above is based upon inspection of the positive transparency and therefore reflects more realistically the value of this film type when reproduced properly.

In vegetation management, the location of water bodies is of great importance. Therefore, conclusions were also reached with respect to detection of surface water features. The contrast between water and all other features (except cloud shadows) is greatest on black-and-white infrared images. This spectral band is superior even to color IR for surface water detection. The detection of small water bodies and narrow or intermittent streams is more easily accomplished with higher resolution systems (such as EREP) than with ERTS-type systems.

\section{Vegetation Mapping}

A delineation test was not undertaken for natural vegetation mapping because of the recognized difficulty in judging the correctness of delineated areas on several images. There would be little difficulty in judging whether pure types are correctly mapped. 
However, vegetation mapping may be done correctly in several fashions in the Colorado Plateau where vegetation complexes (mixtures of pure vegetation types) occur. As long as

(1) the delineation lines follow ecotones on the ground and

(2) the components of each delineation are correctly and adequately defined, the delineation is correct. Hence, it was recognized that a. comparison of delineated test images would be a difficult task .

As an alternative, the diversity of distinct image signatures as interpreted in six, one-square-inch samples from each image type was evaluated. Identical large and essentially cloud-free areas were laid out on each of the test images. Within this area of approximately 21 square inches, the above samples were drawn. Two experienced interpreters examined and discussed each sample area together. They decided first on the number of image classes (areas of distinct signatures) that could be easily discerned and mapped within each one-square-inch area and then on the total number of classes that could be mapped after very intensive study.

The average total number of classes discerned and the average number easily discerned gives a further indication of relationship between color and black-and-white images for mapping purpose. These totals are:

$\begin{array}{lcc}\begin{array}{l}\text { Image } \\ \text { Type }\end{array} & \begin{array}{c}\text { Total Classes } \\ \text { Discerned }\end{array} & \begin{array}{c}\text { Classes Easily } \\ \text { Discerned }\end{array} \\ \text { Color } & 40 & 33 \\ \text { Black-and-White } & 29 & 22\end{array}$


The number of image classes that were discerned on each image type are summarized in Table 14. One must remember that this subjective test has not addressed the question of image identification where the advantage of color over black-and-white imagery is most important. The above results are also in line with the quantitative tests, but in this subjective test the black-and-white images would not have ranked nearly as close to color had identification of delineations been a part of the subjective evaluation. Many vegetation types could be delineated on black-and-white images but delineation areas known to be different looked much alike in black-and-white. It is reasonable to state that visual identification of vegetation categories from a single band of black-and-white imagery can rarely be justified in an operational program if color can possibly be made available.

3. Image Quality

In terms of the adequacy of print quality for visual interpretation, some of the black-and-white images had such high contrast that mapping of detail across the entire image would have been difficult without LogEtronic or other special printing. The EREP S190A B/W red image was worst among the black-and-white images in this regard. The lower elevation sagebrush (shrub-steppe) and salt desert (semidesert) areas are very highly reflective because of the large amount of bare soil common to these environments. In the absence of special precautions, vegetation and landform details are frequently lost in processing this band for 


\section{TABLE 14}

ERTS-SKYLAB SUBJECTIVE COMPARISON

OF IMAGE TYPES FOR DISCERNING AND MAPPING

NATURAL VEGETATION TYPES

NO. OF IMAGE CLASSES

IMAGE TYPE $1 /$

EREP S190A CoIor IR

EREP S190B Color

EREP SI90A B/W Red

ERTS Color Composite (bands 5 and 7 )

ERTS Band 5

EREP S190A B/W IR

ERTS Band 7
TOTAL DISCERNED

50

40

36

31

30

25

24
EASILY DISCERNED

41

29

24

29

19

19

21

\section{1/ EREP SI9OA Color not evaluated because color quality of test print was suboptimal.}


visual interpretation, even though good data were recorded by the sensor. The problem is most serious when a single scene includes the gradient from semidesert to forested vegetation types. This problem is encountered with red band data for both ERTS and Skylab. In the case of the working materials, the falloff in the semidesert and shrub-steppe types was worse with the S190A working materials than with ERTS.

This problem of uneven and extremely high reflectivity was not evident in the black-and-white IR prints for either the ERTS or Skylab system, but a higher percentage of vegetation-soil boundaries were non-contrasting (thus harder to distinguish) on both of these infrared images as compared to the red band. 
VII. CONCLUSIONS

A. VEGETATION COMPLEX IDENTIFICATION

\section{Agricultural Crops}

\section{Crop Identification - Late Summer Seasonal State}

For the identification of agricultural crops at the late summer seasonal state, the EREP ST90A color IR and the ERTS color composite images were significantly different from (and better than) all the other image types. For the test area studied, the spectral differentiation afforded by the color infrared medium is more useful for crop type discrimination than is the sharper resolution of the EREP S19OA and S190B color images. Since all agricultural fields selected as test and training examples were well above the minimum detectable field size, little added information regarding crop type was derived from sharper image detail.

A11 four color images ranked higher than the black-andwhite images for crop identification. Image ranking is summarized below (from Table 3):

Image Type

EREP S190A Color IR

ERTS Color Composite

EREP S190B Color

EREP S190A Color

EREP S190A B/W IR

ERTS Band 7

EREP ST90A B/W Red

ERTS Band 5
Overal1 Average Correct Responses (all crop categories) $1 /$

7.5

7.4

6.8

6.7

6.6

6.4

6.0

5.5

II Maximum possible $=10$ 
Crop Identification - Late Spring Seasonal State

The EREP S190A color and color IR images were significantly different from the other image types for crop identification at the late spring seasonal state. All three color images ranked higher than the black-and-white images. Image ranking is summarized below (from Table 5):

Image Type

EREP ST $90 A$ Color

EREP ST 90A Color IR

ERTS Color Composite

ERTS Band 5

EREP SI90A B/W Red

ERTS Band 7

EREP ST $90 A$ B/W IR
Overall Average

Correct Responses

(a)1 crop categories) 1

7.1

7.0

6.1

5.9

5.8

5.6

5.4

I/ Maximum possibie $=10$

Crop Identification - Seasonal Comparisons

Overall interpretation results for both image dates were very similar; only for the identification of specific crops can one date be recommended over another.

In both cases, al1 the color images ranked higher as a group than the black-and-white images. For the late summer seasonal state, the EREP SI90A color IR and ERTS color composite were better than the other types; for the late spring seasonal state, the EREP SI9OA color IR and color images were best. The numerical rankings of the remaining images were not significantly 
different; hence, it is impractical to attempt to specify a composite ranking for interpretation at the two seasonal states.

The utility of additive color enhancement techniques for displaying (1) the regional extent of and (2) changes in areas devoted to rice culture over a two year period was demonstrated with ERTS imagery.

\section{Land Use Identification and Delineation}

The combination of high resolution and spectral discrimination afforded by the EREP color images results in the highest subjective estimate of accuracy for land use identification and delineation. Whereas crop identification per se is accomplished most accurately on color infrared (EREP) or color infrared simulations (ERTS), the identification of land use categories frequently depends upon the detection of image pattern or detail as well as a unique image signature (e.g., urban areas are characterized by regular street patterns, and dryland pasture has a unique texture and pattern). Ranking of image type according to total certainty ranking is as follows, best image appearing first (from Table 11):

Image Type

EREP S190B Color

EREP S190A Color

EREP S190 Color IR

ERTS Color Composite

EREP S190A B/W Red

EREP ST $90 A$ B $/ W$ IR

ERTS Band 7

ERTS Band 5
Total Certainty Ranking $1 /$

8
11
14
15
16
19
20
22

If $6 \equiv$ Certain ranking for all categories 


\section{Natural Vegetation}

For identification of natural vegetation, the EREP S190A color infrared image was significantly different from (and better than) the other image types. The four color images tested ranked higher than the four black-and-white images. Image ranking is summarized below (from Table 7):

$\begin{array}{lc}\text { Image Type } & \begin{array}{c}\text { Overall Average } \\ \text { Correct Responses } \\ \text { (all crop categories) }\end{array} \\ \text { EREP S190A Color IR } & 7.9 \\ \text { ERTS Color Compos ite } & 7.0 \\ \text { EREP S190B Color } & 6.4 \\ \text { EREP S190A B/W IR } & 6.4 \\ \text { ERTS Band 7 } & 6.2 \\ \text { EREP S190A Color } & 5.5 \\ \text { EREP S190A B/W Red } & 5.2 \\ \text { ERTS Band 5 } & 4.6 \\ \text { II Maximum possible }=10 & \end{array}$

Results from interpretation by 10 students using monoscopic viewing $(82.7 \%$ correct) and stereoscopic viewing $(77.3 \%$ correct) of the EREP ST9OA color IR image were not significantly different (paired $t$ test). Interpretation was undertaken by one of the investigators who was experienced at stereoscopic interpretation and understood the relationships of the vegetation types to landforms and topography. The result of this interpretation was improved accuracy from stereo viewing (85\% correct identification with stereo viewing, $60 \%$ without). Inexperience on the part of 
students (both with stereo viewing and understanding of ecological relationships) caused their relatively poor results and enforces the point that trained interpreters can use stereo viewing to good advantage.

3. Combined Ranking for Agricultural Crop and Natural Vegetation Identification

All eight image types tested have been ranked according to the overall mean correct identification for Tests 1 and 4 . The ranking of each image type was identical on both tests with one exception (from best to worst): 1 -

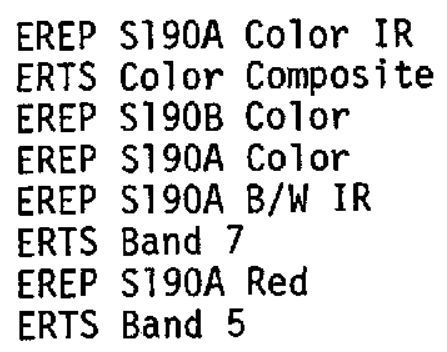

These results indicate that, for the vegetation complexes interpreted, and for the relatively large areas occupied by each test item, the spectral information from a color infrared image or ERTS color infrared simulation is more valuable than increased resolution provided by EREP color (S190A and S190B) images.

I) The EREP S190A color image ranked lower in Test 4 (Natural Vegetation) than in Test 1 (Agricultural Crops). However, it was predicted (Section III-A) that the poor color quality of the test print (only for the Colorado Plateau Test Area) might affect its interpretability for natural vegetation types. Its composite ranking here is assigned on the basis of the agricultural crop test results only. 


\section{B. VEGETATION COMPLEX DELINEATION}

1. Agricultura1 Crops

Minimum Field Size

Minimum field size consistently detectable is directly related to image resolution for targets of both high and low contrast (Table 10). The image types can be ranked as follows (no statistical significance associated with order):

Image Type

EREP S190B Color (high res.)

EREP S190A Color

EREP SI9OA B/W Red

EREP S190A Color IR

EREP SI90A B/W IR

ERTS Color Composite

ERTS Band 5

ERTS Band 7
Minimum Field Size (Acres) High Contrast Low Contrast

$5-8$

$5-8$

5-10

$12-17$

$30-40$

20-30

$30-40$

$30-40$

\section{Rice Crop Delineation}

Both the ERTS color composite and EREP S190A color IR images produced highly accurate delineations of a rice-growing region (Table 6). Commission errors were also minimal, indicating that the early summer season is an appropriate time of year for separating rice-growing from non rice-growing areas. Using the ERTS color composite, $90.7 \%$ of the rice-growing area was correctly identified; the accuracy obtained with the EREP S190A color IR image was $82.1 \%$. 


\section{Natural Vegetation}

The number of discrete, mappable image areas within several sample areas was determined for each image type (except the EREP S190A color print which was of suboptimal quality and not evaluated) by two skilled interpreters. The ranking of the image types is as follows (from Table 14):

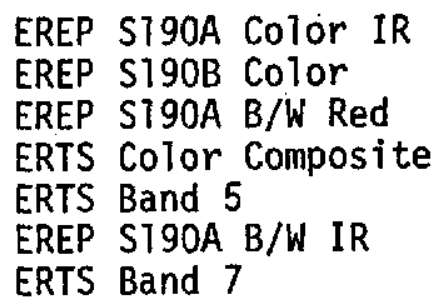

C. VEGETATION VIGOR AND CONDITION

1. Agricultural Crops

Either of the systems tested, EREP or ERTS, has adequate spatial resolution for regional agricultural crop survey purposes. Such surveys usually do not require absolute identification of the crop type in every field throughout the region. In this regard, the value of ERTS for making year-to-year comparisons of regional drought patterns was clearly stated with an example from Young County, Texas. Distinct regional image signatures were displayed (Figure 19) for drought (1974) and normal (1973) conditions.

For more detailed agricultural surveys, however, such as those used by farm managers, market analysts and tax assessment officials, ERTS data do not provide adequate image spatial resolution for such uses. 
EREP S190A will provide adequate images for some management applications but usually not those requiring local decisions related to plant vigor and stress, such as weed and pest control or soil additives (nitrogen, minerals, etc.).

EREP S190B, on the other hand, provides improved resolution over the other systems and, when used under favorable atmospheric conditions (clear skies - minimum haze), can be applied by farm managers to make on-site decisions regarding field practices, particularly for fields of five acres or larger in size.

The high resolution afforded by a system such as the EREP S190B camera is essential for detection of such yield-reducing factors as lodging which have sharp, well-defined boundaries and contrast sharply with the surroundings. Lodging patterns could be frequently confirmed only on the EREP S19OB color image. The high spatial resolution of this system is much more critical for lodging recognition than is the spectral detail of the particular film type used in it.

Because color infrared images provided the most useful data in this study for crop identification, it is recommended that color infrared film be specified for systems such as the EREP SI90B when used for crop monitoring applications. This recommendation is justified even though only color film from the S190B system was available for testing in this study. 
The frequency of timing of coverage for regional crop surveys and farm management practices is difficult to specify precisely because of the uncertainty of the occurrence of certain critical environmental events which may alter an otherwise "normal" season. These factors include such events as drought, frost damage, excessive precipitation and wind storms. As noted earlier, some agricultural areas are more prone to unfavorable weather conditions for remote sensing coverage and thus may be difficult to cover with any inflexible schedule. One factor is certain, however, and that relates to the delay in receipt of images once they have been exposed. For regional surveys a delay of several weeks may be acceptable to the agricultural analyst. For the market analyst and the farm manager remote sensing images are a perishable item and a delay of more than a few days can render the images almost useless for making current management decisions because of the irreversability of some crop problems if action to counteract a faulty condition is not taken promptly.

Experience with both ERTS and EREP by the investigators indicates that data from both systems were not available in time to be applicable to market analysis or farm management and only marginally useful for regional agricultural analysis. 


\section{Natural Vegetation}

The utility of the various ERTS and EREP images for assessment of vigor and condition of natural vegetation in the Colorado Plateau area was not addressed in this study.

\section{IMAGE QUALITY CONSIDERATIONS}

Photo quality of prints can significantly affect the interpretability of many features, particularly where tonal contrasts and feature sizes are at or near the threshold of detectability. It is therefore important to produce photos for visual interpretation with great care and to insure that information is not lost in the photo reproduction phase to any significant degree.

Multidate images can provide improved detectability of vegetation types by exploiting the differences in target reflectances as seasonal changes occur. However, the photo systems tested did not show any inter-system differences in usefulness for the problems studied related to the multidate approach although we only evaluated two dates of Skylab data and seven dates of ERTS imagery. 
APPENDIX A

\section{TEST IMACE EXAMPLS}


IEST(S)

1

1

2

$2 \& 3$

4

$4 \& 5$

5
TEST AREA

Northern Great Valley

(Marysville Test Site)

Northern Great Valley

(Sutter Test Site)

Northern Great Valley

(Marysville Test Site)

Northern Great Valley

(Marysville Test Site)

Colorado Plateau

Colorado Plateau

Colorado Plateau
IMAGE TYPE

ERTS Band 5

ERTS Band 7

ERTS Color Composite

EREP ST $90 A$ B/W Red

EREP S190A B/W IR

EREP S190A Color

EPEP S190A Color IR

EREP ST9OB Color

ERTS Band 5

ERTS Band 7

ERTS Color Composite

EREP S190A B/W Red

EREP SI9OA B/W IR

EREP S190A Color

EPEP S190A Color IR

EREP S190B Color

ERTS Band 5

ERTS Band 7

EREP ST $90 A$ B/W Red

EREP ST $90 A \quad B / W$ IR

EREP S190A Color

ERTS Color Composite EREP ST $90 A$ Color IR

ERTS Band 5

ERTS Band 7

ERTS Color Composite

EREP ST 90A B/W Red

EREP S190A B/W IR

EREP S190A Color

EREP S190B Color

EREP SI9OA COTOr IR

EREP SI9OA COIOr IR (Stereo) 


\section{KEY TO TEST ITEMS}

\section{AGRICULTURAL CROP TESTS}

\begin{tabular}{cccc} 
TEST ITEM \# & TYPE & TEST ITEM \# & TYPE \\
\cline { 2 - 4 } 1 & 0 & 31 & $\mathrm{~F}$ \\
2 & 0 & 32 & $\mathrm{G}$ \\
3 & $\mathrm{R}$ & 33 & 0 \\
4 & $\mathrm{X}$ & 34 & 0 \\
5 & $\mathrm{X}$ & 35 & 0 \\
6 & $\mathrm{~F}$ & 36 & $\mathrm{~A}$ \\
7 & $\mathrm{G}$ & 37 & $\mathrm{R}$ \\
8 & $\mathrm{R}$ & 38 & $\mathrm{R}$ \\
9 & $\mathrm{R}$ & 39 & $\mathrm{R}$ \\
10 & $\mathrm{~F}$ & 40 & $\mathrm{G}$ \\
11 & $\mathrm{R}$ & 41 & $\mathrm{~F}$ \\
12 & $\mathrm{G}$ & 42 & $\mathrm{X}$ \\
13 & $\mathrm{~F}$ & 43 & $\mathrm{R}$ \\
14 & $\mathrm{X}$ & 44 & $\mathrm{R}$ \\
15 & $\mathrm{X}$ & 45 & $\mathrm{~F}$ \\
16 & 0 & 46 & $\mathrm{G}$ \\
17 & $\mathrm{~F}$ & 47 & $\mathrm{G}$ \\
18 & $\mathrm{~A}$ & 48 & $\mathrm{X}$ \\
19 & $\mathrm{X}$ & 49 & $\mathrm{R}$ \\
20 & $\mathrm{X}$ & 50 & $\mathrm{~A}$ \\
21 & $\mathrm{~F}$ & 51 & $\mathrm{~A}$ \\
22 & $\mathrm{X}$ & 52 & 0 \\
23 & $\mathrm{~F}$ & 53 & $\mathrm{~A}$ \\
24 & $\mathrm{~A}$ & 54 & $\mathrm{~A}$ \\
25 & $\mathrm{~A}$ & 55 & $\mathrm{~A}$ \\
26 & $\mathrm{~F}$ & 56 & $\mathrm{G}$ \\
27 & $\mathrm{~A}$ & 57 & 0 \\
28 & $\mathrm{G}$ & 58 & 0 \\
29 & $\mathrm{G}$ & 59 & \\
30 & $\mathrm{G}$ & 60 &
\end{tabular}

KEY TO CROP TYPES:

$\mathrm{R}$ - rice

0 - orchard

A - alfalfa

$F$ - fallow

$G$ - dryland pasture

$X$ - other agricultural crops 


\section{KEY TO TEST ITEMS \\ NATURAL VEGETATION TESTS}

TEST ITEM \#

1

3

4

5

6

7

8
9

10

11

12

13

14

15

16

17

18

19

20

21

22

23

24

25

26

27

28

29

30
TYPE

$\mathrm{S}$

W

W

$P$

$P$

A

$S$

$S$

A

$S$

A

P

$w$

P

$W$

P

J

J

$\mathrm{J}$

J

$X$

W

$W$

$W$

$J$

A

A

$S$
TEST ITEM \#

31

32

33

34

35

36

37

38

39

40

41

42

43

44

45

46

47

48

49

50

51

52

53

54

55

56

57

58

59

. 60
TYPE

W

J

J

A

J

A

A

A

$X$

$X$

A

$P$

P

$P$

$p$

$X$

W

$S$

$S$

$X$

$S$

$S$

W

$S$

$X$

$X$

$x$

\section{KEY TO NATURAL VEGETATION TYPES:}

$\mathrm{J}$ - pinyon-juniper woodland

$P$ - ponderosa pine forest

$W$ - sedge (wet) meadow

A - aspen forest

$S$ - spruce-fir firest

$X$ - other vegetation types 
NORTHERN GREAT VALLEY TEST AREA

Marysville Test Site
ERTS Band 5

September 13, 1973

Test \#1

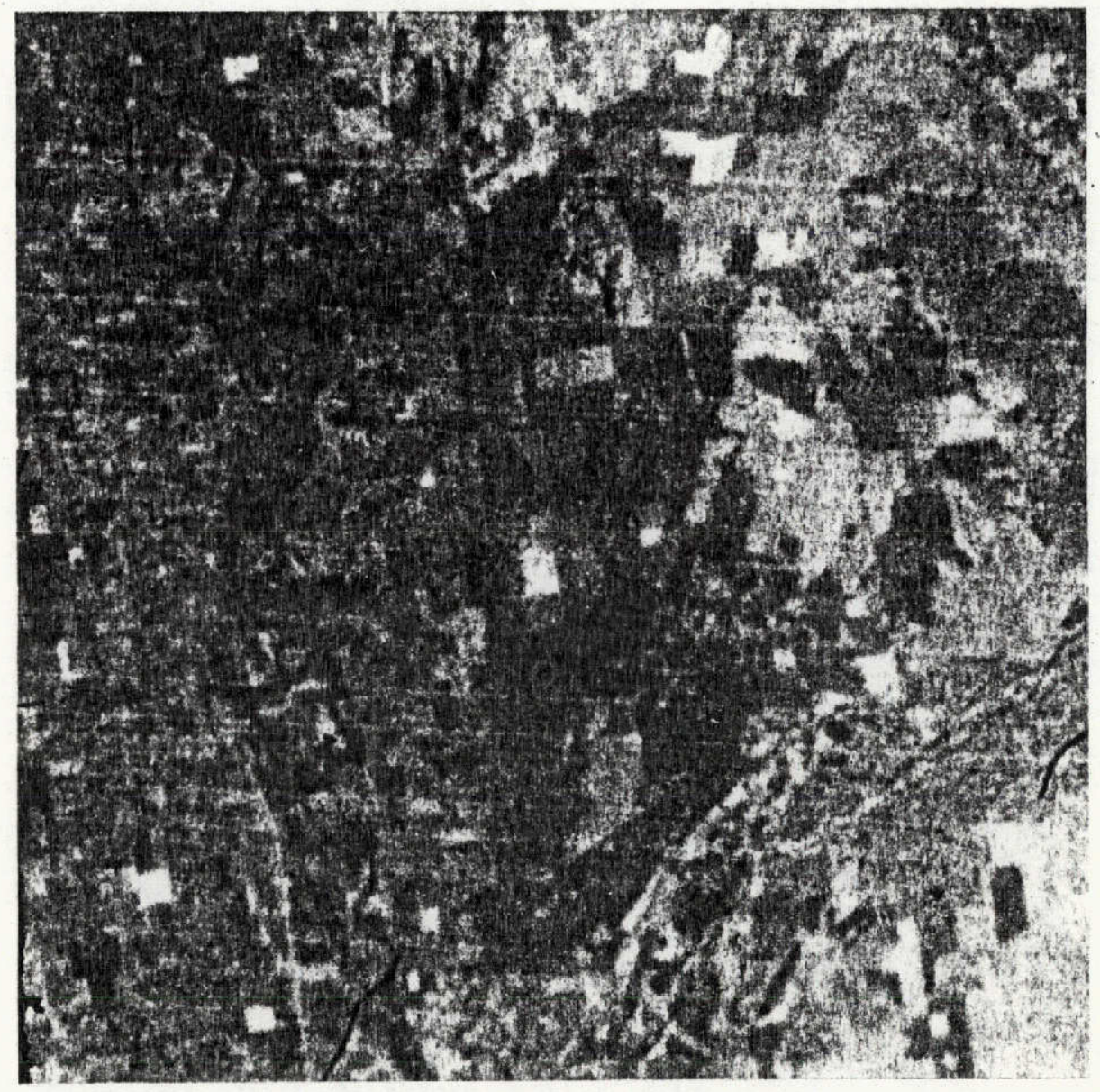


NORTHERN GREAT VALLEY TEST AREA

Marysville Test Site
ERTS Band 7

September 13, 1973

Test \#1

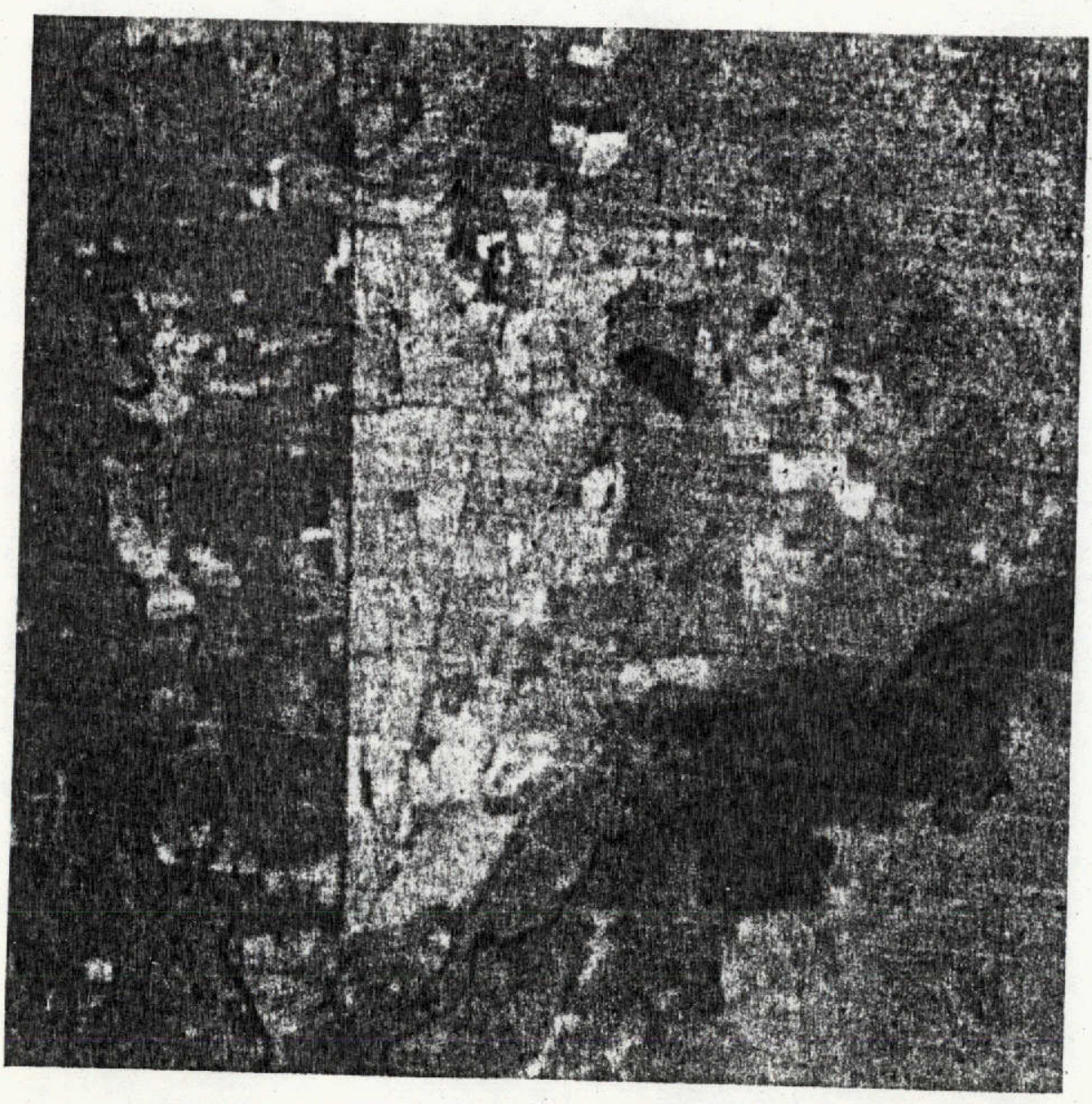


NORTHERN GREAT VALLEY TEST AREA

Marysville Test Site
ERTS Color Composite

September 13, 1973

Test \#1

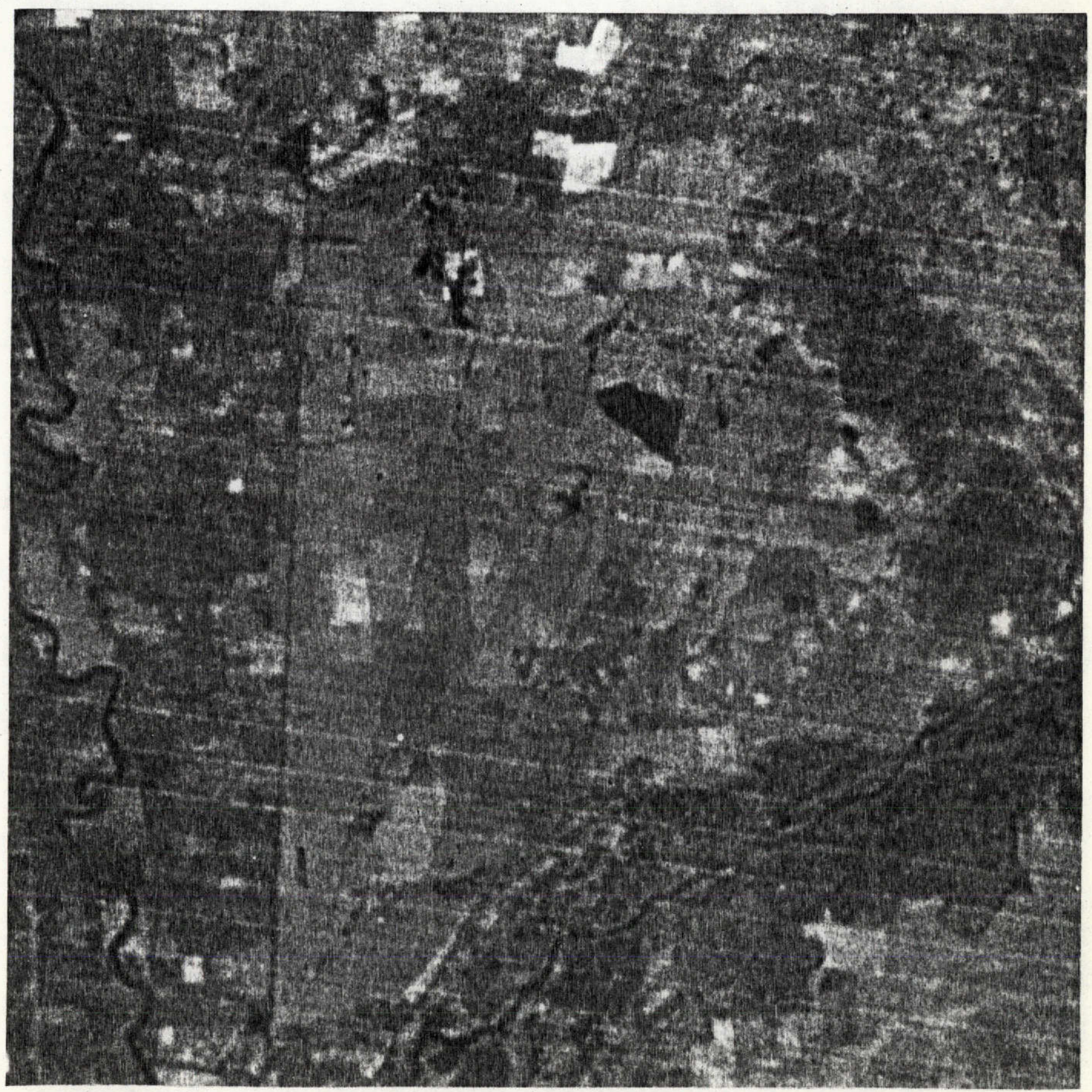


NORTHERN GREAT VALLEY TEST AREA Marysville Test Site

EREP. S190A B/W Red

September 12, 1973

Test \#1

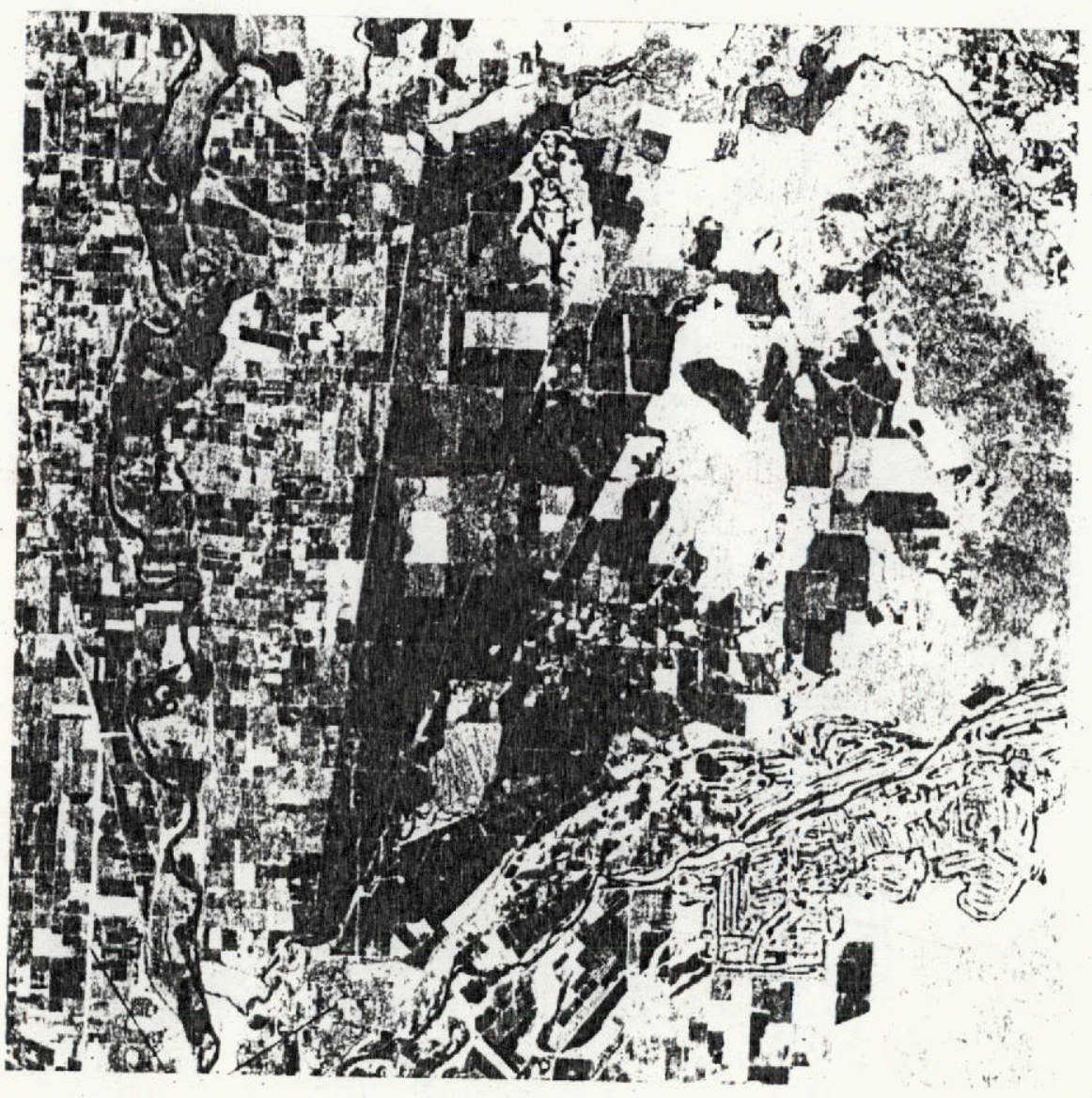


NORTHERN GREAT VALLEY TEST AREA Marysville Test Site
EREP S190A B/W IR

September 12, 1973

Test \#1

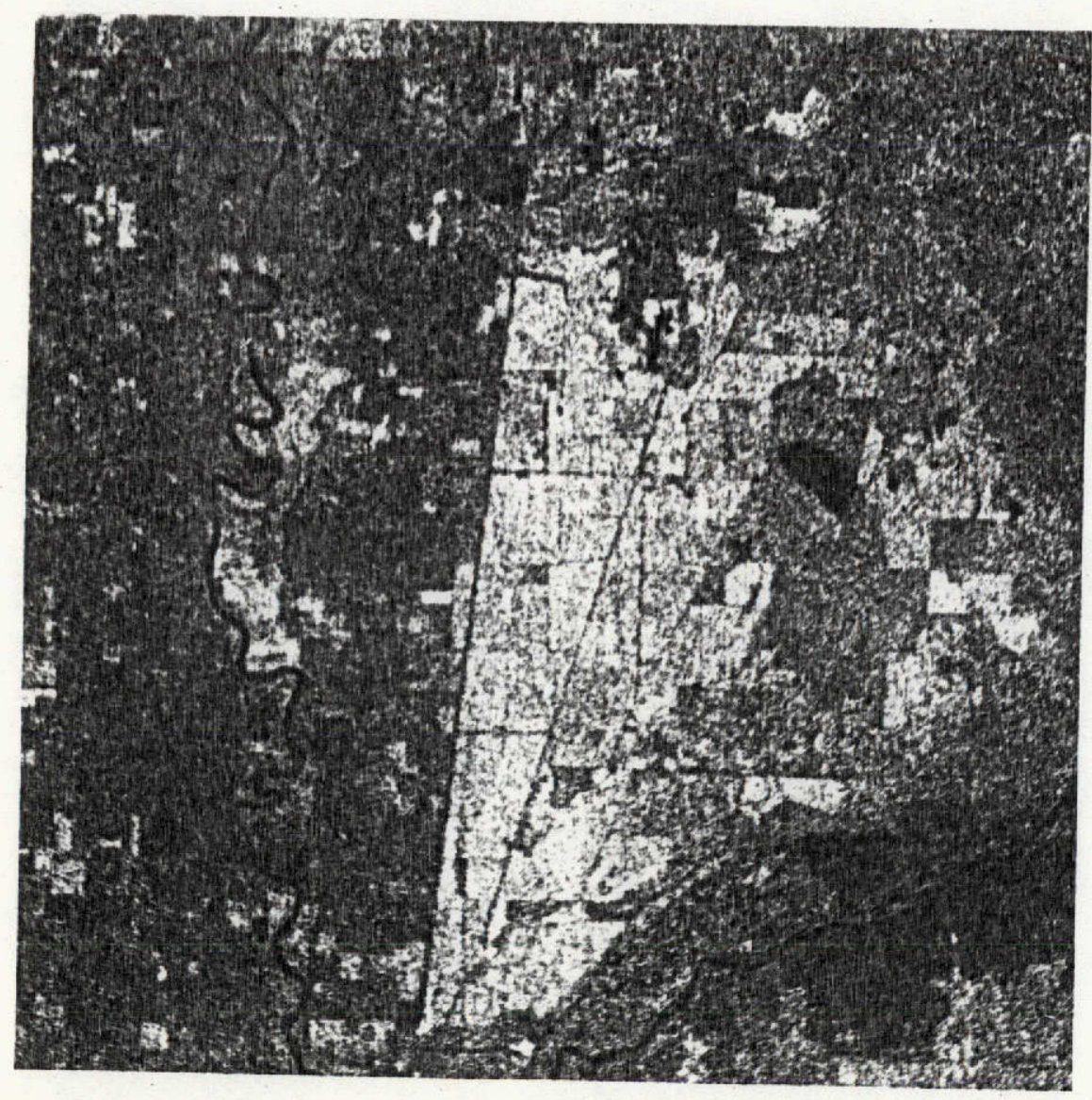


NORTHERN GREAT VALLEY TEST AREA Marysville Test Site
EREP ST $190 A$ COIOr

September 12, 1973

Test \#1

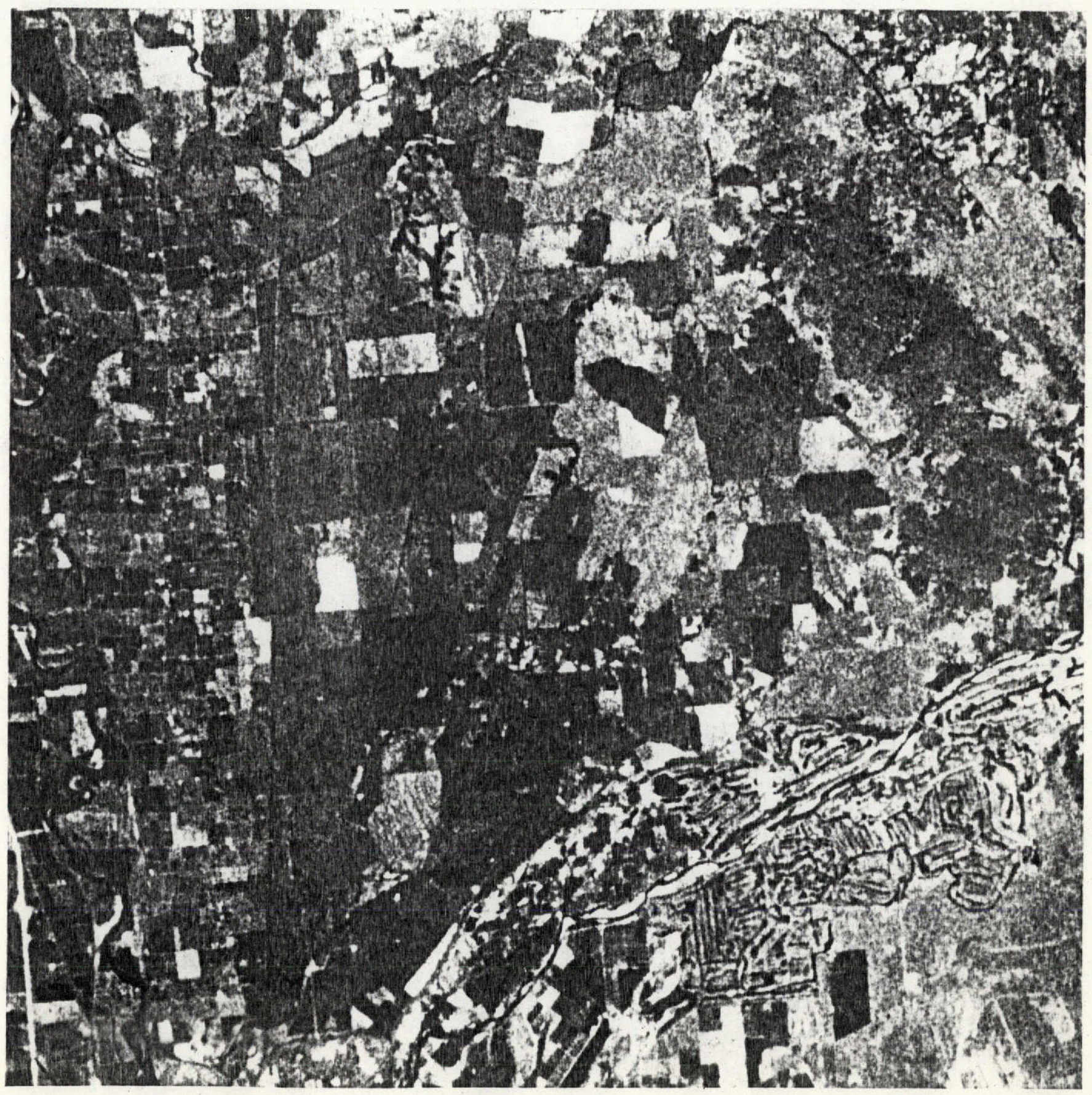


NORTHERN GREAT VALLEY TEST AREA

Marysville Test Site
EREP S190A Color IR

September 12, 1973

Test \#1

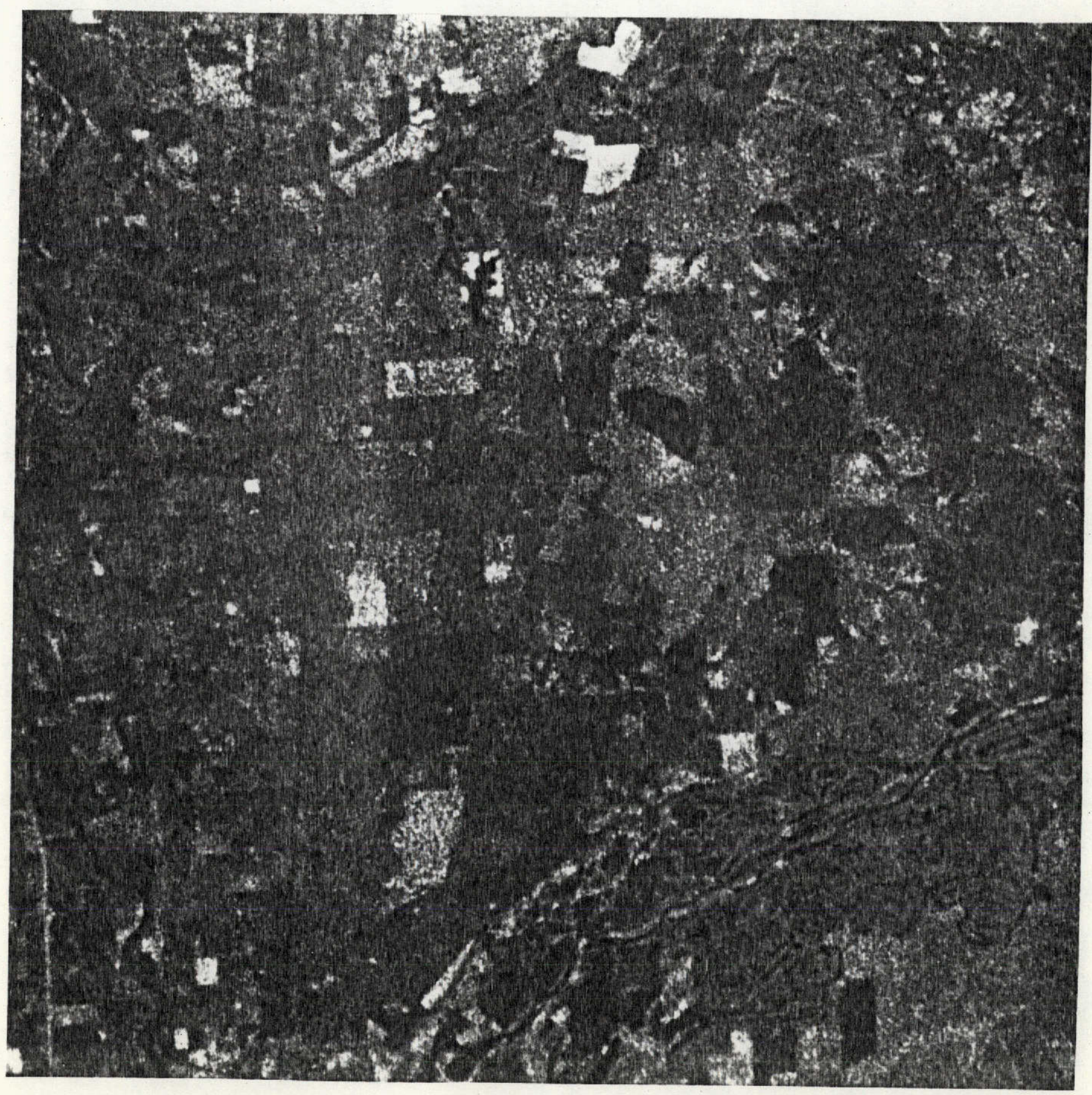


NORTHERN GREAT VALLEY TEST AREA Marysville Test Site
EREP S190B Color

September 12, 1973

Test \#1

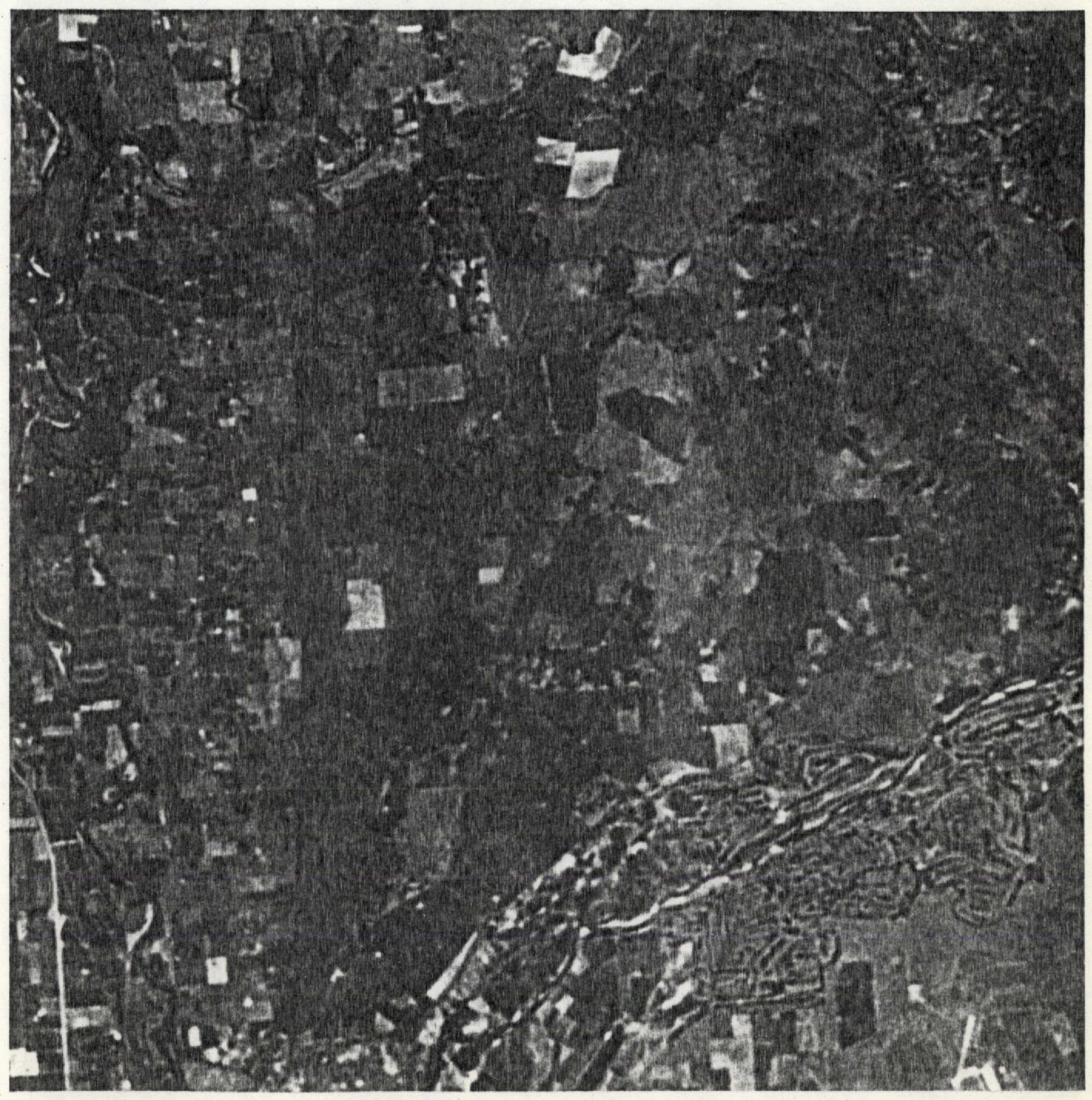


NORTHERN GREAT VALLEY TEST AREA Sutter Test Site
ERTS Band 5

September 13, 1973

Test \#1

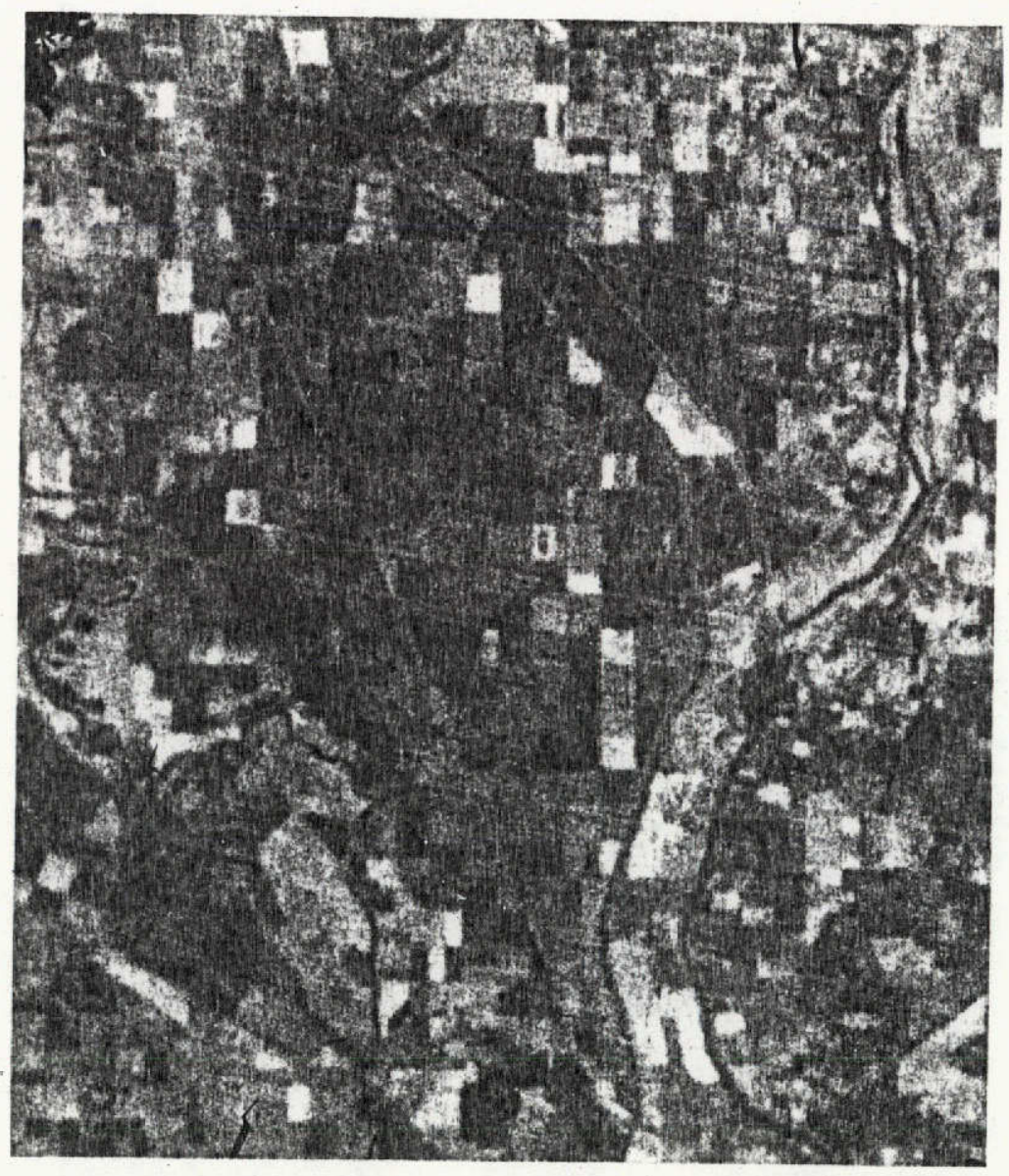


NORTHERN GREAT VALLEY TEST AREA

Sutter Test Site
ERTS Band 7.

September 13, 1973

Test \#1

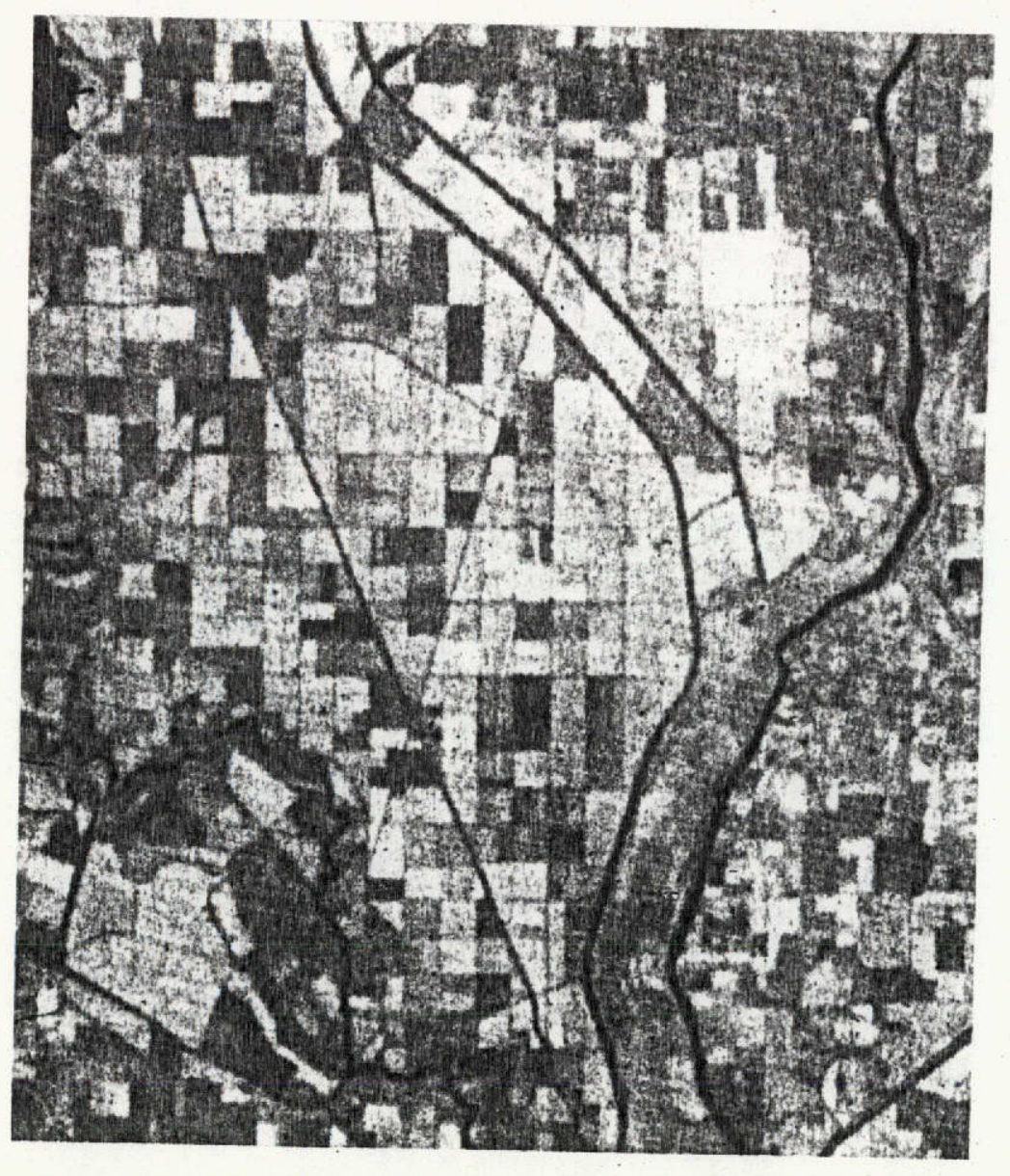


NORTHERN GREAT VALLEY TEST AREA

Sutter Test Site
ERTS Color Composite

September 13, 1973

Test \#1

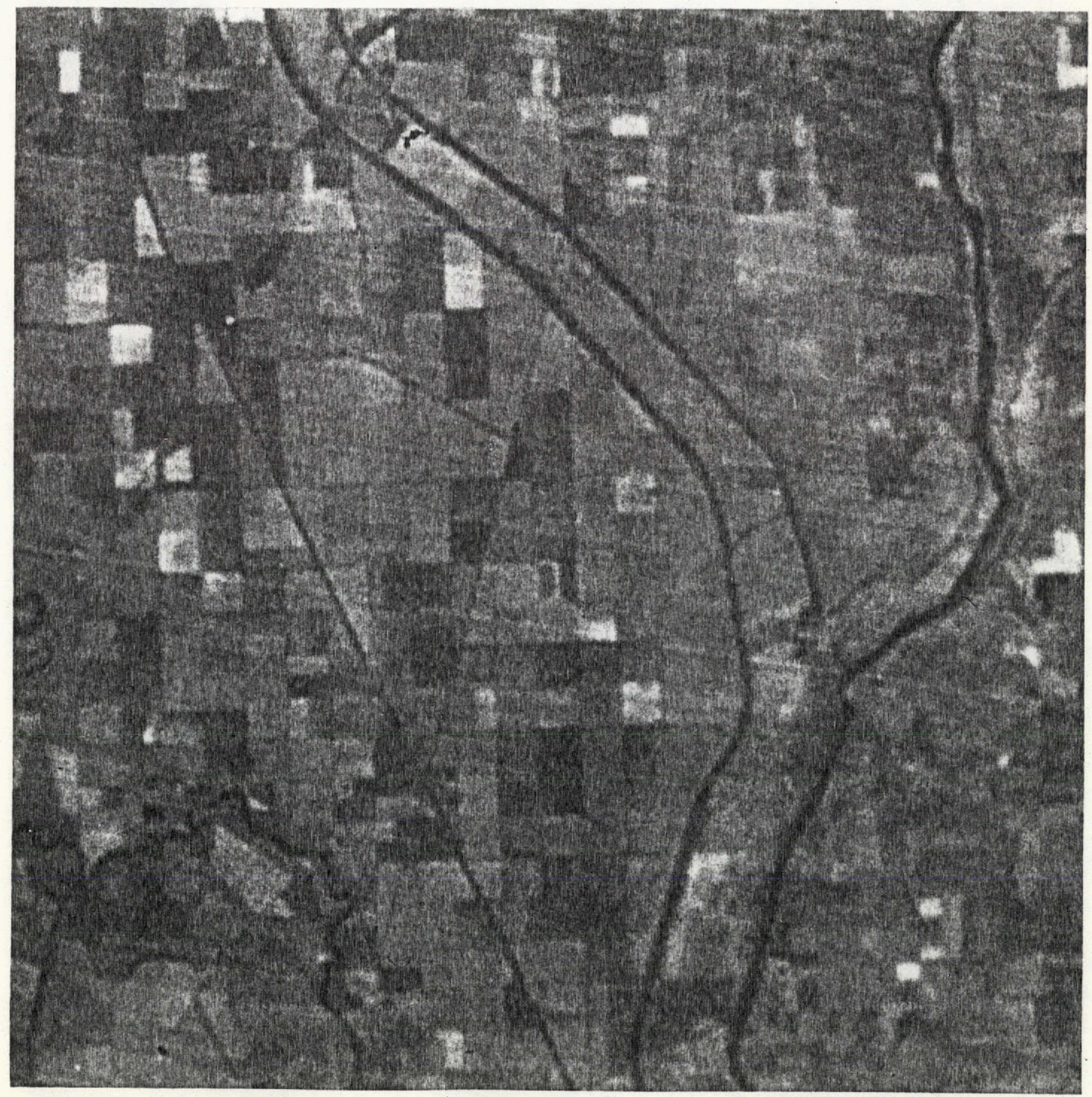


NORTHERN GREAT VALLEY TEST AREA
Sutter Test Site
EREP S190A B/W Red

September 12, 1973

Test \#1

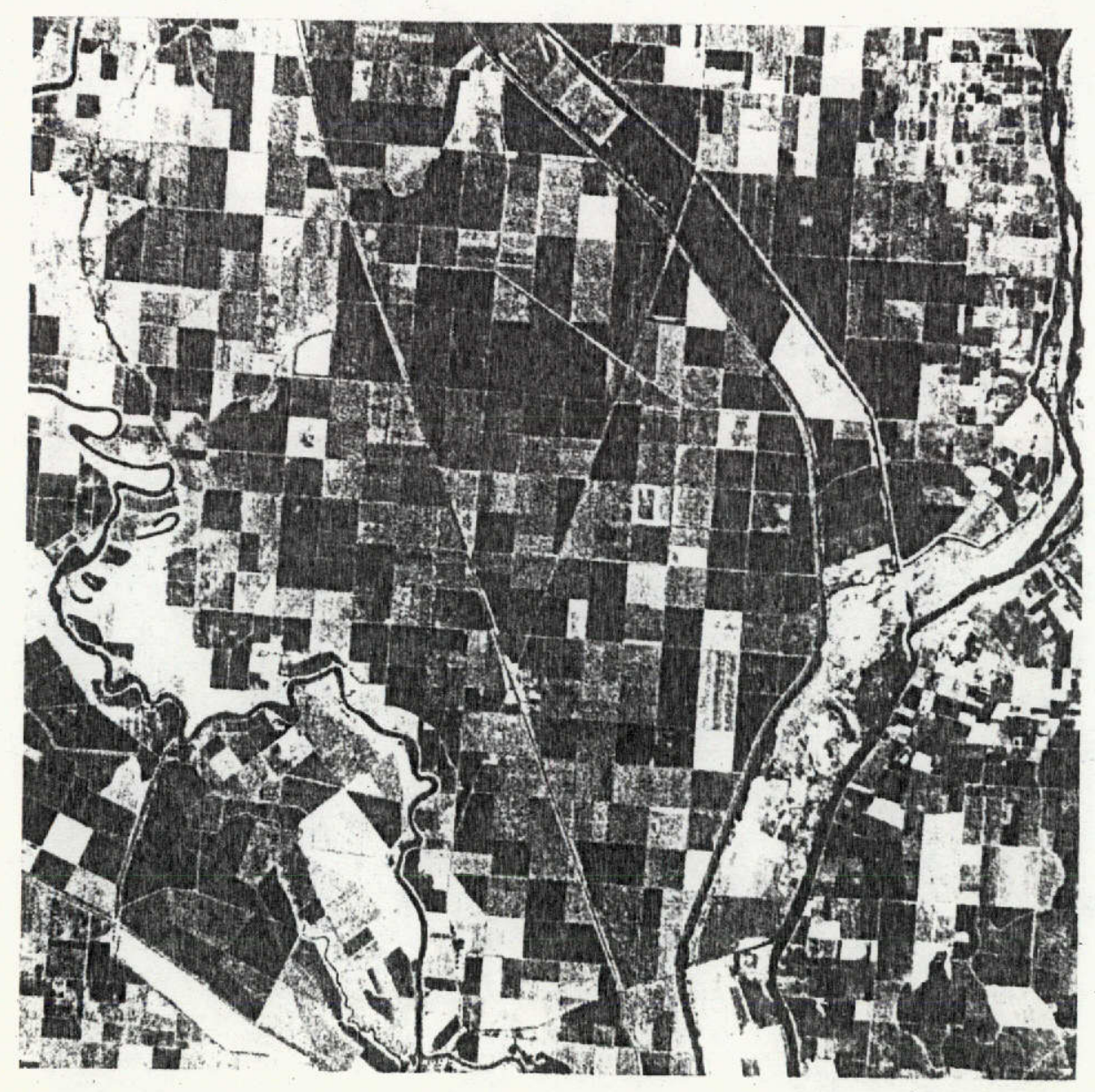


NORTHERN GREAT VALLEY TEST AREA Sutter Test Site
EREP S190A B/W IR

September 12, 1973

Test \#1

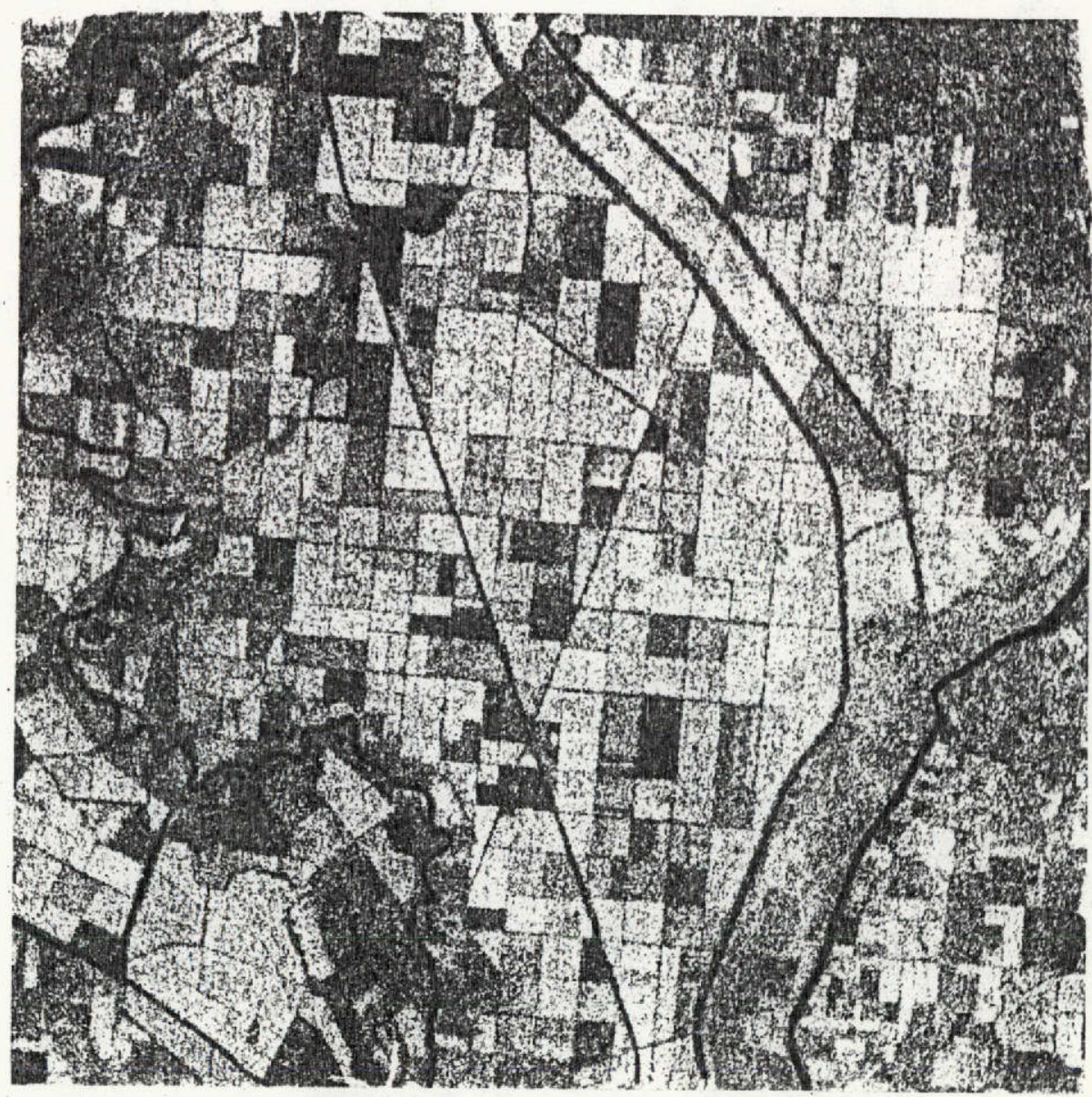


NORTHERN GREAT VALLEY TEST AREA Sutter Test Site
EREP S190A Color

September 12, 1973

Test \#1

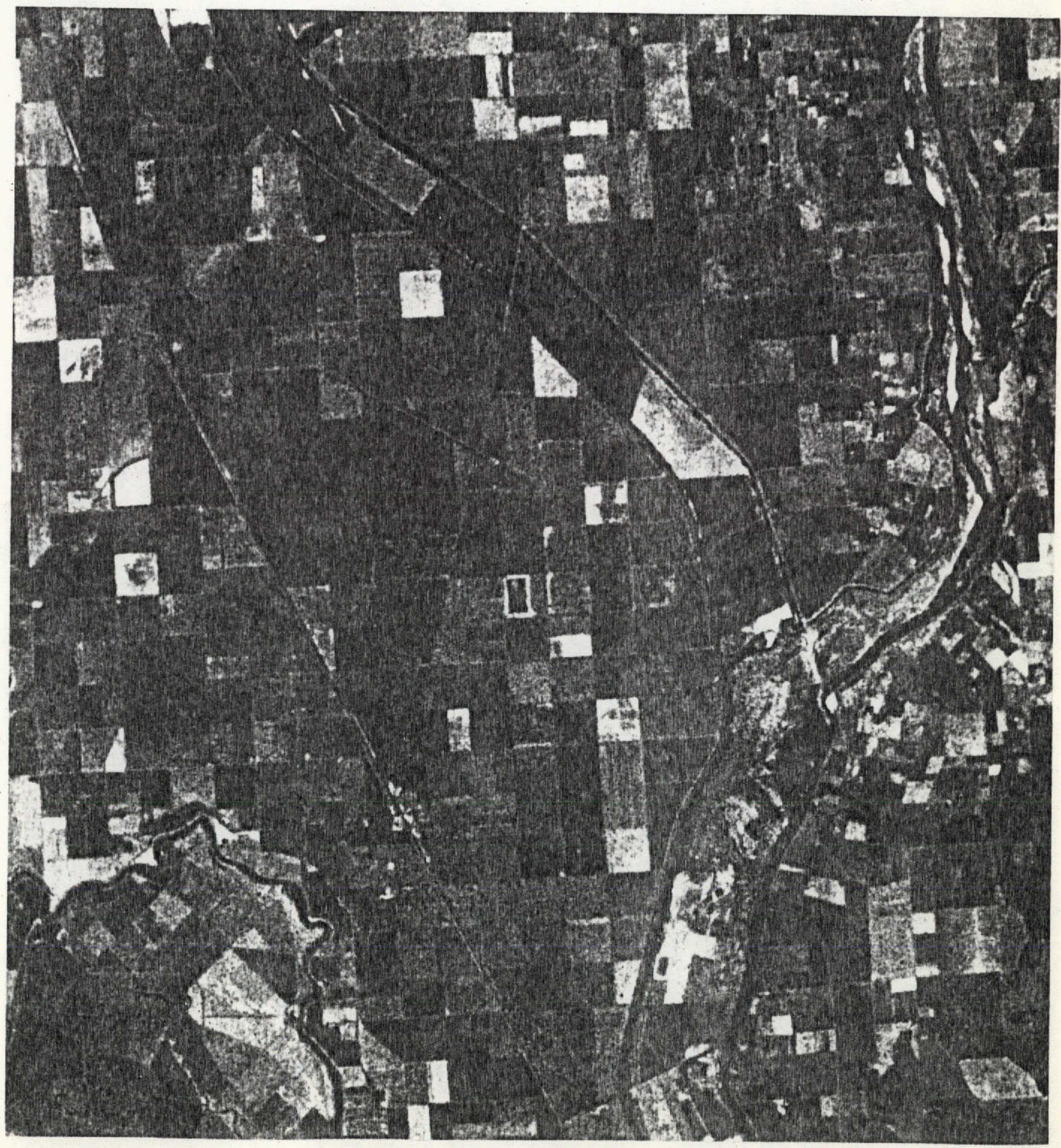


NORTHERN GREAT VALLEY TEST AREA

Sutter Test Site
EREP S190A Color IR

September 12, 1973

Test \#1

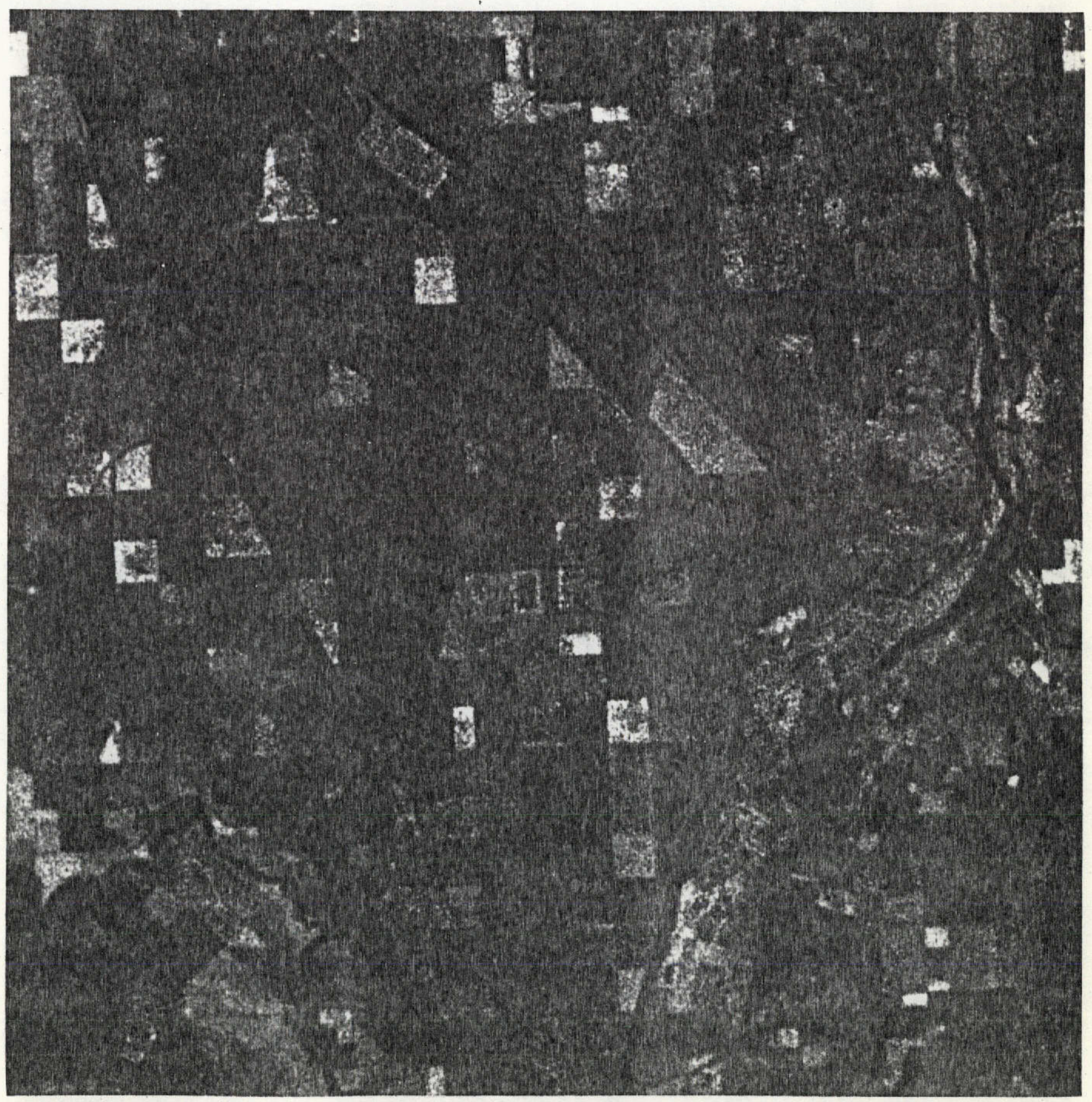


NORTHERN GREAT VALLEY TEST AREA

Sutter Test Site
EREP ST190B Color

September 12, 1973

Test \#1

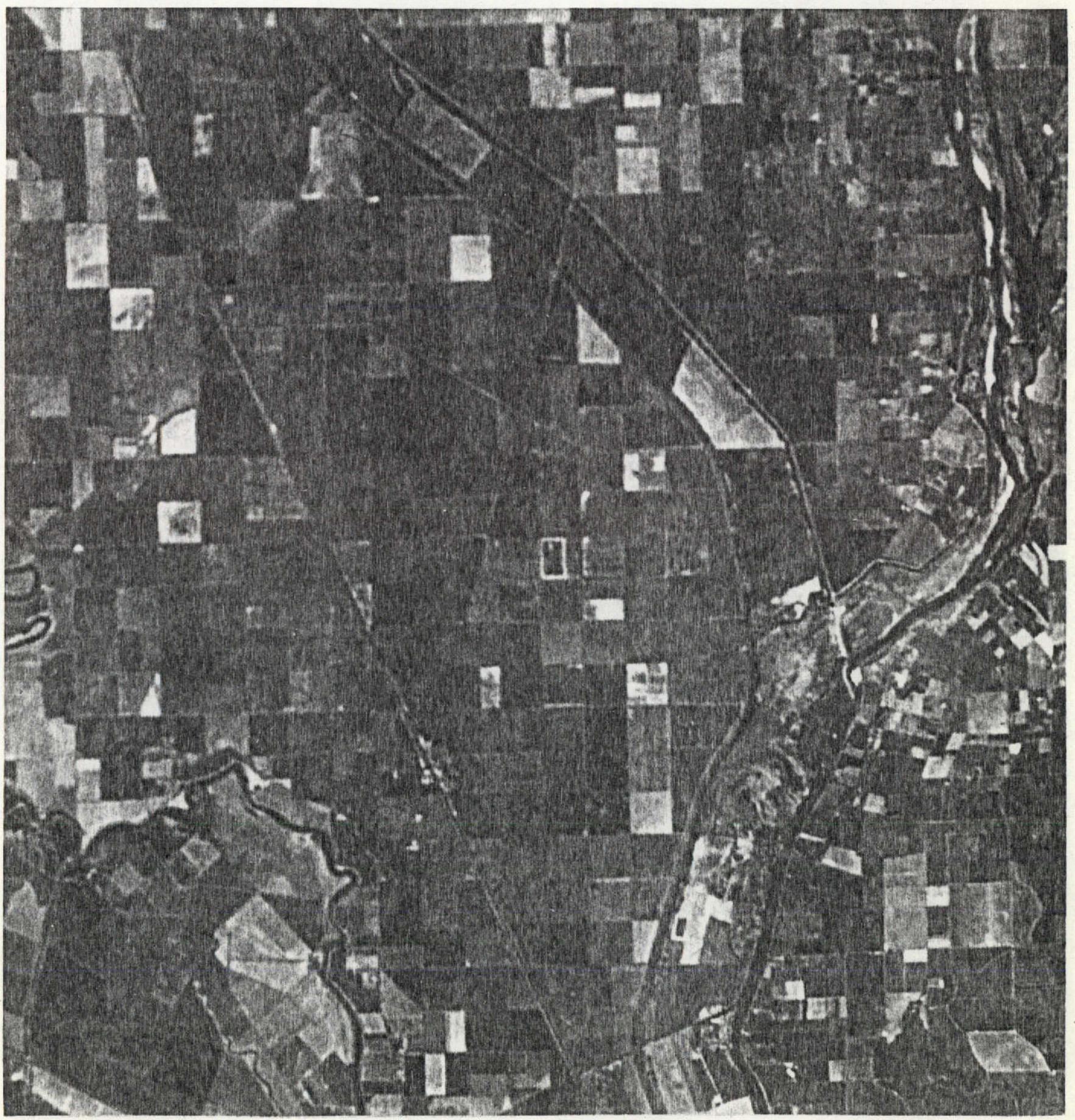


NORTHERN GREAT VALLEY TEST AREA

Marysville Test Site
ERTS Band 5

May 28, 1973

Test \#2

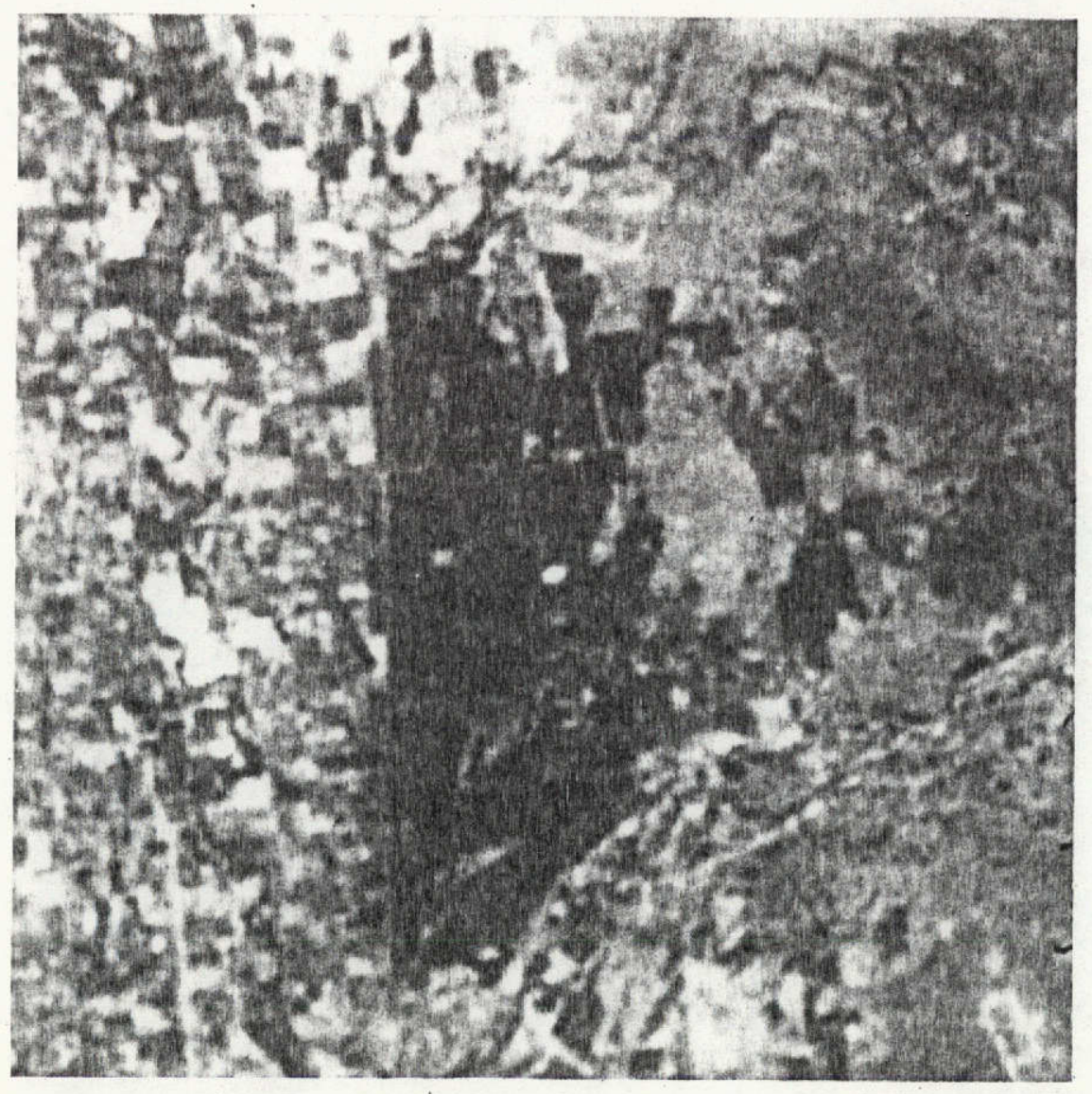



NORTHERN GREAT VALLEY TEST AREA
Marysville Test Site
ERTS Band 7

May 28, 1973

Test \#2

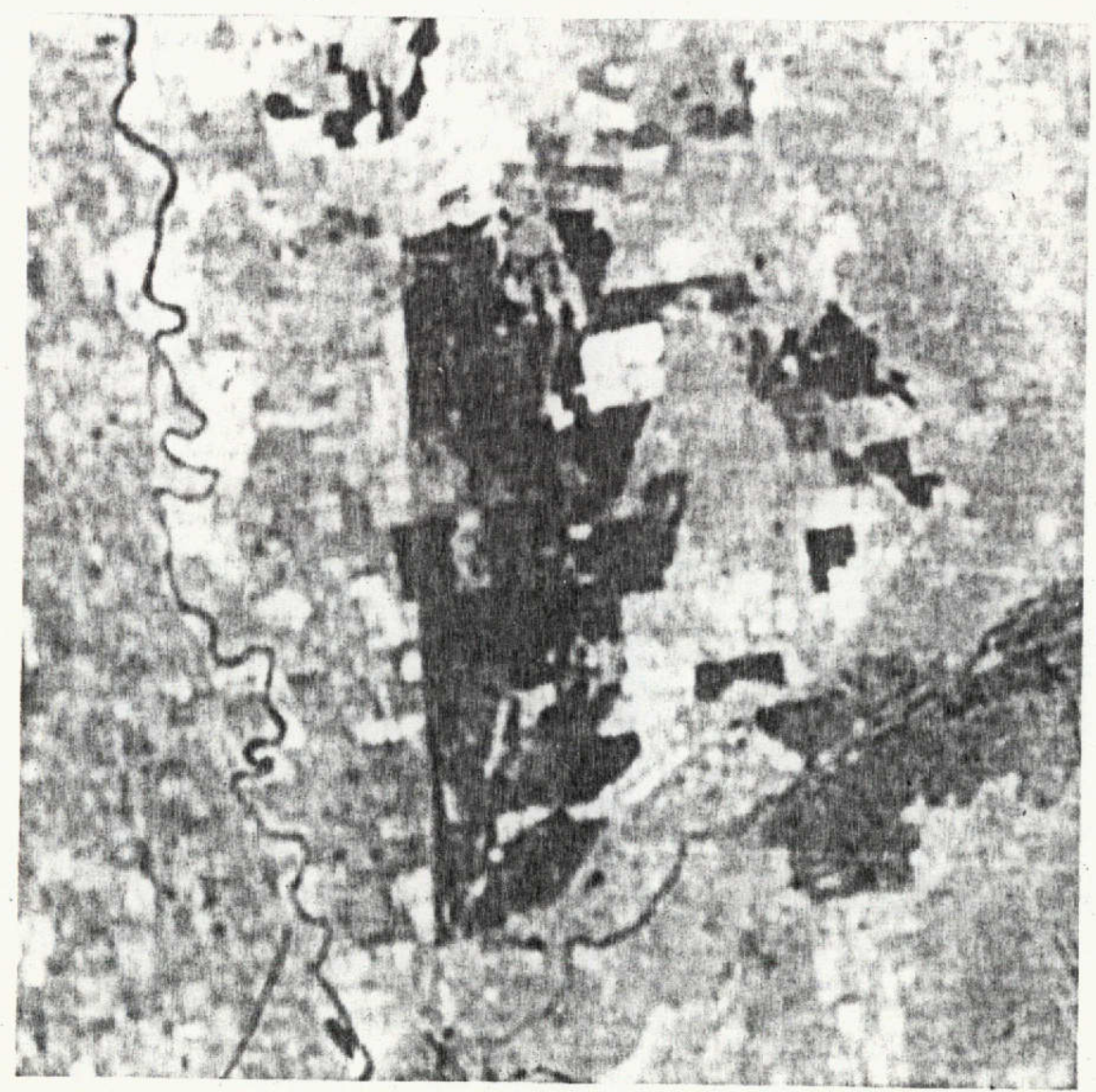


NORTHERN GREAT VALLEY TEST AREA Marysville Test Site
EREP S190A B/W Red June 3,1973

Test \#2

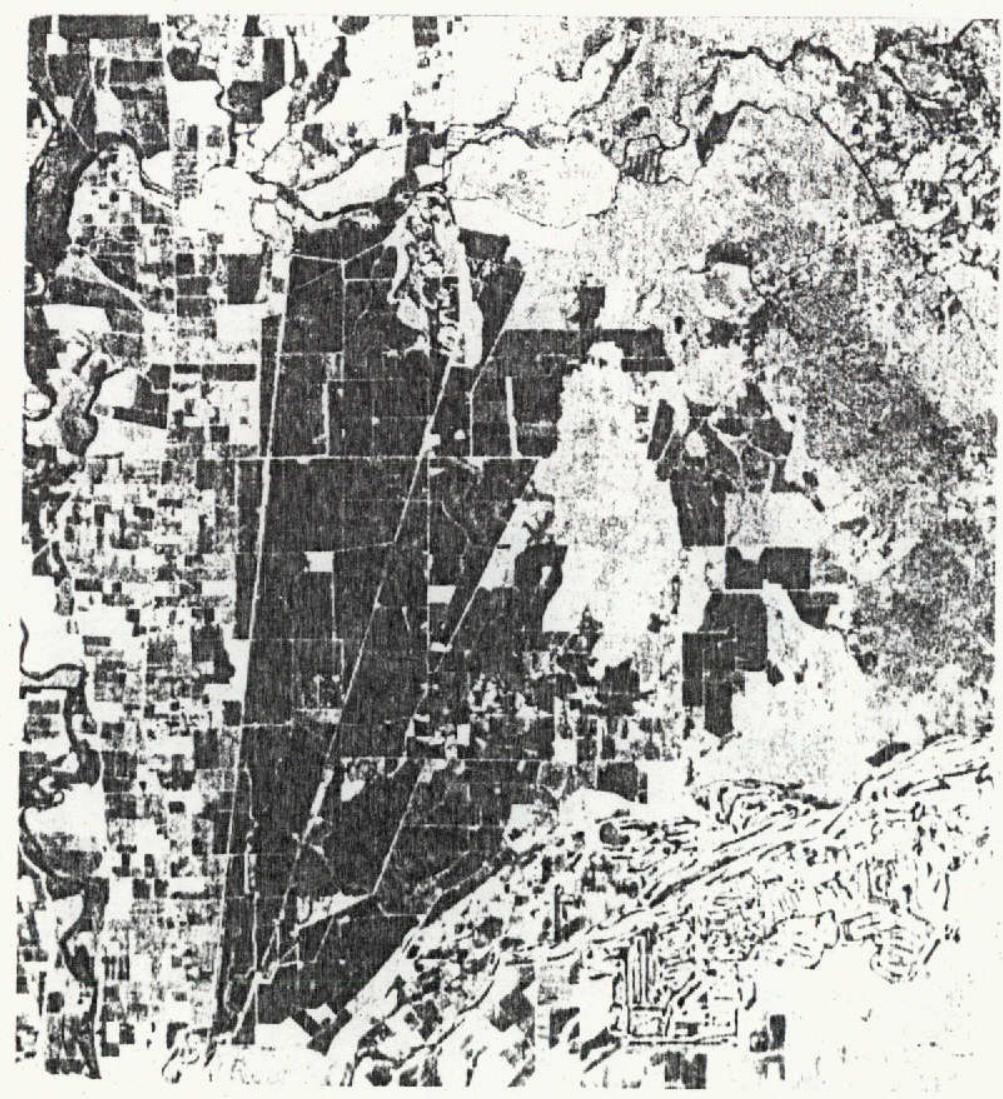


NORTHERN GREAT VALLEY TEST AREA Marysville Test Site
EREP S ST 90A B/W IR

June 3,1973

Test \#2

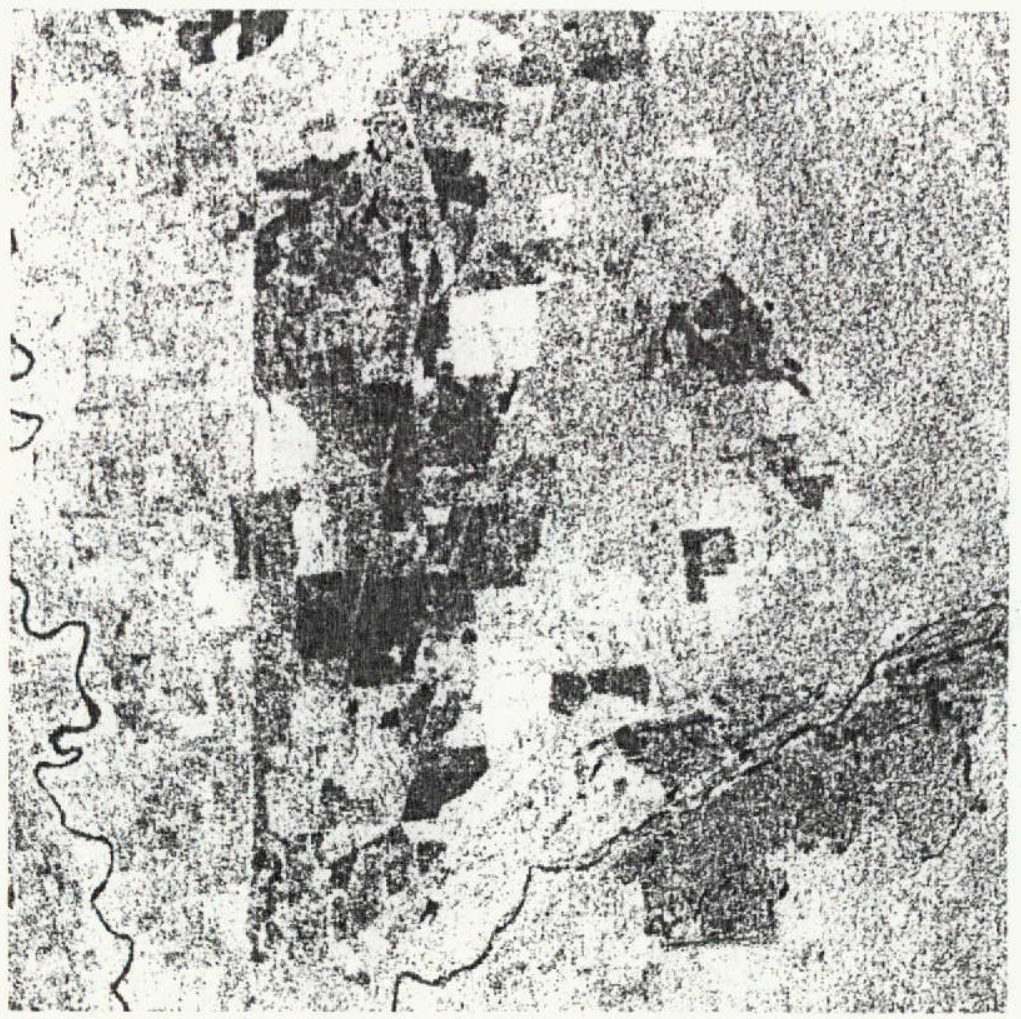


NORTHERN GREAT VALLEY TEST AREA

Marysvi.1. Te Test Site
EREP S190A Color

June 3,1973

Test \#2

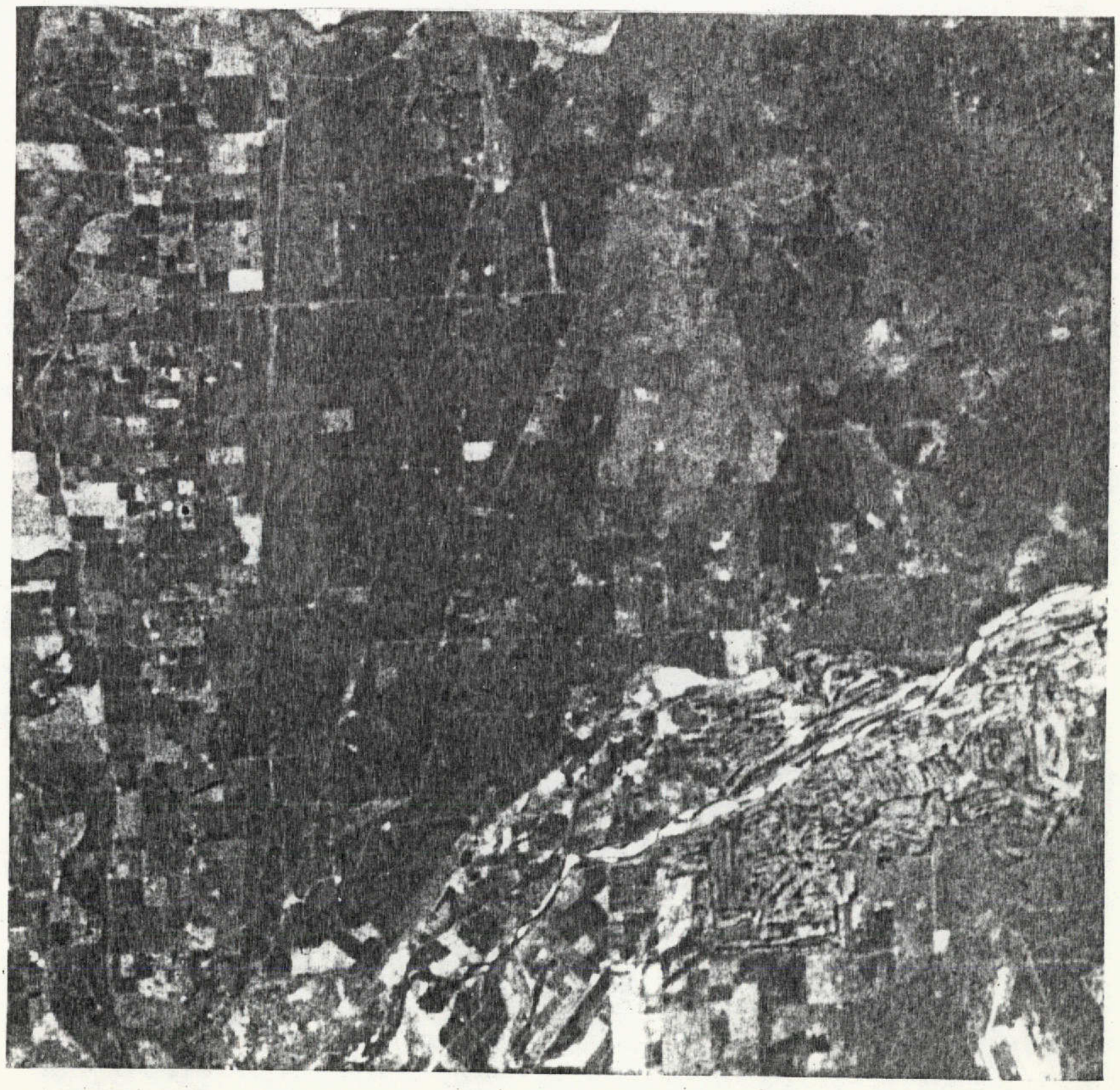


NORTHERN GREAT VALLEY TEST AREA

Marysville Test Site
ERTS Color Composite

May 28, 1973

Tests \#2 and \#3

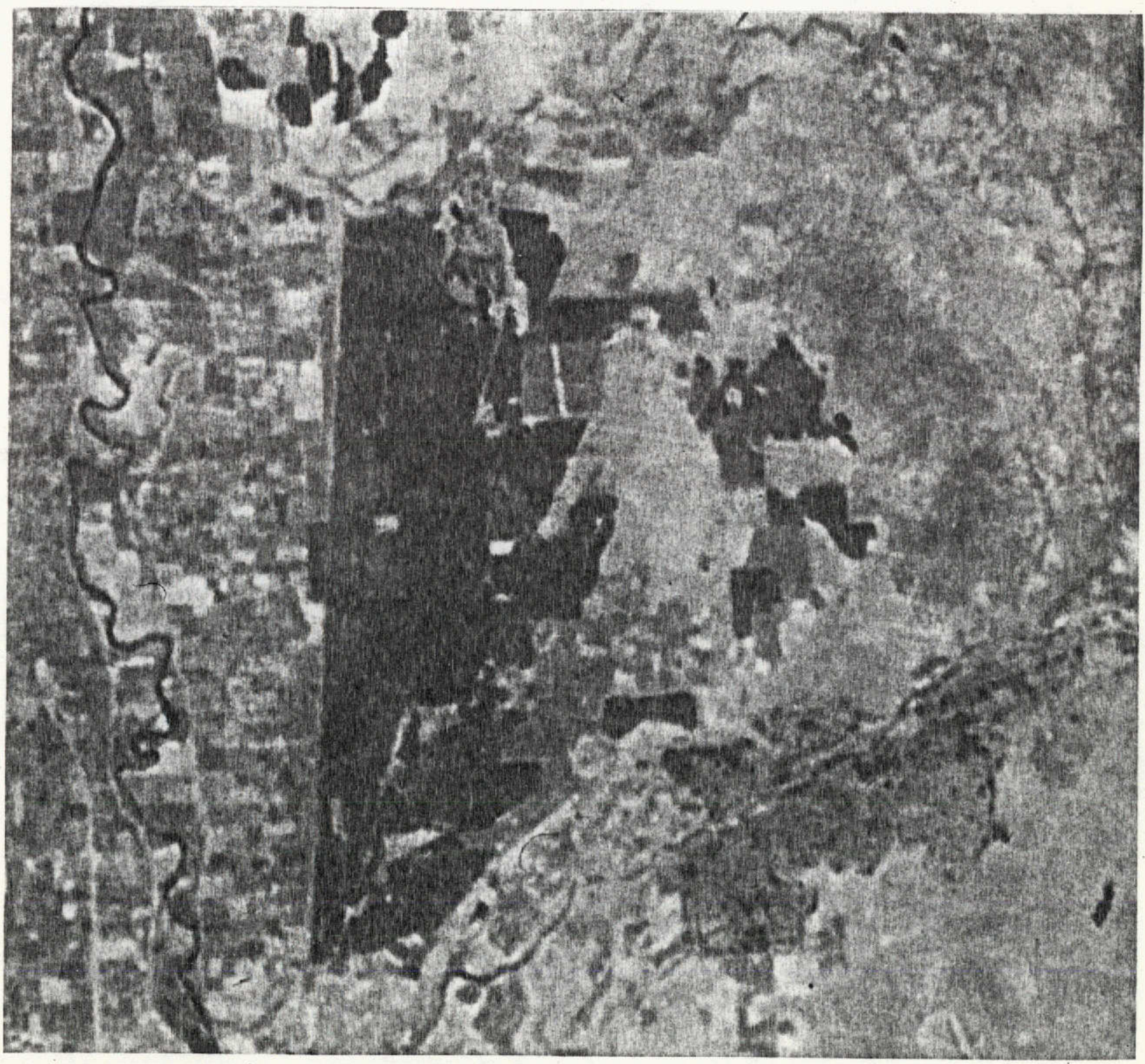


NORTHERN GREAT VALLEY TEST AREA Marysville Test Site
EREP S190A Color IR

June 3,1973

Tests \#2 and \#3

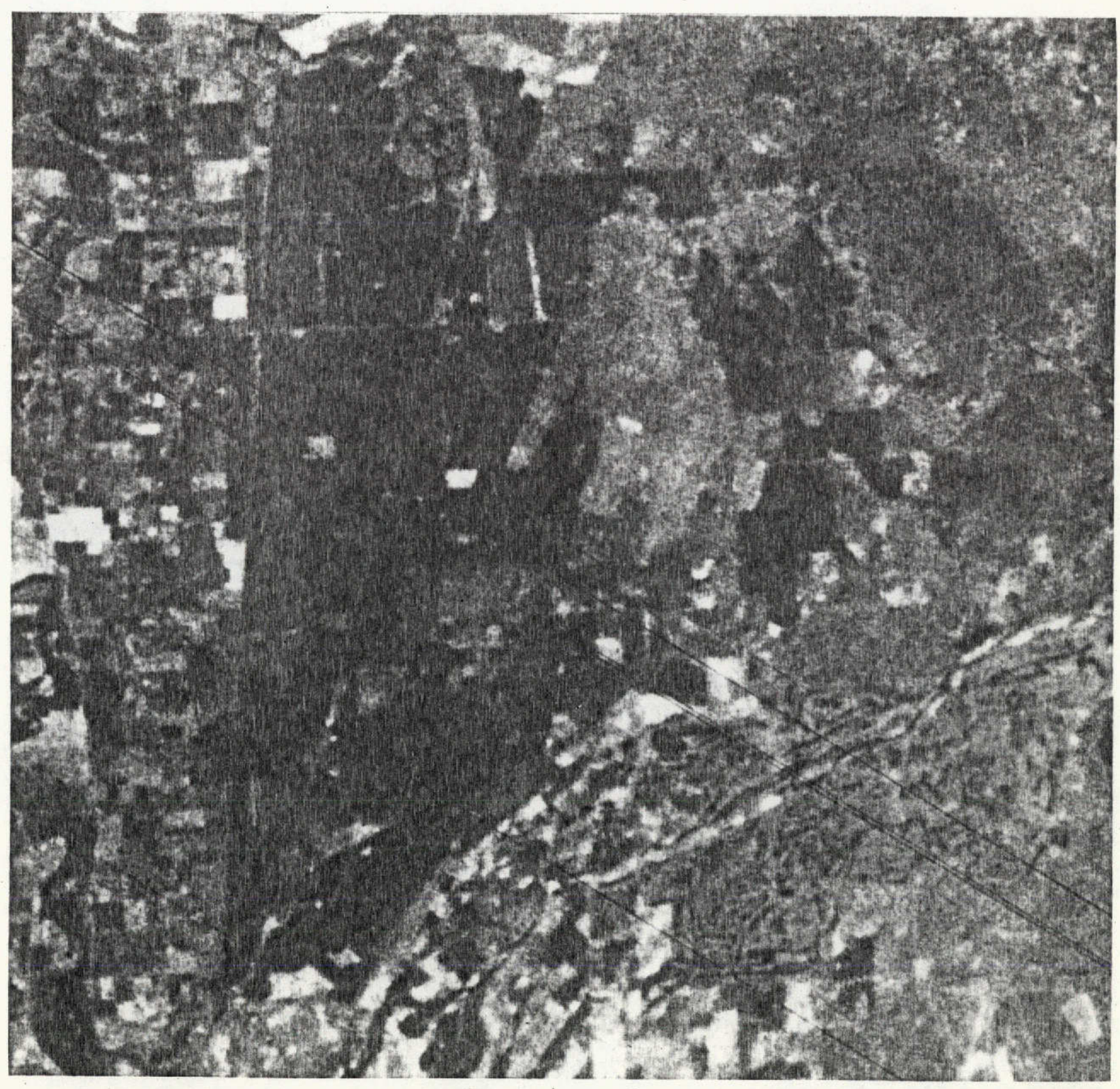


Test \#4

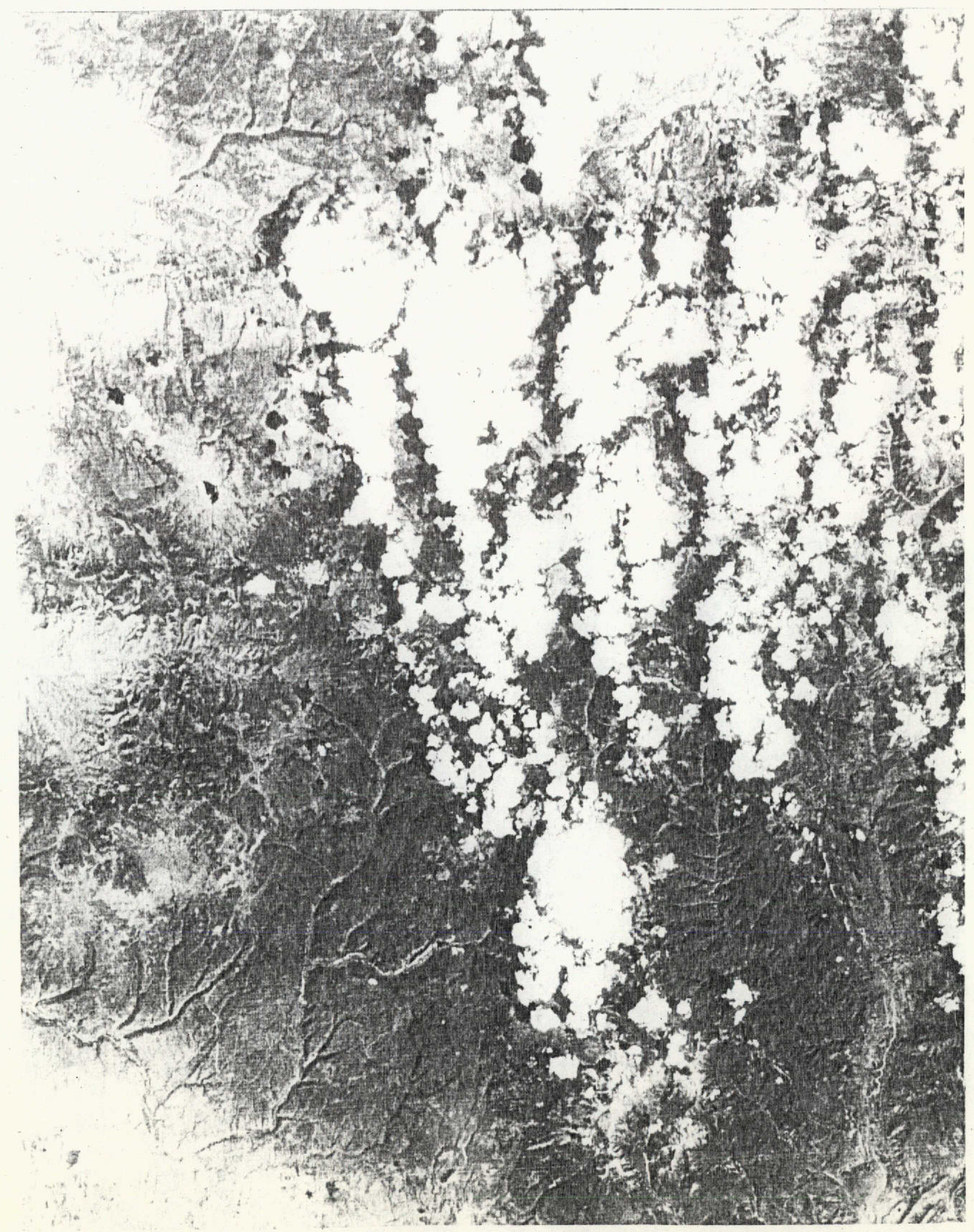


ERTS Band 7

August 16, 1973

Test \#4

$$
\text { - }
$$

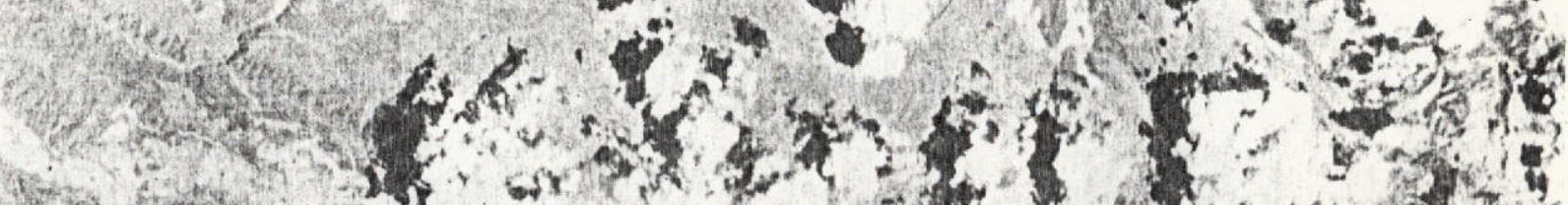

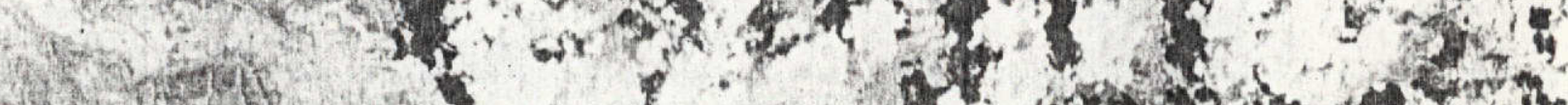

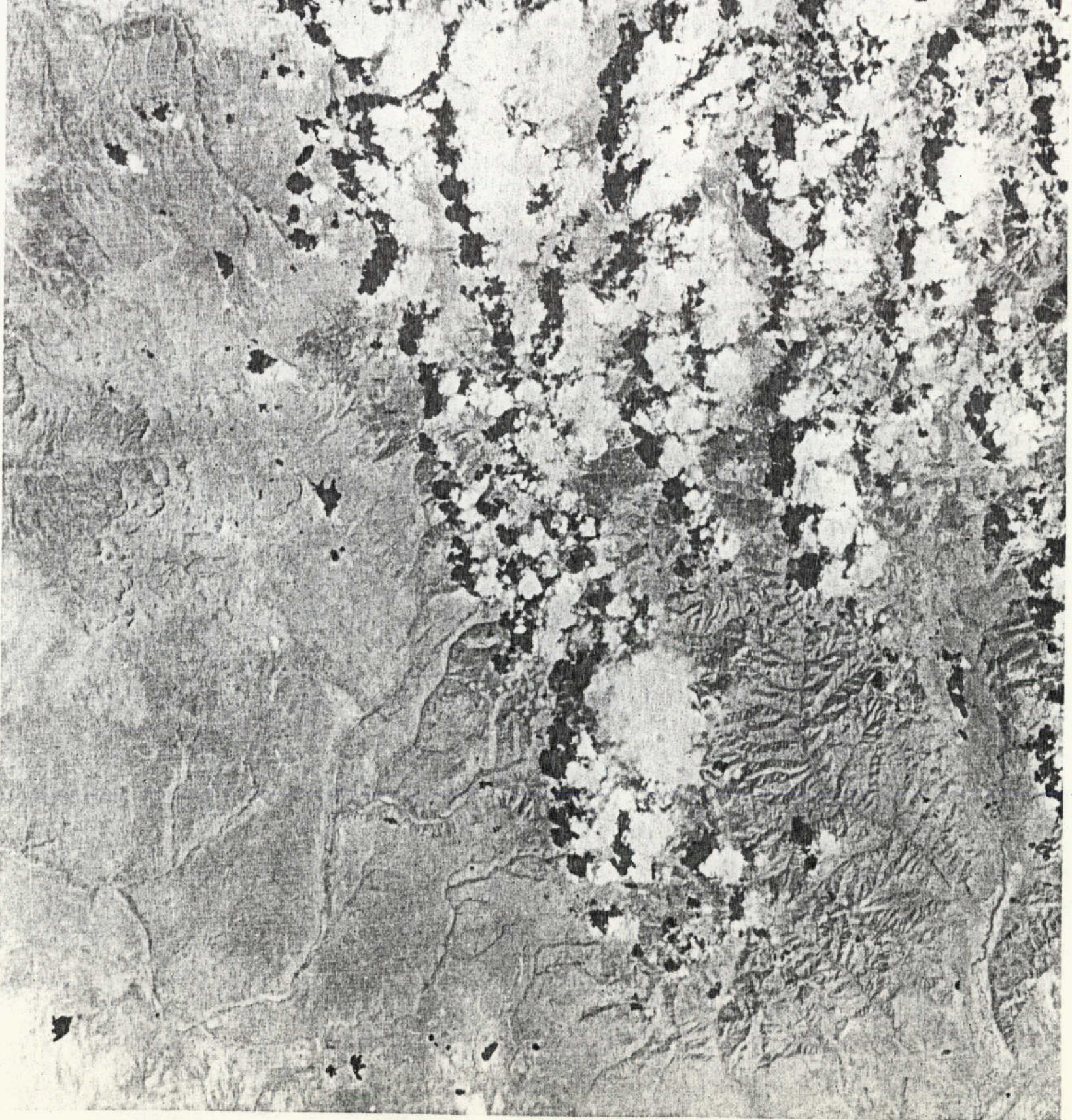


COLORADO PLATEAU TEST AREA

ERTS Color Composite

August 16, 1973

Test \#4

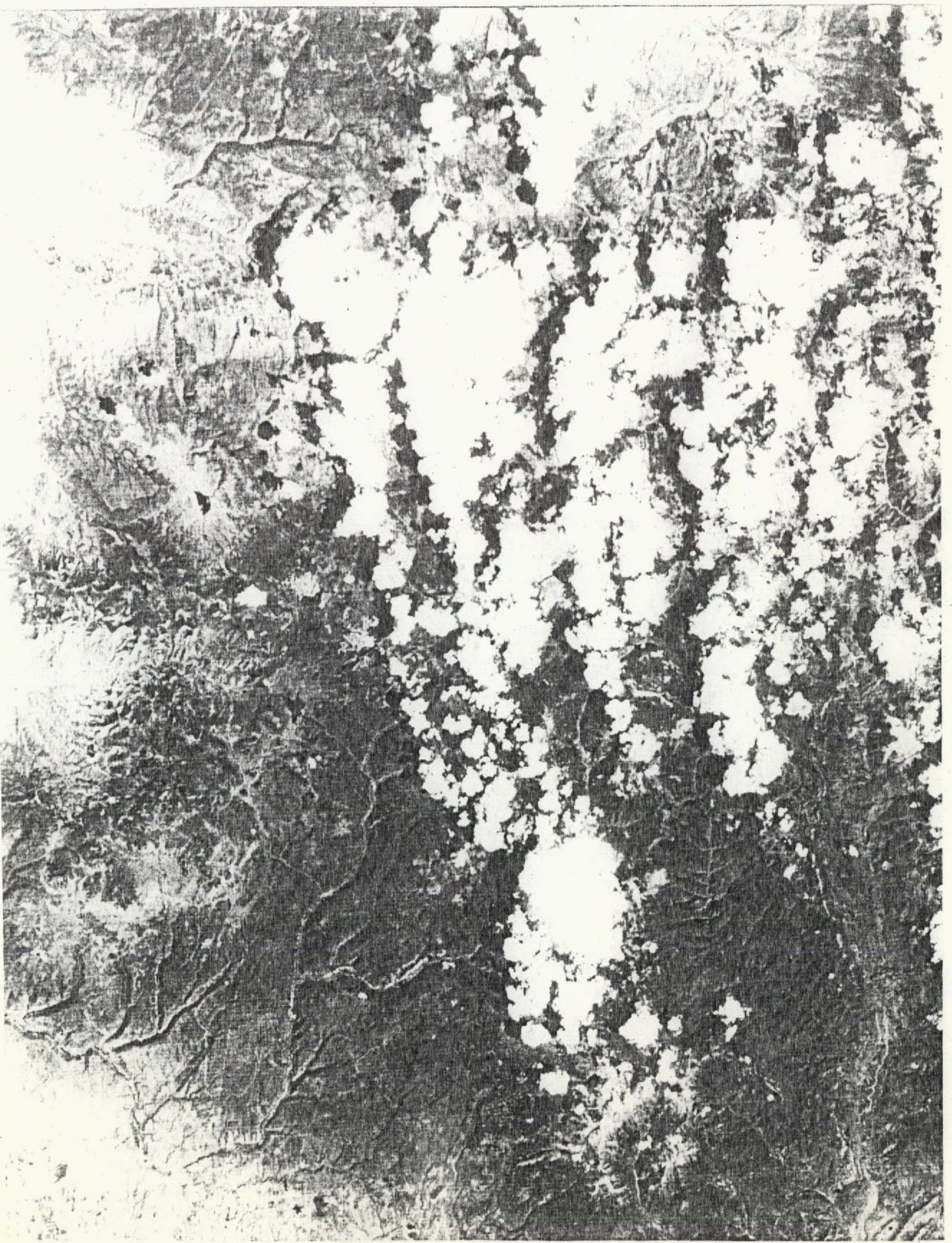




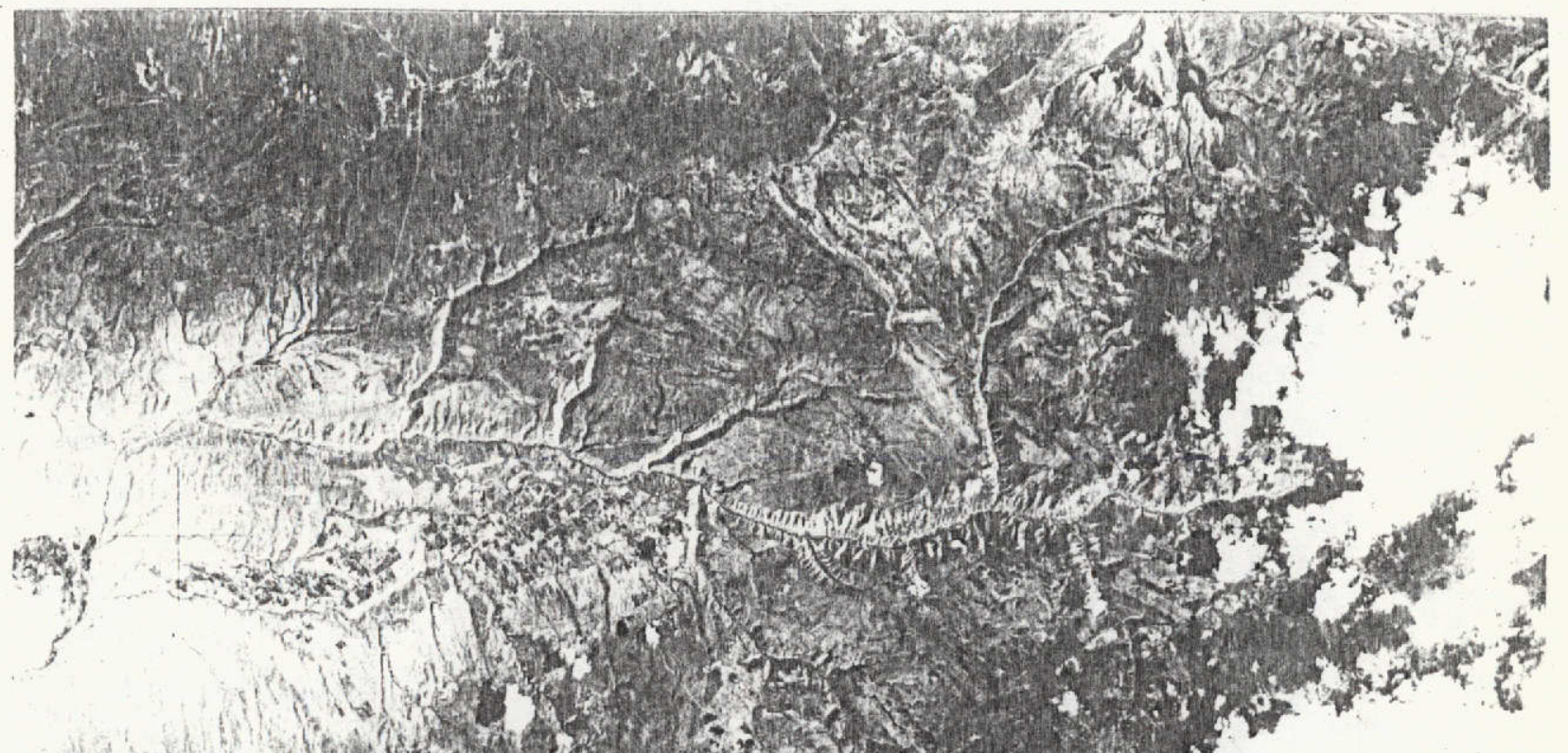

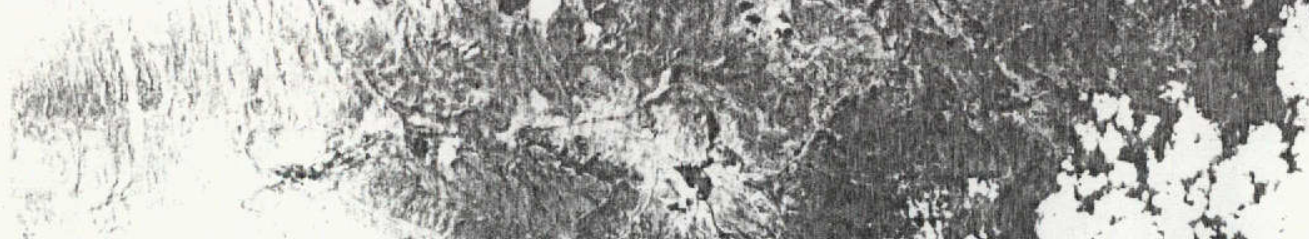
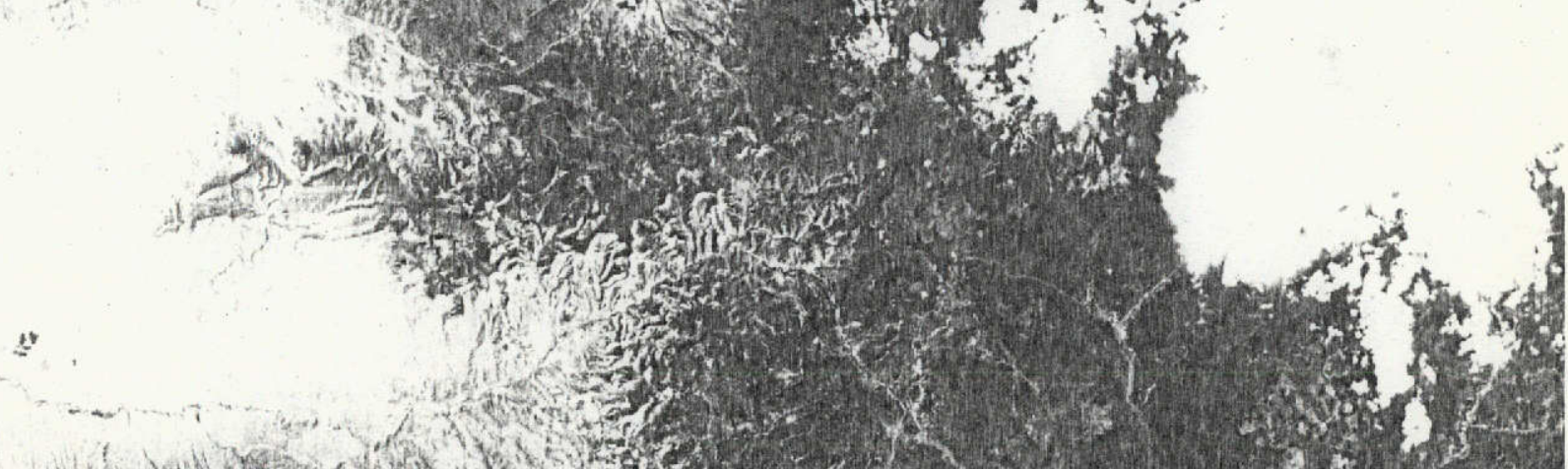

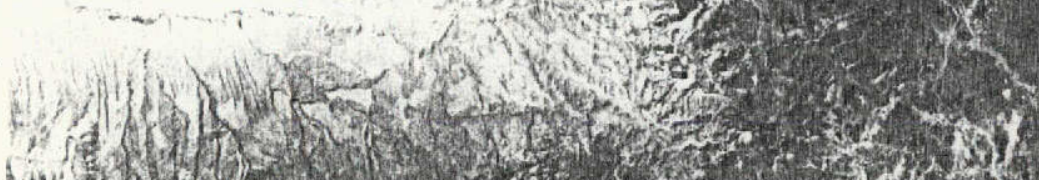

W.
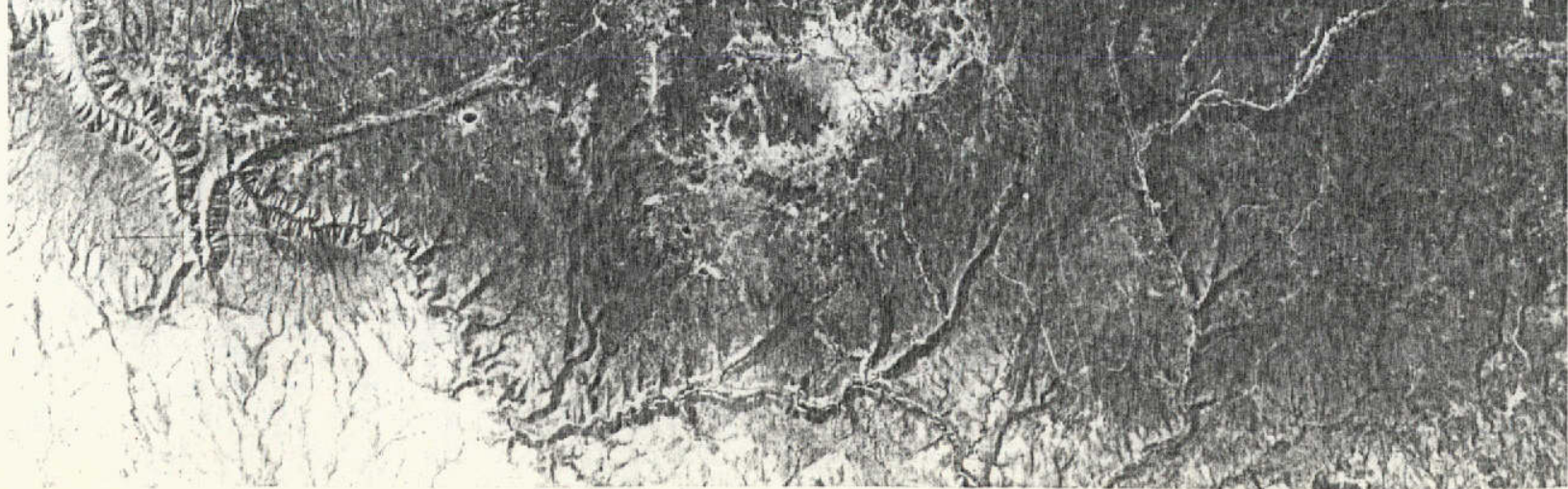


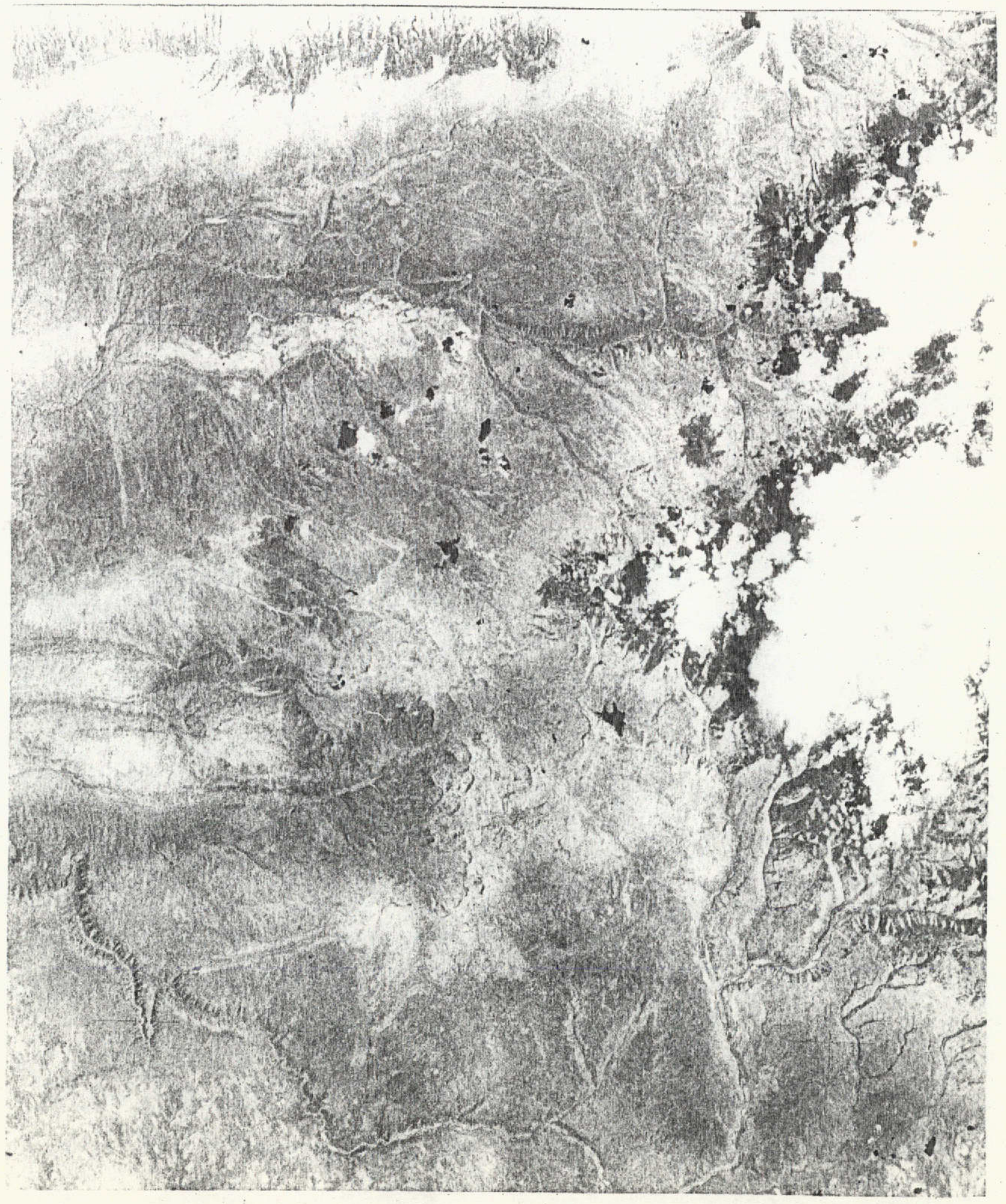


COLORADO PLATEAU TEST AREA
EREP S190A Color

August 3, 1973

Test \#4

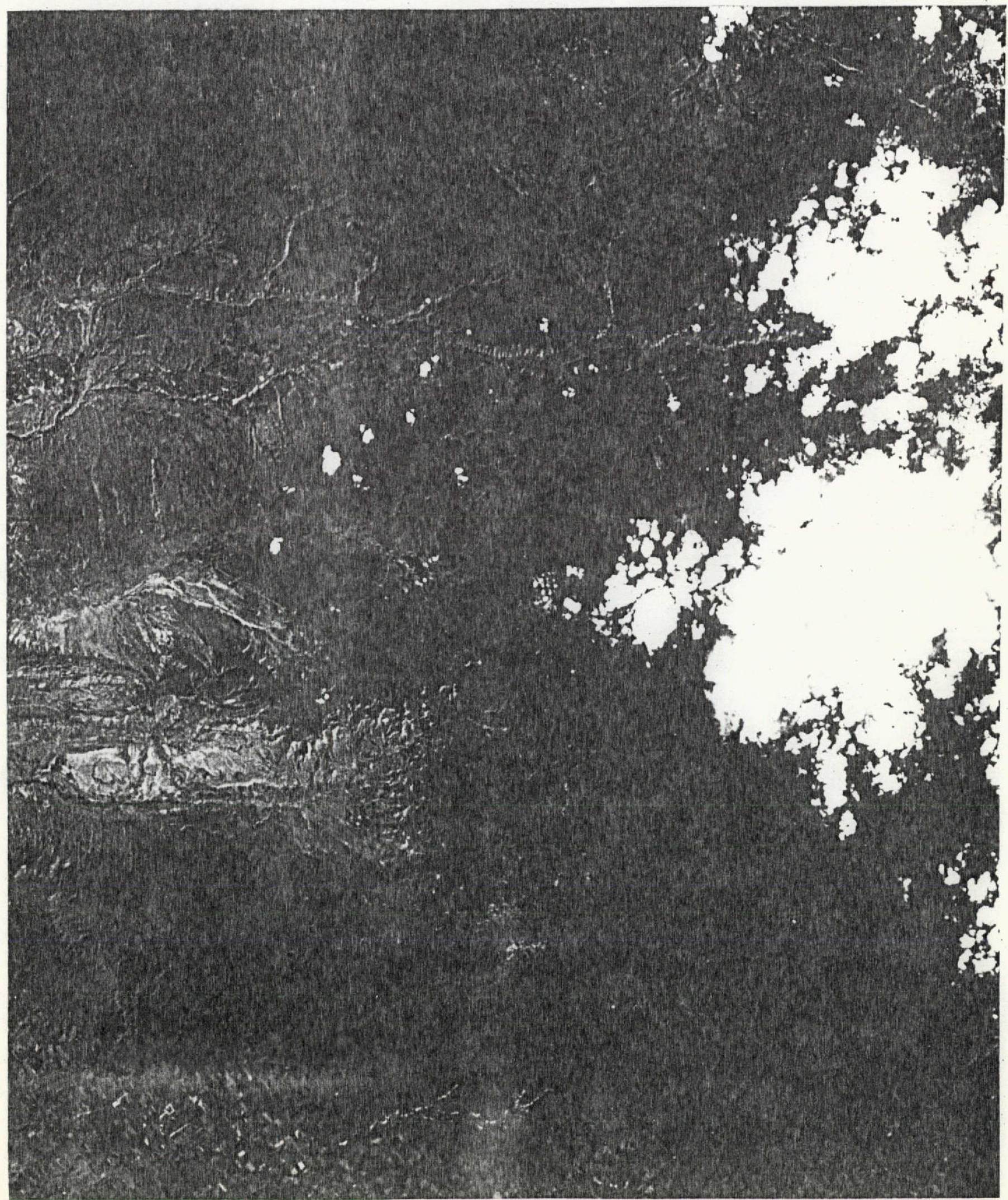




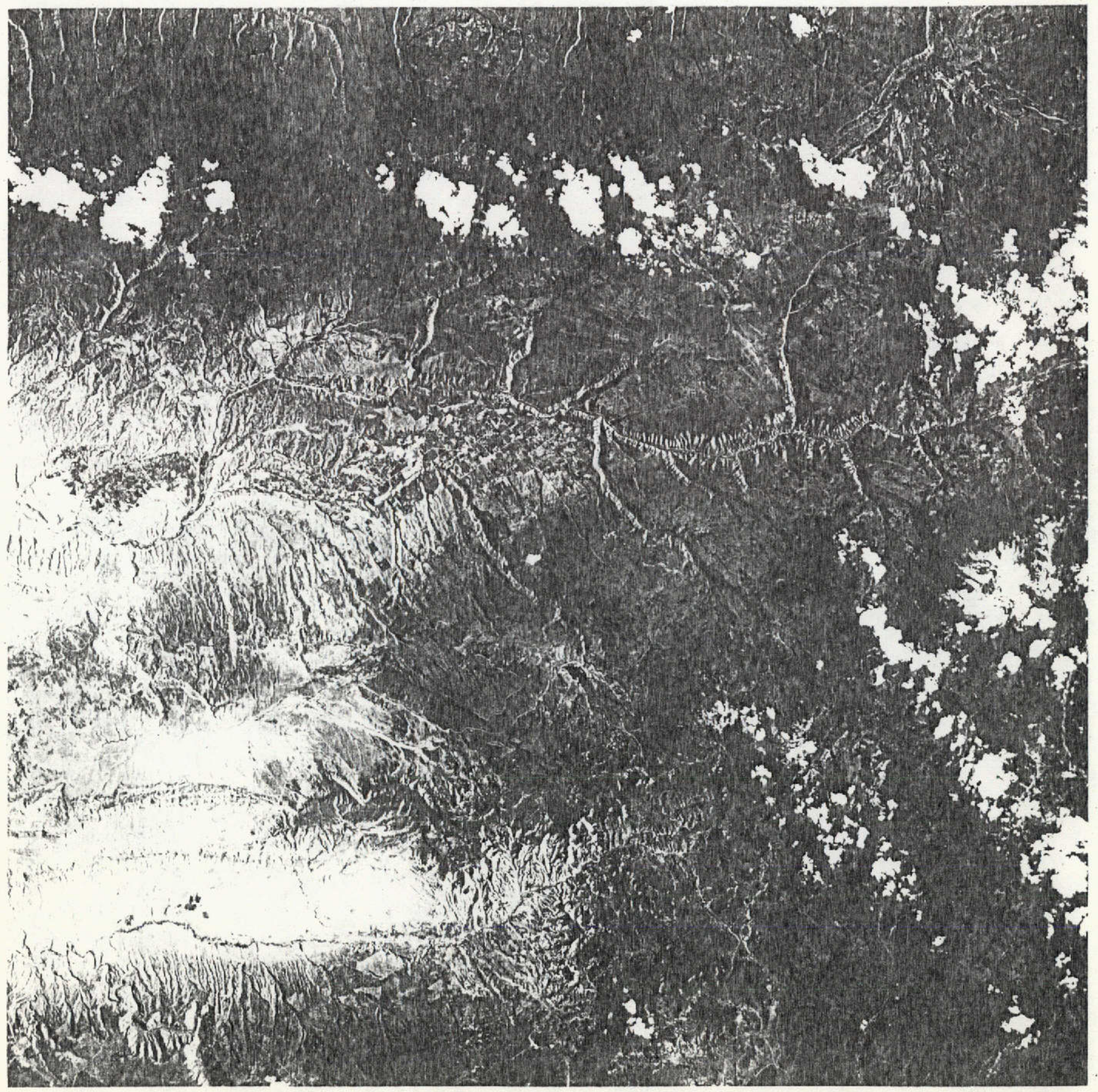




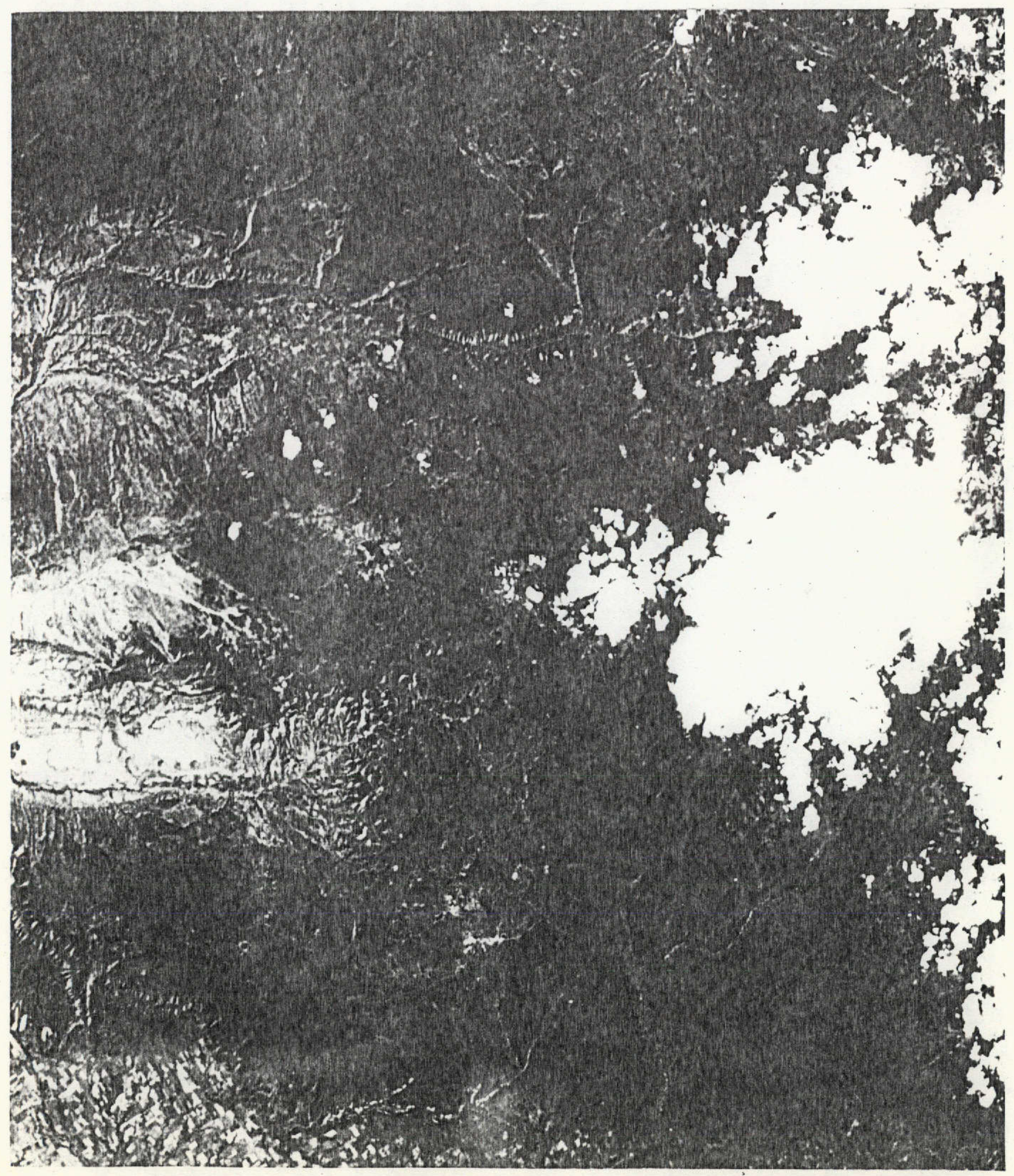




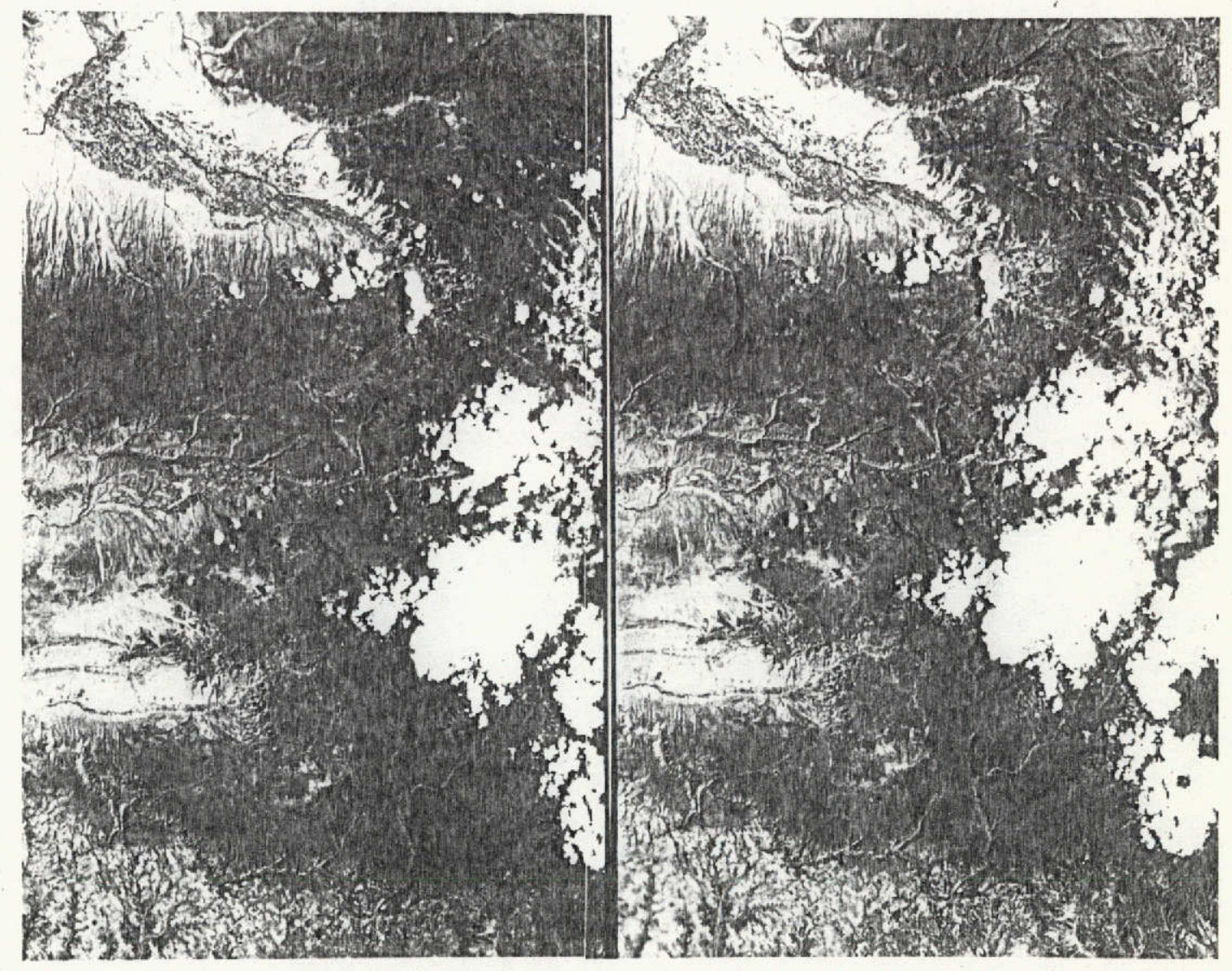




\section{APPENDIX B}

\section{INFOPMATION AND PROCEDURES \\ FOR PHOTO INTERPRETERS \\ TAKING QUAATITATIVE TESTS}


I. Tests involving 40 students from the University of California:

A. Relevant background information regarding the students used in this test is as follows:

1. Each student used in the test was enrolled at the time in one or the other of the following two courses on the Berkeley campus of the University of California under the instruction of Professor Robert N. Colweli.

a. Forestry 102--"Forest Photogrammetry and Photo Interpretation"--4 units.

b. Interdepartmenta] Course 186--."Remote Sensing of Natura' 7 Resources" --5 units.

2. Each of these courses was of 10 weeks duration and was in the seventh week of instruction when these tests were conducted.

3. As of the time when these tests were administered, students in both classes had received essentially the same training in the interpretation of aerial and space photography, and all of them had done acceptably well both in midterm examinations and in other phases of the course work.

B. The group of 40 students was divided into two groups, based on the time they were available for taking the tests. 
C. For each of the two groups, 12 hours of testing time was used:

Group I--from $1: 30$ to $4: 30$ p.m. on May $16,17,23$, and 24 Group II--from 7:00 to 10:00 p.m. on May 16, 17, 23, and 24

D. Information sheets, issued to the students on May 15 (when they applied for assignment to a test group) and at the start of the first test period appear in this appendix. One purpose of these written instructions was to ensure that all 40 students could be treated essentially as a single population for testing purposes as a result of having received uniform instructions.

E. Advantages of dividing the 40 students into two groups of 20 were as follows:

1. As will presently be seen, it was necessary to produce on ly 5 sets of prints and accompanying overlays from each ERTS-1 or SKYLAB (EREP) image example used in these tests. Otherwise 10 sets of each would have been required with a consequent substantial increase in both the cost and the time required to produce the test materials.

2. The classroom at the EarthSat Berkeley office comfortably accommodates a maximum of 20 students.

3. Potential problems with respect to the hours of availability of students for testing purposes were minimized since some could be available for afternoon work, but not at night, while for others the reverse was true.

4. During the course of each three-hour testing period, it was far easier to monitor the performance of each student in a group of 20 than it would have been in a group of 40 . 


\section{OF ERTS AND SKYLAB IMAGERY}

Each student who is to participate in these tests must either work entirely with Group I or else entirely with Group II. throughout all four of the 3-hour sessions as scheduled below:

GROUP I will meet from $1: 30$ to $4: 30 \mathrm{p} . \mathrm{m}$. on Thursday and Friday of this week (May 16th and 17th) and also from 1:30 to 4:30 p.m. on Thursday and Friday of next week (May 23rd and $24 \mathrm{th}$ ).

GROUP II will meet on those same four days but from 7:00 to 10:00 p.m.

Rigid compliance with this schedule is essential because, for a student's test results to be valid, he must participate in all 12 hours of work assigned to his Group and at the time when the Group is scheduled to meet. Those who cannot fulfili this requirement, including prompt arrival by the scheduled time at each of the 4 sessions, should not apply.

At the conclusion of the fourth session each student w111 be patd $\$ 60.00$ for his 12 hours of work. Payment will be in the form of a check from Earth Satellite Corporation.

The tests will be conducted in a classroom that is located on the top floor of the Great Western Bank Building, 2150 Shattuck Avenue, Berkeley (about 4 blocks from Mulford Hall). Selection of this meeting place has been dictated by the fact that the NASA contract for the conduct of these tests has been awarded, not to the University of California (as had once been presumed), but to the Berkeley Office of Earth Satellite Corporation, which is located at the foregoing Shattuck Avenue address. Upon entering the lobby on the ground floor of the Great Western Bank Building the student should ride the elevator to the top floor by pushing the elevator button labelled "PH" for Penthouse. A receptionist on the top floor will meet him and escort him to the classroom.

The EarthSat Berkeley group, like the University of California Remote Sensing Group, has performed many NASA funded remote sensing projects in the past and the testing will be based on ERTS and SKYLAB imagery of two of EarthSat's test sites, viz, an Agricultural Test Site in the Sacramento Valley, and a W1Idland Test Site in the Colorado Plateau region.

A11 necessary instruction for this testing program will be given to the student during the 3 -hour sessions. No advance preparation is necessary. However, for each of the 4 sessions the student should bring with him a pen or pencil and a lens-type stereoscope of the type that he has been using in class at the University. Although the image examples will not lend themselves to stereoscopic study, the magnification offered by such a stereoscope makes it ideal for use as a monocular viewing device for the study of some features of the ERTS and SKYLAB imagery. 
A total of 40 students will be needed for this testing exercise ( 20 for Group' I and 20 for Group II). A somewhat larger number of students have expressed a desire to participate. If more students apply than can be accommodated, the few who will need to be rejected will be those who recelved the lowest grades on the first midterm in the photo interpretation course in which they currently are enrolled at U.C. A list of the students accepted for Groups I and II, respectively, will be posted on the door of Room 131 Mulford Hall by 1:00 p.m., Wednesday, May 15th.

In order to apply, simply f1ll out the attached form, tear it from the sheet, and leave it on the table in front of this room as you leave.

STUDENT'S NAME:

Could you make all 4 Group I sessions if selected for that Group? Yes No

Could you make all 4 Group II sessions if selected for that Group? Yes __ No

If your answer to both of the above is "Yes," which Group do you prefer to be in? Group I Group II 


\section{OBJECTIVE:}

This series of photo interpretation tests is designed to determine the relative utility of both ERTS and SKYLAB imagery for identifying a variety of wildland and agricultural features. For each image type tested, the student will examine a marked set of training items. Having become familiar with the image characteristics of each category, he will then classify the annotated test items according to the list of category choices provided.

\section{INSTRUCTIONS:}

Each test image is accompanied by an acetate overlay on which the following annotations appear:

(a) Registration marks for use in orienting the overlay to the corresponding marks on the image,

(b) Training examples (marked by letters) of each of the same types of features as the student will eventually be asked to attempt to identify on the test image, and

(c) Numbered test items (1 through 60) on which interpretation tests will be conducted.

The tests will be administered by following these instructions:

(a) Match up the registration marks, making sure that the acetate overlay is in proper registration with respect to the image. Annotated dots on the overlay mark the location of training and testing items. The overlay is taped to the image so that it can be lifted periodically in order to study certain parts of the image more carefully.

(i) Training phase: Study the lettered training examples and learn the recognition features of each category.

(c) Testing phase: Proceed to test item number "T." Study it, compare it with the training (letter) examples, and decide which of the lettered examples it most closely resembles. Then write this letter opposite the corresponding number on the test response sheet that has been provided. Only one letter should be specified as the answer for each test item. If there is uncertainty as to which answer is correct, select that category which most closely resembles the training examples. Do not leave blanks. 
(d) It is anticipated that 30 seconds will be adequate for each identification and recording of results as described in step (c). At the end of 25 seconds, the instructor will state "5 seconds," and thus the student will be able to complete the necessary work with respect to that example. (If for any particular example the student feels that he could have used more time to advantage, he should place a check mark opposite that example with the prospect of returning to it briefly at the end of the test.)

This procedure will be followed for each of several image types during the test period. The sequence of images will be randomized so that no single image is always tested first, thus minimizing interpreter bias due to image sequence.

\section{LETTER CODE TO CATEGORY TYPES:}

$$
\begin{array}{ll}
\text { Agricultural Crops: } & \text { R - rice } \\
& 0 \text { - orchard } \\
& \text { A - alfalfa } \\
& \text { F - fallow } \\
& \text { D - dryland pasture } \\
& X \text { - other agricultural crops }
\end{array}
$$


Memorandum to students who have been selected to perform additional ERTS and SKYLAB photo interpretation tests.

1. You are among those who have indicated that you would be available to perform such tests and have been selected to do so.

2. These additional tests will require an estimated period of 4 to $4-1 / 2$ hours and are to be conducted in a sinale session on the evening of Thursday, June 6,1974 beginning promptly at 7:00 p.m. The tests will be conducted in the same EarthSat classroom as was previously used at 2150 Shattuck Avenue in Berkeley.

3. Payment will be a fixed sum of $\$ 20$ per student and will be made by check on Thursday evening, immediately following completion of the tests.

4. In order that we can be sure that you will be participating in these additional tests, we ask that you sign the note appearing at the bottom of this page and hand it in immediately. Otherwise we will find it necessary to arrange for someone else to take your place.

I' 11 be there!

Signed 
Information for University of California Students Relative to the

Additional ERTS and SKYLAB Photo Interpretation Tests

to be Conducted on June 6,1974

The additional space photos that you will be asked to interpret today cover the same agricultural and wildland areas as you previously studied, and you will be asked to attempt to identify on them the same categories of vegetation and land use. However, there are these important differences in the photos themselves:

1. The additional space photos of the agricultural area were taken at an earlier date in the same growing season (viz. May 28 and June. 3 vs September 12 and 13, 1973). Therefore it is probable that you will find some categories easier to interpret and others more difficult. In fact, our primary purpose in giving this additional test is to determine to what extent this is true.

2. The additional space photos of the wildland area were taken on the same date as the previous ones, but in this case will be presented to you in the form of a stereoscopic pair rather than as single photos. Hence, the primary purpose in our giving you this additional test for the wildland area is to determine whether stereoscopy facilitates the interpretation of wildland features on space photography and, if so, to what extent.

In order to ensure that these additional test results will be comparable to the previous ones, we are taking the following measures:

1. Each of you should sit in the same seat as before so if any differences in lighting exist throughout the room, the comparability of your test results will not be affected by this factor.

2. Since the stereo pair examples are mounted on stiff cardboard, you can hold the card in your hand if you like and thus place it in the same position with respect to the light source as you placed the previous photo examples, in order to achieve the most favorable lighting. 
Not only are the same geographic areas covered in these additional photos, but the same training spots and test spots also have been marked, using the same symbols and annotated on the same kind of acetate overlay. You may find, however, that the numbering sequences for the individual test fields have been changed. This factor, together with the fact that 2 or 3 weeks have elapsed since your previous tests, should minimize the likelihood that your interpretation results today will be significantly affected by your earlier study. of these 120 spots.

Today's testing procedure will be the same as previously in that you should first study the two training areas for each category, make brief notes for your own use as to the identifying characteristics, and then proceed to the identification, in sequence, of the numbered test examples.

Consistent with the procedure used in the previous tests, you will be allowed 30 seconds, if needed, to identify each example. 
The objective of this portion of the test is to ascertain the accuracy with which the rice-growing portions of marked areas can be identified and delineated. A clear acetate sheet with areas marked for delineation is provided. For each image assigned, proceed by following these steps:

1. Study the training examples for rice (R) and the other crop categories. Determine the image characteristics which distinguish rice from other crops.

2. With the criteria established in (1), stratify the test areas into rice-growing and non rice-growing regions by drawing directly on the acetate sheet. Make sure that all lines close and that there are no gaps.

3. Label each discrete area as ejther rice-growing (R) or non rice-growing $(N)$. When you have finished, each delineated area contained within the bounds of the test area should be labeled either $R$ or $N$. 